INTERNATIONAL MONETARY FUND
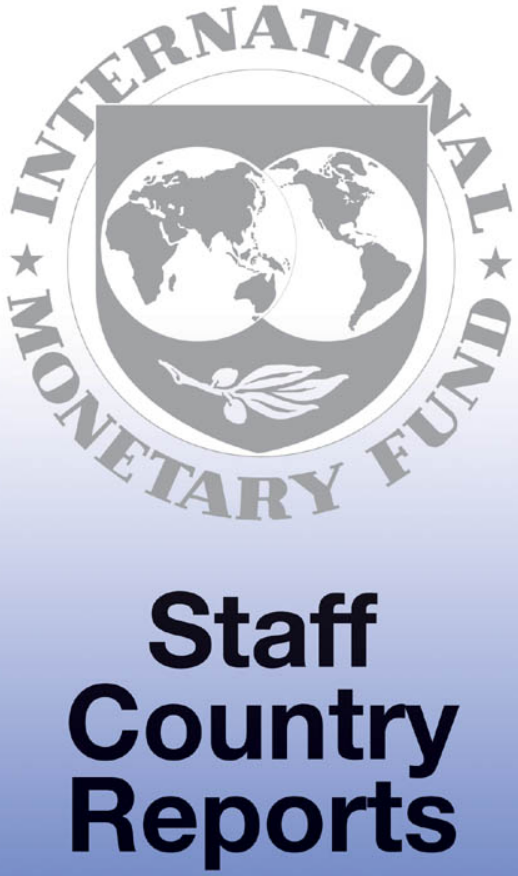


\section{Union of the Comoros: Poverty Reduction and Growth Strategy Paper}

Poverty Reduction and Growth Strategy Papers (PRSPs) are prepared by member countries in broad consultation with stakeholders and development partners, including the staffs of the World Bank and the IMF. Updated every three years with annual progress reports, they describe the country's macroeconomic, structural, and social policies in support of growth and poverty reduction, as well as associated external financing needs and major sources of financing. This country document for the Union of the Comoros dated September 10, 2009, is being made available on the IMF website by agreement with the member country as a service to users of the IMF website.

Copies of this report are available to the public from

International Monetary Fund $\bullet$ Publication Services

$70019^{\text {th }}$ Street, N.W. • Washington, D.C. 20431

Telephone: (202) 623-7430 • Telefax: (202) 623-7201

E-mail: publications@imf.org Internet: http://www.imf.org

\section{International Monetary Fund Washington, D.C.}




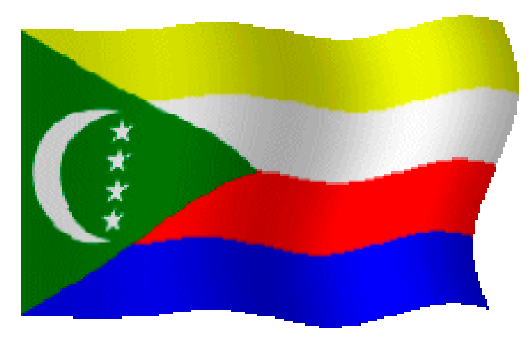

UNION OF THE COMOROS

UNITY - DEVELOPMENT - SOLIDARITY

PRESIDENCY OF THE UNION OF THE COMOROS

OFFICE OF THE COMMISSIONER GENERAL FOR PLANNING

POVERTY REDUCTION AND GROWTH STRATEGY PAPER (PRGSP)

September 2009

CInternational Monetary Fund. Not for Redistribution 


\section{PREFACE}

This paper presents the Poverty Reduction and Growth Strategy (PRGS) for the Union of the Comoros. It outlines the country's development priorities for the next five years, that are supported by all Comorians. This vision reflects the hopes of the population as well as the current socioeconomic situation; the medium-term macroeconomic outlook; the most recent findings from quantitative and qualitative studies of household living conditions, poverty, and various forms of inequality; and a review of the performance, strengths, and weaknesses of the country's key social and economic sectors.

Based on this comprehensive diagnostic assessment, six core strategies and 32 priority programs were identified and addressed in several discussion and validation workshops, which confirmed the relevance and priority status of these programs for the country's development.

The Government of the Union of the Comoros intends to support these priority programs, as its resources allow, and to implement the institutional reforms required for true recovery of growth and reduction of poverty. Through the practical implementation of this strategy, the government intends to spare no effort to reach the Millennium Development Goals (MGDs). The Comorian people firmly believe that, with the support of the international community, the many challenges impeding the country's development process can be addressed. This strategy is the first step in setting the stage to restore the Comoros to the path of robust economic growth and sustainable poverty reduction.

The President of the Union of the Comoros

$/ \mathrm{s} /$

Moroni, September 10, 2009 


\section{ACRONYMS AND ABBREVIATIONS}

AAIDA

ACTIV

AFD

AfDB

AGOA

AIEB

AIMPSI

AMIE

ANPI

APSA

APSP

ASC

ASECNA

BADEA

$\mathrm{BCC}$

$\mathrm{BDC}$

BIC

c.i.f.

CCIA

CEN-SAD

$\mathrm{CF}$ or $\mathrm{KMF}$

CGP

$\mathrm{CHN}$

CHR
Arab Authority for Agricultural Development and Investment

Comorian Association of Veterinary Technicians and Nurses

Agence Française de Développement

African Development Bank

African Growth and Opportunity Act

Support for basic economic initiatives

Moroni Prince Said Ibrahim International Airport

Micro and small-scale enterprise support project (UNDP)

National Investment Promotion Agency

Association of Animal Health Professionals

Association for Private Sector Promotion

Anjouan Stevedoring Company

Air Navigation Safety Agency

Arab Bank for Economic Development in Africa

Central Bank of the Comoros

Banque de Développement des Comores

Banque pour l'Industrie et le Commerce des Comores

Cost, insurance, and freight

Chamber of Commerce, Industry, and Agriculture

Community of Sahel-Saharan States

Comorian franc

Office of the Commissioner General for Planning

National hospital center

Regional hospital center 


$\begin{array}{ll}\text { CIPR } & \text { Regional Education Inspection District } \\ \text { CNAD } & \text { National Committee for Development Support } \\ \text { CNDRS } & \text { Center for documentation and scientific research } \\ \text { CNE } & \text { Caisse Nationale d'Epargne } \\ \text { CNLS } & \text { National Committee to Fight HIV/AIDS and Sexually-Transmitted } \\ \text { COI } & \text { Infections } \\ \text { COMACO } & \text { Compagnie de Manutention des Comores } \\ \text { COMESA } & \text { Common Market for Eastern and Southern Africa } \\ \text { COPSED } & \text { Comités de Planification de Suivi-Evaluation du Développement } \\ \text { CURE } & \text { [Committees for Development Planning, Monitoring, and Evaluation] } \\ \text { DECVAS } & \text { Emergency Loan for Economic Recovery } \\ \text { DFI } & \text { Développement des Cultures Vivrières et Appui Sémencier [Development } \\ \text { DIJEC } & \text { Decentralized financial institutions } \\ \text { DOTS } & \text { Comorian comprehensive early childhood development } \\ \text { EAP } & \text { Directly-observed treatment course (tuberculosis treatment strategy) } \\ \text { EBC } & \text { Environmental action plan } \\ \text { EDF } & \text { Budget and consumption survey } \\ \text { EDIC } & \text { European Development Fund } \\ \text { EDS } & \text { Water and electricity fund } \\ \text { EFA } & \text { Diagnostic study on trade integration } \\ \text { EIM } & \text { Demographic and Health Survey } \\ \text { EPI } & \text { Education for All } \\ \text { EU } & \text { Comprehensive household survey } \\ \text { EVF } & \text { Expanded Program on Immunization } \\ \text { EVIH } & \text { European Union } \\ \text { FADC } & \text { Education for family living } \\ \text { FAO } & \text { HEE }\end{array}$




$\begin{array}{ll}\text { FER } & \text { Road maintenance fund } \\ \text { FP } & \text { Family planning } \\ \text { GAFTA } & \text { Greater Arab Free Trade Area } \\ \text { GDP } & \text { Gross domestic product } \\ \text { GFCF } & \text { Gross Fixed Capital Formation } \\ \text { GNP } & \text { Gross national product } \\ \text { GTS } & \text { Sectoral Technical Group } \\ \text { HDI } & \text { Human Development Index } \\ \text { HIPC } & \text { Heavily Indebted Poor Countries Initiative } \\ \text { HIV/AIDS } & \text { Human immunodeficiency virus/Acquired immune deficiency syndrome } \\ \text { HPI } & \text { Human Poverty Index } \\ \text { ICPD } & \text { International Conference on Population and Development } \\ \text { ICT } & \text { Information and communication technologies } \\ \text { IEC } & \text { Information, Education, and Communication } \\ \text { IFAD } & \text { International Fund for Agricultural Development } \\ \text { IGE } & \text { Income-generating activities } \\ \text { ILO } & \text { International Labour Office } \\ \text { IMCI } & \text { Integrated Management of Childhood Illness } \\ \text { IMF } & \text { International Monetary Fund } \\ \text { IsDB } & \text { Islamic Development Bank } \\ \text { KAP } & \text { Knowledge, attitude, and practice } \\ \text { MA-MWE } & \text { Comoros water and electricity company } \\ \text { MDG } & \text { Millennium Development Goals } \\ \text { MECK } & \text { Mutuelle d'Epargne et de Crédit ya Komori } \\ \text { MFI } & \text { Microfinance institutions } \\ \text { MICS } & \text { Multiple Indicators Cluster Surve } \\ \text { MIGA } & \text { Multilateral Investment Guarantee Agency } \\ \text { MTEF } & \text { NAP-EFA }\end{array}$




\begin{tabular}{|c|c|}
\hline NEPAD & New Partnership for Africa's Development \\
\hline NGO & Non-governmental organization \\
\hline NITC & New information and communication technologies \\
\hline NN & National network \\
\hline OCI & Organization of the Islamic Conference \\
\hline ODA & Official development assistance \\
\hline OHADA & Organization for the Harmonization of Business Law in Africa \\
\hline OPACO & Comoros employers' organization \\
\hline PIP & Public investment program \\
\hline PNAC & National autonomous pharmacy of the Comoros \\
\hline PNDRH & National human resource development plan \\
\hline PNDS & National health development plan \\
\hline PNE & National program on environment \\
\hline PNLP & National program to fight malaria \\
\hline PNLS & National program to fight AIDS \\
\hline PNS & National health policy \\
\hline POP & Persistent organic pollutants \\
\hline PRGF & Poverty Reduction and Growth Facility \\
\hline PRGS & Poverty Reduction and Growth Strategy \\
\hline PRGSP & Poverty Reduction and Growth Strategy Paper \\
\hline RF & Road fund \\
\hline RGPH & General population and housing census \\
\hline $\mathrm{RH} / \mathrm{FP}$ & Reproductive health/family planning \\
\hline RNFD & National network for women and development \\
\hline SIDS & Small Island Developing States \\
\hline SME & Small and medium-scale enterprises \\
\hline $\mathrm{SME} / \mathrm{SMI}$ & Small and medium-scale enterprises and industries \\
\hline SNAC & National Union of Comorian Farmers \\
\hline SNPSF & National Postal and Financial Services Company \\
\hline
\end{tabular}




$\begin{array}{ll}\text { SNPT } & \text { National Postal and Telecommunication Company } \\ \text { STI } & \text { Sexually-transmitted infections } \\ \text { UA } & \text { African Union } \\ \text { UCCIOI } & \text { Union of Chambers of Commerce and Industry of the Indian Ocean } \\ \text { UN } & \text { United Nations } \\ \text { UNDAF } & \text { United Nations Development Assistance Framework } \\ \text { UNDP } & \text { United Nations Development Programme } \\ \text { UNFPA } & \text { United Nations Fund for Population Activities } \\ \text { UNICEF } & \text { United Nations International Children's Emergency Fund } \\ \text { UNS } & \text { United Nations System } \\ \text { VAT } & \text { Value-added tax } \\ \text { WB } & \text { World Bank } \\ \text { WHO } & \text { World Health Organization } \\ \text { WTO } & \text { World Trade Organization }\end{array}$




\section{CONTENTS}

Preface

Acronyms and abbreviations

ii

Table of Contents

CHAPTER I. CONTEXT AND BACKGROUND TO THE POVERTY REDUCTION AND GROWTH STRATEGY

1.0. Context of the Union of the Comoros

1.1. Background and foundation of the PRGS

1.2. Contents of the paper

CHAPTER II. ANALYSIS OF LIVING CONDITIONS AND POVERTY

2.0. Introduction

2.1. Population's perception of well-being and poverty

2.2. Scope of monetary poverty

2.3. Effect of inequalities

2.4. Determinants of poverty

2.5. Non-monetary poverty

2.6. Impact of unemployment and under-employment

2.7. Restoring growth and reducing poverty

CHAPTER III. ANALYSIS OF SECTORAL PERFORMANCE AND CONSTRAINTS

3.0. Introduction

3.1. Agriculture, stockbreeding, and fishing

3.1.1. Agriculture subsector

3.1.2. Stockbreeding subsector

3.1.3. Fishing subsector

$\underline{19}$

$\underline{19}$

3.3. Economic and communication infrastructure

3.3.1 Economic infrastructure

3.3.2 Port infrastructure

3.3.3 Airport infrastructure

3.3.4 Telecommunication infrastructure 
3.4. Energy, water, and sanitation sector

3.4.1. Energy subsector

3.4.2. Drinking water sector

3.4.3. Sanitation subsector

3.5. Environment

3.6. Governance and social cohesion

3.7. Education

3.8. Health

3.9. Private sector and microfinance

3.9.1. Private subsector

$\underline{65}$

3.9.2. Financial and microfinance subsector

4.0. Introduction

4.1. PRGS Core strategies

$\underline{73}$

4.2. Cross-cutting stakes

4.3. Priority programs by core strategy

4.3.1. Core strategy I. Stabilize the economy and lay the groundwork for strong and equitable growth

4.3.2. Core strategy II. Strengthen key sectors by focusing on institutionbuilding and ensuring a broader role for the private sector

4.3.2.1. Strengthening the private sector

4.3.2.2 Restoring growth through key sectors

4.3.3. Core strategy III. Strengthen governance and social cohesion

4.3.4. Core strategy IV. Improve the health status of the general public

$\underline{98}$

4.3.5. Core strategy V. Promote education and vocational training with the aim of developing human capital

$\underline{102}$

4.3.6 Core strategy VI. Promote environmental sustainability and civilian security

$\underline{105}$

\section{CHAPTER V. ECONOMIC ENVIRONMENT AND MACROECONOMIC FRAMEWORK}

5.0. Introduction

5.1. Recent economic developments in the Comoros

5.2. Short-term economic outlook

5.3. Macroeconomic framework

5.3.1 PRGS scenario

5.3.2 MDG scenario

5.3.3 IMF scenario 
6.1. Core strategy I. Stabilize the economy and lay the groundwork for Strong and equitable growth

6.2. Core strategy II. Strengthen key sectors by focusing on institution building and ensuring a broader role for the private sector

6.3. Core strategy III. Strengthen governance and social cohesion

6.4. Core strategy IV. Improve the health status of the general public

6.5. Core strategy V. Promote education and vocational training with the aim of developing human capital

6.6. Core strategy VI. Promote environmental sustainability and civilian security

\section{CHAPTER VII. PRGS MONITORING AND EVALUATION} FRAMEWORK

7.0. Context

7.1. Principles and objectives of the monitoring and evaluation system $\frac{130}{140}$

7.2. Institutional framework for monitoring and evaluation $\quad \underline{141}$

7.3. Features of the monitoring and evaluation system $\quad \frac{146}{148}$

7.4. Progress reports and output timetable $\frac{148}{148}$

7.5. Implications for the national strategy on statistical development $\quad \frac{148}{148}$

7.6. Implications for capacity building $\frac{148}{149}$

7.7. Implications for efficacy and harmonization of official development assistance $\quad \underline{149}$

CONCLUSION

ANNEXES

Annex 1. Performance indicators for PRGS monitoring

Annex 2. Survey of programs and projects in progress supporting achievement of the PRGS objectives

Annex 3. Financing available for each PRGS core strategy and Priority program
151

159

$\underline{152}$

$\underline{155}$

$\underline{175}$ 


\section{CHAPTER I}

\section{CONTEXT AND BACKGROUND TO THE POVERTY REDUCTION AND GROWTH STRATEGY}




\subsection{Context of the Union of the Comoros}

The Union of the Comoros is an archipelago comprised of four main islands at the northern entrance of the Mozambique Channel, with a land area totaling 2,236 square kilometers. Despite the unanimous disapproval of the international community and the protests of the Comorian authorities, one of the islands, Mahoré (or Mayotte in Creole, 424 square kilometers), remained under administration of France, the former colonial authority, when the territory became independent on July 6, 1975. Accordingly, the sovereignty of the Republic of the Comoros applies in practice to the other three islands, which are Mwali (Mohéli, 290 square kilometers), Ndzuwani (Anjouan, 374 square kilometers), and Ngazidja (Grande Comore, 1,148 square kilometers).

The 2003 General Population and Housing Census (RGPH) registered a population of 576,000 on the three islands, with women accounting for slightly more than half of the total, and an average annual growth rate of 2.1 percent. The population was estimated at 670,000 in 2009 and is expected to reach 785,000 by 2015-runaway demographic growth exerting substantial pressure on available land. Population densities have reached critical limits in Ndzuwani; and in the region of Nyumakélé, where they exceed 1,000 inhabitants per square kilometer of arable land.

Accordingly, the current major environmental conservation problems could worsen if the country does not take appropriate measures immediately to address this demographic trend.

According to the RGPH, another feature of the Comorian population is that it is quite young (53 percent of the population is under 20 years of age). Further, the average age of the population is 24.1 years. Of course, such an age structure will pose substantial challenges, primarily in providing young people with services in the areas of education, health, nutrition, vocational training, employment, leisure activities, etc. The dependency ratio (children under 15 years of age and aged persons over 64 as a share of the population 15-64 years of age) is 198.5 percent and registers a clear gap between urban areas (169.3 percent) and rural areas (210.6 percent). These figures are still quite high if we consider the low estimated gross activity rate ( 25.3 percent) of the Comorian population.

The RGPH registers gross births and overall fertility rates respectively of 35.6 per thousand (33 per thousand in urban areas and 36.7 per thousand in rural areas) and 150.8 per thousand (128.1 per thousand in urban areas and 161 per thousand in rural areas). The country's synthetic fertility index is 5.3 children per woman. This fertility rate is much higher in rural areas (5.6 children per woman) than in urban areas (4.5 children per woman). These socio-demographic variables register substantial growth as compared with the 1996 Demographic and Health Survey (EDS).

Comorian children are still exposed to substantial mortality risks. The data indicate that infant mortality levels are still substantial, despite a downward trend. In 2003, infant mortality was estimated at 79.3 per thousand, as against 86.2 per thousand in 1991 and 121.7 per thousand in 1980. Many Comorian women die as a result of pregnancy or childbirth complications, attributed mainly to high fertility levels and the substantial prevalence in the Comoros of home births, often without the assistance of qualified personnel (38 percent according to the 2000 Multiple Indicator Cluster Survey-MICS). The maternal mortality rate is estimated at 381 women per 100,000 live births (RGPH 03). 
Anthro-political research in the Comoros has shown a highly structured social organization deeply rooted in tradition, in which the individual blends into the community and can only be affirmed through the mechanisms imposed by society. The family is the foundation on which society is organized and operates. More generally speaking, the concept of family, in practice, includes four levels: nuclear family, extended family, lineage, and clan. The supremacy of the family is confirmed through marriage, which expands and strengthens the family structure. Marriage also enables individuals to gain access to the social hierarchies.

The introduction of the Islamic religion in the Comoros is thought to date back to the Thirteenth Century, and almost all of the Comorian population is Muslim. However, Islam in the Comoros still reflects a mixture of social practices and beliefs influenced by customs and tradition. As a result of these combined influences, traditional Islam resists militant Islam, as religious authority is only ultimately acknowledged in combination with traditional power.

Koranic school is the Comorian child's first contact with the education system, and it teaches the basic principles of Islam and socio-cultural values, while introducing children to reading the Koran and writing in Arabic. Koranic school therefore plays a fundamental role in forming the Comorian personality.

Since the Comoros gained independence, the country has not experienced political stability conducive to socioeconomic development and the establishment of a viable political and institutional framework consistent with the population's expectations. The public authorities did not officially acknowledge the existence of political parties until the early 1990s.

A series of political crises culminated with the secession of the Island of Ndzuwani in 1997, which also led to an institutional crisis. This secession process plunged the country into a lengthy period of political and institutional uncertainty which threatened the very existence of the Comoros as a nation state. With the support of the international community, a process of national reconciliation was undertaken with the signing of the Fomboni Agreements in February 2001, which led to the December 2001 adoption by referendum of a fundamental law instituting a new Comorian grouping known a the "Union of the Comoros" within which each island had broad autonomy and its own constitution.

Under the 2001 Constitution, at the level of the Union, executive power was vested in the President of the Union (assisted by two Vice Presidents from each of the two islands other than the President's, and a government appointed by the President) elected to a four-year term by one round of direct universal suffrage, on a rotating basis between the islands. Legislative power lies with a unicameral parliament comprising deputies, some of whom are elected by direct universal suffrage and some appointed by the island assemblies. At the island level, executive power is vested in the President of the Island (assisted by a government appointed by the President), elected to a five-year term by direct universal suffrage in a two-round uninominal election. Legislative power is vested in the Island Assembly, whose members are elected by direct universal suffrage.

This complex institutional architecture has led to multiple, recurrent conflicts of authority between the executive powers of the Islands and the Union, particularly as the Constitution only 
specified the exclusive scope of the central authority and gave the future Assembly of the Union the task of passing the organic laws defining the scope of exclusive authority and prerogatives of the Islands, and those shared by the Union and the Islands. These conflicts took a serious turn in 2007, when, after the failed election of the chief executive of Ndzuwani, the outgoing president proclaimed himself re-elected and took power. This act would plunge the country back into a period of acute political and institutional turbulence. It would take almost a year and an intervention by the Comorian army supported by the African Union forces on the Island of Ndzuwani for the three islands to be re-unified.

The President of the Union took the initiative of presenting the population with a draft revision of the 2001 Constitution for a referendum in 2009. Among other matters, the referendum law adopted on May 17, 2009 restricted the prerogatives of the island powers and replaced the terms "President of the Island," " Minister of the Island," and "Deputy of the Island" respectively with "Governor of the Island," "Commissioner," and "Counselor." At the level of the Union, the principle of a rotating presidency between the islands was maintained, and the President is elected for a five-year term, with three Vice Presidents, one representing each island.

\subsection{ORIGIN AND BASIS OF THE PRGSP}

The Comoros in 2003 established an Interim Poverty Reduction and Growth Strategy Paper (IPRGSP) prepared in a highly participative, inclusive process with all national players and international development partners. Based on the lessons learned from the past in the area of national development planning, and on the experiences of other countries, the government decided the foundations and reference framework that guided the preparation of the interim poverty reduction and growth strategy. The adopted approach was based on the following four principles:

- A strategy devised with a participative approach designed to involve the public, key players in civil society, and the private sector in poverty reduction;

- A gradually developed strategy, starting with existing information and limiting the collection of new information to a strict minimum, focusing instead on dialog and exchange through regional and national workshops and roundtable discussions. The strategy will be improved and updated as the data on household living conditions are collected and the impact studies are conducted;

- A strategy targeting potential growth areas, and particularly the economic sectors comprising the vulnerable and poor groups, to achieve sustainable poverty reduction while being mindful of the essential social dimensions identified;

- A cross-cutting strategy to ensure that the macroeconomic environment and sectoral programs and policies are effectively integrated, to reflect more effectively the dimensions characterizing poverty, and to propose innovative operations to address the multiple factors impeding growth and poverty reduction. 
This paper, which was positively received by all parties, including the Bretton Woods institutions, has since that time served as a benchmark for all development activities in the Comoros. It was updated in 2005 and accompanied with an action plan covering the period 20062009 to serve as a basic document for the December 2005 Comoros Donors' Conference. Despite the comprehensiveness of the paper, the country authorities decided to maintain its interim status pending conclusion of a formal program with the IMF.

When relations resumed between the Comoros and the IMF and with a view to the formal conclusion of a program with the Fund, the government decided in 2008 to start work on preparing the final version of the PRGSP. In light of the completeness of the interim poverty reduction and growth strategy paper, the government established the following key tasks in the preparation of the final version of the strategy:

- To update the sectoral diagnostic study and profile of poverty and adjustment to reflect the core strategies, programs, and operations adopted;

- To reflect more effectively the achievement of the Millennium Development Goals;

- To integrate trade more accurately by taking into account the Diagnostic Study on Trade Integration (EDIC);

- To take better account of human rights and gender issues;

- To reflect decentralization more effectively.

Comprehensive studies were conducted on these topics, including an evaluation of the costs of the requirements to reach the MDGs so that they can be taken into account when the paper is finalized.

Similarly, drawing lessons from the weaknesses registered in connection with IPRGSP implementation, monitoring, and assessment, the government decided to focus on the institutional approach to be used in preparing the final paper to gain maximum support for the final version of the strategy from the government and the various sectors involved. It was also decided to review and reconfigure the PRGS monitoring and evaluation framework by simplifying it to make it more operational, and harmonizing it with the mechanism used to coordinate the aid the country has recently secured.

Accordingly, the government has maintained and consolidated the highly participative process used in preparing the preliminary version of the strategy. The institutional steering mechanism for the process was reinforced to further involve the islands, the various national and nongovernmental players in development, as well as the technical and financial partners. The sectoral working groups, the mainstays involved in preparing the strategy at the national level, are now chaired by the secretaries-general of the ministerial departments involved, to ensure effective government support. The sectoral working groups were assembled with great care to ensure that all players were fully involved in the development of this final version of the strategy. 
The basic insular structures of the PRGSP process, the Committees for Development Planning, Monitoring, and Evaluation (COPSED), that replaced the steering committees, were broad contributors to the process. They participated in and facilitated the conduct of preliminary studies, including the assessment of requirements to achieve the Millennium Development Goals, and their representatives were involved in the work of the sectoral working groups. These COPSEDs are chaired by representatives from civil society and the private sector, and the Island Planning Directorates cover their technical secretariat functions.

\subsection{CONTENTS OF THE PAPER}

This paper is comprised of seven chapters, including this one. Chapter Two covers the qualitative and quantitative analysis of living conditions and poverty in the Comoros. Chapter Three provides a diagnostic assessment of the different sectors involved in the PRGS. Chapter Four describes the objectives, core strategies, and priority programs adopted in connection with the strategy. Chapter Five examines the macroeconomic environment of the country and presents the macro-financial framework. Chapter Six presents the estimated costs of the PRGS. The last chapter presents framework for monitoring and assessment of the strategy. 


\section{CHAPTER II}

\section{ANALYSIS OF LIVING CONDITIONS AND POVERTY}




\subsection{Introduction}

The repeated political, institutional, and economic crises the Union of the Comoros has endured during the past 10 years have done little to improve the living conditions of the population. On the contrary, the situation has aggravated poverty and has led to deterioration in the social climate and relations with the international community. In fact, the resulting decline in development aid in times of economic crisis has further exacerbated the country's vulnerability and poverty problems. Many households are now surviving, with difficulty, on transfers from Comorian expatriates. The private sector is being weakened increasingly as a result of the persistent economic deterioration and the accumulation of government arrears and household debt.

Since the publication of the IPRGSP in November 2005, there has been no real positive change in the country's sociopolitical and economic situation. The Union of the Comoros once again experienced a period of political instability in 2006-2007 with new secessionist attempts by the Island of Nzwani. The easing of political tensions marked by organizing the election of the chief executive of the Island of Nzwani in June 2007 finally enabled the Comorian authorities to define and implement an economic program, to undertake efforts to rehabilitate the road system in the capital, and to renew ties with the international financial institutions. The government concluded a post-conflict program with the IMF in October 2008, and CF 1.8 billion in much-needed financial support was finally released in December 2008.

According to the data from the Office of the General Commissioner for Planning, which are still provisional, the real GDP growth rate amounted to approximately 0.2 percent in 2008 as against 0.8 percent in 2007 (10-year lows). This growth slowdown has led to shortages of certain commodities such as rice and petroleum products.

The energy crisis that struck the country during the latter half of 2008 paralyzed the economic sectors and helped worsen an already severe economic crisis. The inflation rate reached 6.5 percent in 2008 , as against 4.5 percent in 2007 , directly affecting the population's already low purchasing power, with a substantial and growing dependency on imports.

The fiscal situation has deteriorated even further. Despite improved domestic revenue, the increase in current expenditure has led to deterioration in the key budget balances and the overall deficit (not including grants). With this trend, the balance of payments current account deficit also registered sharp deterioration in connection with the erosion of the balance of trade. This situation has exerted further pressure on the government's capacity to meet its domestic liabilities. Arrears to staff and enterprises are still substantial and are contributing to even further deterioration in the general economic climate and household living conditions.

Despite the absence of recent data to assess current household living conditions and poverty in the Comoros, information on the economic environment supports the assumption that the socioeconomic situation is deteriorating and that poverty is on the rise. Household purchasing power is now eroding as a result of inflationary pressure. In 2008, we observed occasional shortages of basic foodstuffs creating upward pressure on prices. 
The crisis has also affected the Comorian expatriate community. We can already anticipate a drop in the short to medium term in transfers, leading to a decline in household income, particularly in Ngazidja. Rural areas have also been affected. The substantial decline in production and prices for key export products supports the assumption that living conditions have deteriorated and that poverty has increased. Apart from ylang-ylang production and prices, which seem to have remained stable or to have improved slightly in 2008, the prices of cloves and vanilla have declined substantially, as have the quantities produced and exported.

Last, we should emphasize that financial commitments the international community made at the time of the Mauritius Conference have yet to materialize. Very few new resources likely to generate renewed growth, or at least to stabilize the population's living conditions, have been injected into the economy in recent years.

This chapter presents an analysis of the living conditions of the Comorian people based on the available data, and places the scope of poverty and inequalities that characterize the Union of the Comoros in perspective. It is important to bear in mind that the available information already date back several years, and that the most recent economic information tends to indicate that living conditions are probably less favorable than the analysis presented in this chapter would indicate.

\subsection{POPULATION'S PERCEPTION OF WELL-BEING AND POVERTY}

The qualitative study conducted in 2002 on perceptions of well-being and poverty enabled Comorian men and women to express their opinions on their living conditions and to identify ways to reduce poverty. The survey shed light on perceptions of well-being and causes of poverty. The results of this study were confirmed by the results of the 2004 comprehensive household survey (EIM). Unfortunately, no recent data are available to establish a current profile. However, as indicated in the introduction, no significant changes have occurred during recent years to imply that substantial differences or improvements might be present.

To define well-being, the Comorian population refers primarily to the satisfaction of basic requirements such as housing, education, clothing, food, health, hygiene, and sanitation. The same applies to the definition of poverty, which is characterized as the situation in which such requirements are not being met.

The 2002 survey on perceptions of poverty revealed that it is difficult for many households to meet their food requirements. Many households in fact indicated that they did not eat sufficient quantities, while the majority indicated that they did not have a high quality diet. Products such as meat, fish, rice, bananas, chicken, and even cassava are not accessible to a substantial proportion of the population. These perceptions confirm the quantitative indicators on the fragile nutritional status of several social groups, particularly young children and pregnant women in rural areas.

The population also referred to social problems such as theft and delinquency to describe poverty. Of course, some resurgence of social problems is inevitable with an increase in poverty. 
Employment is an indirect means for the population to meet its needs, while money is a direct means to do so. Road infrastructure, commercial activities, and access to energy and telecommunications are mechanisms to improve the economic environment, and indirectly, to improve household living conditions. The deterioration in the energy supply in recent years has been one of the main obstacles to economic development and poverty reduction.

Owning furniture, a radio or television, or having a grand wedding seem to be some of the signs of an improved quality of life, to demonstrate social status, or to improve one's social standing.

There are few differences between the islands, environments, and socioeconomic groups in terms of the perceptions of well-being and poverty. For example:

- In Ngazidja, road infrastructure and grand weddings are more important than in the two other islands;

- In Ndzuwani, trade is a more important factor in well-being than it is on the other two islands.

Poverty is perceived as a consequence of several factors, and specifically the insufficiency of physical and human capital, insufficient performance of institutional capital, influence of external factors, and behavior of individuals, households and communities. The main reasons cited by the population for not escaping poverty are laziness, lack of education, unemployment, lack of occupational training, and not being remunerated for work.

The main strategies households use to escape poverty are self-employment, education, credit and savings, development of income-generating activities, occupational training, trade, and investment.

The populations perceive the following to be key factors to improve well-being: (i) access to quality health care; (2) access to drinking water in sufficient quality and quantities; (iii) education (important to 57 percent of the population, and specifically occupational training); (iv) housing (55 percent); (v) religion (particularly in rural areas); (vi) employment; (vii) credit; (viii) capital goods; (ix) trade; (x) cash crops; (xi) electricity; (xii) telecommunications; and (xiii) roads.

Problems in accessing basic social services are substantial, in both rural and urban areas.

1. To improve access to health services, the people propose an increase in the number of health workers, reduction in costs of health care to a minimum or providing care free of charge; job creation, reduction in the costs of medicine and construction of heath centers.

2. To enhance access to primary education, the resources proposed include financial aid for education, free school supplies, child minding at school, better public education, and children's awareness of the importance of school.

3. The public believes that improved access to drinking water requires implementation of water systems, construction of wells, and financial assistance. 
4. Improvement of health infrastructure requires development of waste disposal sites, waste incineration, technical assistance, construction of water drainage conduits, and studies to identify landfill sites.

The main economic activities of the Comorian population are listed as follows in order of importance: (i) agriculture, (ii) fishing, (iii) small business, (iv) small-scale works, (v) stockbreeding, (vi) masonry, (vii) civil service, (viii) artisanal industry, (ix) unskilled labor, and (x) domestic service. Stockbreeding was found to be more prevalent in Mwali than the other islands.

These activities, and particularly agriculture and fishing, are facing substantial difficulties that are impeding their development. Lack of equipment, theft of crops and animals, low prices for products, insufficient inputs, insufficient market outlets for agro-food products, crop destruction by slugs and snails, and poor yields are the main weaknesses identified in agricultural production. Substantial drought problems were emphasized in Ngazidja and Mwali.

In the fishing sector, the main concern is insufficient fishing equipment, and particularly boats, lack of safety at sea for fishermen, and low market prices for fish, particularly in Ndzuwani and Mwali.

Last, problems related to economic activities are insufficient training, wage payment delays for civil servants, electricity and drinking water shortages, high taxes, transportation costs, insufficient pastures for animals, etc..

Access to production equipment is a major problem in the development of the key economic activities (agriculture and fishing). The means to improve access to equipment according to the population are, inter alia, technical assistance, financial aid, equipment grants, credits for purchase of equipment, equipment loans, and employment.

Access to agricultural land appears to be an important problem, particularly in Ndzuwani, where overpopulation and geography restrict the available agricultural area. The mechanisms to improve access to agricultural land, according to the population, are land redistribution, upgrading of land quality, and job creation for the purchase of agricultural land.

Access to financial services is quite limited, particularly in Mwali. According to the population who participated in the survey, the resources to enhance the population's access to financial services are easier credit terms, creation of savings and loan associations, job creation, and lower interest rates.

\subsection{SCOPE OF MONETARY POVERTY}

A poverty profile for the Comoros has been established based on the latest poverty data (EIM 2004). The data indicate that monetary poverty is still widespread in the Comoros. For the overall country, the incidence of poverty at the household level was estimated at 36.9 percent in 2004. On an individual basis, we should therefore expect one out of two individuals (44.8 percent) to be classified as poor according to the monetary poverty index. 
Monetary poverty on an individual basis was, a priori, higher in Ndzouani and Mwali, as compared with Ngazidja (respectively 46.4 percent, 49.1 percent, and 42.7 percent). Poverty levels are clearly higher in rural areas, particularly in Ndzouani, which reportedly accounted for 78.8 percent of the household poverty in the Comoros.

Table 2.1. Poverty measurements by household, individual, and geographic location ${ }^{1}-$ Comoros 2004

\begin{tabular}{|c|c|c|c|c|c|c|c|c|c|}
\hline \multirow[t]{3}{*}{ Parameter } & \multicolumn{7}{|c|}{$\mathrm{FGT}^{2}$} & \multirow{4}{*}{$\begin{array}{c}\text { Real per } \\
\text { capita } \\
\text { Consumption } \\
(000 \mathrm{FC})\end{array}$} & \multirow[b]{4}{*}{$\mathrm{N}^{4}$} \\
\hline & & louseholds & & & & Individuals & & & \\
\hline & Incid & nce $(\alpha=0)$ & Intel & ity $(\alpha=1)$ & Inequ & lity $(\alpha=2)$ & & & \\
\hline Island/area & $\begin{array}{c}\text { Value - } \\
\text { P0 }\end{array}$ & Contribution $^{3}$ & $\begin{array}{c}\text { Value } \\
-\mathrm{P} 1\end{array}$ & Contribution $^{3}$ & $\begin{array}{c}\text { Value - } \\
\text { P2 }\end{array}$ & Contribution $^{3}$ & $\mathrm{P} 0$ & & \\
\hline Ngazidja & 0.353 & 0.46 & 0.12 & 0.449 & 0.058 & 0.452 & 0.427 & 661.3 & 1,433 \\
\hline Moroni & 0.278 & 0.069 & 0.095 & 0.067 & 0.044 & 0.065 & 0.374 & 578.4 & 273 \\
\hline $\begin{array}{l}\text { Secondary } \\
\text { urban }\end{array}$ & 0.195 & 0.021 & 0.054 & 0.017 & 0.021 & 0.013 & 0.279 & 897.6 & 118 \\
\hline Rural & 0.391 & 0.37 & 0.134 & 0.365 & 0.066 & 0.373 & 0.454 & 656.2 & 1,042 \\
\hline Ndzouani & 0.384 & 0.477 & 0.138 & 0.492 & 0.066 & 0.492 & 0.464 & 764.1 & 1,368 \\
\hline Urban & 0.252 & 0.088 & 0.085 & 0.085 & 0.037 & 0.078 & 0.313 & 763.5 & 384 \\
\hline Rural & 0.435 & 0.389 & 0.158 & 0.407 & 0.077 & 0.414 & 0.521 & 764.2 & 985 \\
\hline Mwali & 0.378 & 0.064 & 0.123 & 0.059 & 0.056 & 0.056 & 0.491 & 502.5 & 185 \\
\hline Urban & 0.375 & 0.035 & 0.126 & 0.034 & 0.057 & 0.032 & 0.481 & 552.7 & 102 \\
\hline Rural & 0.383 & 0.029 & 0.119 & 0.026 & 0.055 & 0.025 & 0.502 & 441.1 & 83 \\
\hline Total & 0.369 & 1 & 0.128 & 1 & 0.062 & 1 & 0.448 & 698.5 & 2,987 \\
\hline
\end{tabular}

Sources: EIM 2004.

(1) Not all poverty measurements were multiplied by 100 and the standard deviations are given in parentheses.

The poverty line is CF 285,144 per capita, per annum.

(2) Foster, Greer, and Thorbecke category indices.

(3) Relative contribution $\mathrm{C}_{\mathrm{ij}}$.

(4) Weighted N.

The EIM results point to four relatively distinct socioeconomic categories depending on the poverty incidence: (i) households where the head is a protected wage earner (poverty incidence: 25.5 percent); (ii) households headed by an unprotected wage earner, an independent worker in the informal sector, or a family assistant-apprentice (poverty incidence: $30-35$ percent); (iii) subgroups headed by a subsistence farmer, commercial farmer, unemployed person, or inactive person (poverty incidence: 38-39 percent); (iv) households headed by a microentrepreneur, stockbreeder, or fisherman (poverty incidence: $46-54$ percent).

We observe that three socioeconomic groups account for nearly two-thirds of national poverty: farmers' households (30.2 percent), unprotected wage earners' households (15.8 percent), and households headed by an inactive person (19.6 percent).

\subsection{EFFECT OF INEQUALITIES}

Per-capita expenditure inequality increased substantially at the national level during the period 1995-2004. All inequality indicators register a clear increase in disparities. The Gini index increased 25.7 percent (from 0.443 to 0.557 ). We note that per-capita expenditure inequality increased particularly in Ndzouani, and to a lesser extent in Ngazidja, while the reverse is true for Mwali. In this connection, the breakdown of sources of the level of inequality highlights the role 
of household demography (particularly the number of children 5-14 years of age), education level of the head of household, proportion of employees per household, and spatial location. We also observe that the existence of external transfers leads to increased expenditure inequalities, particularly in Ngazidja.

The determination of elasticities of poverty indices in respect of real per-capita household expenditure and the Gini index in 2004 suggests several observations. First, in the overall economy, the absolute value of inelasticities in respect of per-capita expenditure is substantially higher than 1 for all poverty measurements. A 1 percent increase in per-capita expenditure leads to a reduction in the poverty intensity ratio, respectively, by 1.64 percent and 1.87 percent. We also observe an upward trend in expenditure elasticities during the period 1995-2004.

Next, poverty tends to increase if expenditure inequality is accentuated during the economic growth process. The results show greater social fragility in 2004 as compared with 1995, with regard to economic growth and the change in income inequality: the compensation in terms of growth in expenditure to stabilize poverty, following an exacerbation of inequality, is higher in 2004 than in 1995. The breakdown of the change in poverty during the period 1995-2004 shows that the decline in poverty between 1995 and 2004 would have been higher had the inequalities been less substantial.

Although the available information does not permit us to verify trends in the situation in terms of inequality until 2009, low levels of economic growth combined with substantial inflation imply accentuated inequalities with serious growth in poverty during recent years in the Comoros.

\subsection{DETERMINANTS OF POVERTY}

The analysis of the determinants of poverty and sensitivity analysis — an assessment of the probabilities that households will be located in different segments of the standard of living distribution - is still valid and indicates the following:

- Households headed by stockbreeders (particularly in Ngazidja), fishermen (particularly in Ndzouani) or micro-entrepreneurs (particularly in Mwali) are more likely to be located in the poor rather than affluent segments;

- The effect of education on the standard of living is clearly evident regardless of geographic location. For example, at the national level, households headed by uneducated persons are at least twice as likely to be in the poor segment as those managed by a person having a secondary education. However, it is important to note that the effect of access to primary and lower secondary education, in comparison with no education, only moderately reduces the probability of belonging to the poorest group;

- The results highlight the impact of demographic factors. For the poor segment, the age of the head of household to some extent is directly related to the higher probability that the household will be located in this sector. Next, households managed by a woman are less likely to be exposed to poverty - findings valid for all islands. Last, we will observe the influence the size of the household, particularly in Ndzouani and Mwali. At the national 
level, one to two-person households are about four and one half times less likely to be poor than those comprising six to nine persons, and three and one half times more likely to be affluent than the former;

- While increasing productive employment in each household is one way to reduce poverty, the effect is not linear. There are disparities between the islands: the effect is fairly insignificant in Ndzouani, moderate in Ngazidja, and substantial in Mwali;

- Transfers have a substantial impact on poverty. Households that receive external transfers are less likely to be poor than those receiving none. By contrast, the incidence of transfers shows substantial disparities between the islands. The impact of external transfers clearly reduces the probability of poverty in Ngazidja ( 0.29 and 0.37 respectively, with and without fund transfers); and in Mwali (0.24 et 0.39). The existence of intra or inter-island transfers has no impact in Ngazidja, while the effect is to increase and decrease the probability of poverty, respectively, in Ndzouani and Mwali;

- The spatial dimension of poverty indicates that households are more likely to be poor when they are located in rural areas, particularly in Ndzouani.

\subsection{NON-MONETARY POVERTY}

The intervention mechanisms likely to help reduce poverty can also be found through the analysis of non-monetary poverty.

The EIM data indicate that housing is more informal in Ndzouani and Mwali, as compared with Ngazidja, if we consider that rammed clay or coconut palm leaves for walls, a roof made of straw and leaves, and compacted earth floors are materials characteristic of a highly informal dwelling in terms of housing quality.

Similarly, twice as many households use electricity as a source of lighting in Ngazidja than in Ndzouani and Mwali (53.6 percent, as against respectively 22.6 percent and 28.4 percent), as is also true in affluent houses as compared to poor ones (respectively 48.9 percent and 27.0 percent). There has been no indication in recent years that the electricity supply has improved, with devastating consequences for investment, enterprise profitability, and household well-being.

Wood is still the main source of energy for meal preparation. Approximately three fourths of the households use this energy source. This observation calls for more attention to the environmental impact of intensive firewood use.

Access to education is a highly important factor in development. Accordingly, analyses based on estimated earnings functions show that investment in education, especially for girls, yields substantial returns. For example, women having access to an upper secondary education earn 89.6 percent more income than uneducated women. For men, the marginal rate of return at this level of education is 52.1 percent. 
The disparities are even greater when we consider higher education: 403.5 percent and 131.9 percent, respectively, for women and for men. In this connection, we observe that annual education expenditure per child enrolled in school averages CF 44,000. Wealthy households spend four times more than poor ones per child enrolled in school (respectively CF 86,000 and CF 20,000 per year).

Considering the level of education of employed persons seven years of age and over, we observe that nearly half have no education and that 29.4 percent have no more than a primary education. Although the disparities according to the household living conditions and labor market status prevail, low education levels adversely affect the efficacy of the production system. Further, the literacy rate in adults (15 years of age and older) is registered at 56.5 percent, a figure that seems to reflect a substantial decline in literacy as compared with 1995.

According to the EIM, the net literacy rates at the primary (6-11 years) and secondary (1218 years) levels are respectively 68.8 percent and 66.2 percent. While the overall percentages seem to reveal progress as compared with 1998/1999, they are slightly lower than the figures reported by the Ministry of National Education (73.0 percent) in 2004. The data indicate that girls lag behind boys in terms of school enrollment, and that this lag increases with the level of education.

We observe that Comorian households still prefer to send their children to the Koranic school first. If we consider the type of institution attended, we observe that three fourths of school children are enrolled in public institutions. Last, while less than 1 percent of children drop out of school before they complete the primary level, the drop-out rate increases at the secondary level (5.2 percent).

Access to health care represents another element in human capital formation. The share of the Comorian state budget devoted to health declined in relative value from 5 percent to 3 percent between 2000 and 2003. Annual household expenditure on health, relative to morbidity, child immunization, and pre and post-natal care amount to CF 27,300 (respectively CF 23,000 and CF 25,000 for poor and affluent households), equivalent to less than 1 percent of total household resources.

A number of factors must be highlighted in terms of the scope of health access. First, it was found that 17.6 percent of the persons questioned had suffered from a disease or injury during the 15 days prior to the survey. The proportion was slightly higher in poor households than in wealthy ones, as we might expect. Personnel frequently consulted are physicians (65.3 percent), nurses (21.0 percent) and healers (6.0 percent). Further, we note that certain forms of child malnutrition are still fairly prevalent and that relatively little progress has been made during the past eight years. At the national level, the rate of growth retardation, emaciation, and underweight prevalence are respectively 44 percent, 7.9 percent, and 24.9 percent. Now, according to the 1996 demographic and health survey, these three rates were estimated respectively at 33.8 percent, 8.3 percent, and 25.8 percent. We note that the gender disparities in malnutrition are insignificant and indicate no bias against girls.

Further noteworthy access factors include (i) immunization coverage for children seven years of age and under is 81.3 percent, and we observe some disparities between the islands; (ii) very few 
(39 percent) children five years of age and under have been taken to a medical facility for postnatal care, particularly in Ngazidja; (iii) a substantial proportion of women have had pregnancies ending in still births (23.0 percent), particularly in rural areas (44.2 percent, as against 20 percent in urban areas), while 75 percent of women have had access to prenatal care. In two thirds of the cases, the consultations are with midwives; (iv) 72.0 percent of households own a mosquito net, although there are disparities between the islands, and the use of impregnated mosquito nets is much less widespread, particularly in poor households (one fifth of the population is not aware that impregnated mosquito nets exist); (v) the majority of the population (90 percent) is aware of HIV/AIDS and three fourths of the population knows that there are ways to prevent contracting the virus.

Last, there is an inverse relationship between the household standard of living and child malnutrition, except where growth retardation - a condition independent of the child's gender - is involved. There are, however, substantial discrepancies in child malnutrition by island, being less prevalent in Ngazidja and more prevalent in Ndzouani. We should emphasize that the EIM does not make the distinction between infant and infant-juvenile mortality, registering a mortality rate in children of women 15-49 years of age of 70.7 per thousand live births, which of course increases in direct proportion with the mother's age.

\subsection{IMPACT OF UNEMPLOYMENT AND UNDER-EMPLOYMENT}

The capacity to optimize household assets is of major interest in the analysis of household living conditions and poverty. In this connection, the EIM brought to light several factors.

First, the average household size declined from 6.3 persons in 1995 to 5.8 persons in 2004 . The dependency rate is currently 3.4 , which means that one active employed individual supports an average of 3.4 inactive or unemployed persons. In addition, the differential in dependency rates by gender of the head of household, which is biased against women, tends to be accentuated in poor households as compared with affluent ones. In this context, the activity rate for persons seven years of age and older is 37.5 percent (49.7 percent for persons 15-65 years of age), a relatively low level as compared with the ratios registered in the Middle East and North Africa. However, the descriptive analysis shows that the labor supply is affected by several factors:

(i) gender: 43.2 percent of males seven or more years of age are participating in the labor market, as against only 32.0 percent of females; (ii) age: the labor supply increases with age and then decreases; (iii) education level: supply rates by level of education move in a U-shaped curve; (iv) household living conditions: the labor supply rate for the poor is only 32.7 percent as against 46.5 percent for the affluent.

Second, the EIM shows a dualistic economic structure where an informal (essentially subsistence) agricultural and non-agricultural sector, and a developed tertiary sector are predominant. First, the agricultural sector, including fishing and stockbreeding, accounts for 57.4 percent of the jobs if we include activities conducted in "urban" areas and workers classified as "apprentices" and "family helpers." Individuals employed in agriculture belong primarily to poor households, and the agricultural sector employs many women. In fact, the agricultural sector encompasses 66.9 percent of jobs for women and 51.2 percent of jobs for men. In other words, 46.9 percent of the agricultural jobs are held by women. 
The non-agricultural informal sector is another component of the Comorian productive system. If we include independent workers and micro-entrepreneurs in the informal sector, the contribution of this sector to national employment amounts to 16.2 percent. Further, the role of women in the non-agricultural informal sector is substantial as it accounts for 19.5 percent of female employment, particularly in marginal activities. A total of 48.6 percent of jobs in the nonagricultural informal sector are held by women. Last, if we consider that all wage earners are part of the modern productive system (a high-side assumption), the latter contributes to 26.3 percent of national employment. However, unprotected wage earners are predominant in the modern sector as they account for approximately two-thirds of the jobs. Another characteristic of the modern sector is the small share of employment for women: wage earners contribute only 13.7 percent of women's jobs, 69.2 percent of which are unprotected (71.4 percent for men). This modern sector wage earning structure explains why only 28.4 percent of the individuals working in the sector are located in affluent households.

Against this backdrop, if we consider age and education levels, we can refine the foregoing configuration of labor market integration. First, the mechanisms for integration into the labor market are different for young men and women: nearly 70 percent of the activities for young girls 24 years of age and under are inherent in agriculture and the informal sector, and wage earning occupies a very small place (9.2 percent). By contrast, access to the labor market for young men in the same age group is more diversified and wage earning occupies a substantial place. In these conditions, girls have greater access to the market for "bad jobs" and these ports of entry probably steer them more towards self-employed and often marginal activities. By contrast, young men have access to the labor market of "good jobs," particularly wage earning, which plays an important (but not exclusive) role in their professional careers. Further, the location of labor in certain labor market segments is easily explained by low levels of education. For example, 80.1 percent of the women employed are uneducated, as against 63.9 percent of men.

Third, we observe that women's annual income is much lower than men's: respectively CF 834,400 and CF $1,302,000$, or a ratio of 0.64 . An income distribution by activity is fairly uneven. The estimated earning function shows that (i) education is a substantial determinant of income from the labor market, and marginal yields increase with the level of education; (ii) being a man increases annual income by an average of 116.3 percent; (iii) unprotected wage earners, farmers, and stockbreeders receive less income than protected wage earners; and (iv) the geographic location and environment play an important role in individual income determination. All workers in rural areas and urban areas in Mwali earn less than those in Moroni. When the father has a secondary education, this has positive effects on income from work.

Fourth, household income is derived from three major sources: (i) earnings from the main activity (36.9 percent); (ii) consumption of home-grown food (27.7 percent); and (iii) imputed housing value (23.9 percent). In fact, the average household income (CF 699,000) is quite close to current annual expenditure (CF 698,600), reflecting a low level of savings. Further, there are significant differences depending on the island and various parameters for the head of household or group. In particular, if income from domestic and external transfers represents 2.5 percent of all household income, the amount of funds transferred per capita to Ngazidja, compared with Ndzouani, should be emphasized (CF 95,400 as against only CF 31,100). Similarly, the IEM shows the scope of household transfer resources managed by a woman in comparison with male households (CF 50,800 as compared with CF 88,600). 
Although the level of urban development in the Comoros is not high, unemployment merits special attention. It was found that 13.5 percent of active persons 7 years of age or more were unemployed in 2004- a slight increase as against 1995, albeit a random comparison. The survey shows that the unemployed population includes 47.6 percent of persons who have never worked, i.e., most commonly young people. Further, unemployment rates are slightly higher in Ngazidja (14.9 percent) and in Mwali (15.0 percent) than in Ndzouani (12.1 percent).

In examining the characteristics of unemployed persons, we observe the specificity of unemployment where young people are concerned: (i) for persons under 24 years of age, unemployment strikes one fourth to one third of the active population; (ii) the ratio of unemployment rates for persons 15-19 years of age and 30-49 years of age is approximately five, and it declines to approximately four when we consider the 20-24 year age bracket; (iii) 64.9 percent of unemployed persons are between 7 and 29 years of age, while 44.6 percent belong to the 15-24 year age group ( 42.4 percent boys and 46.1 percent girls); (iv) although the discrepancies tend to decline for the 25-29 year age group, the proportion of young unemployed females as a share of total unemployed girls is nearly twice as high as it is for young boys. We further observe that unemployment also has a more pronounced effect on young persons, regardless of the education level.

Child labor analysis suggests a few parameters that influence school enrollment. Accordingly, the probability of attending school for children aged 7-17 declines: (i) with poverty; (ii) when the head of household is a farmer compared with a protected wage earner; (iii) when the head of household is a man; (iv) when the household is located in Ndzouani. Similarly, children are more likely to go to school when: (i) the head of household is educated; (ii) the head of household is of a certain age; (iii) when households have numerous children, particularly aged 5-14, and adults over 60 years of age; (iv) when the children belong to the head of household. Further, the probability that girls will attend school is lower than it is for boys, and the marginal effect is fairly high.

\subsection{RESTORING GROWTH AND REDUCING POVERTY}

The poverty profile shows that it is an urgent matter to restore the growth process and wage a resolute war against the causes of poverty in the Comoros. The results of the EIM show the importance of recovery in the private sector, particularly in the agro-food areas, to ensure robust economic growth and achieve a significant reduction in poverty. These dynamics, however, must extend to economic transactors in other growth sectors (tourism, trade, and works and construction) which are the only sectors capable of making the necessary investments to restore growth, create jobs, and reduce the poverty in which many Comorian households live.

By contrast, growth alone is insufficient to guarantee a substantial reduction in poverty if the inequalities become accentuated, access to education and health fails to improve, and the environment deteriorates. The government has therefore made access to education, quality health care (particularly in the area of reproductive health) and environmental conservation priorities likely to improve the living conditions for the Comorian people in the context of this PRGS. 


\section{CHAPTER III}

\section{ANALYSIS OF SECTORAL PERFORMANCE AND CONSTRAINTS}




\subsection{INTRODUCTION}

This chapter presents a diagnostic assessment of the key economic and social sectors impacting poverty reduction and growth. Nine sectoral studies were conducted in connection with PRGS preparation. Each study produced a sectoral diagnostic assessment, which is presented in summary form in this chapter. Possible paths of intervention in connection with the PRGS are identified for each sector.

The sectoral diagnostics cover the following: (1) a presentation of the sector to highlight its economic and social importance; (2) sector performance and strengths; (3) weaknesses and constraints; and (4) outlook for the sector.

These analyses identified the endogenous and exogenous factors affecting sector performance. The specific features of each island were mentioned when the data permitted. The following sectors and subsectors were analyzed:

- Agriculture, fishing, and stockbreeding;

- Tourism;

- Energy, drinking water, and sanitation;

- Economic and communication infrastructure;

- Environment and public security;

- Governance and social cohesion;

- Education;

- Health;

- Private and financial sector.

\subsection{AGRICULTURE, STOCKBREEDING, AND FISHING}

The agrofood sector (agriculture, stockbreeding, and fishing) is the foremost engine for the Comorian economy. This sector employs the majority of the population, contributes significantly to household income, constitutes the leading source of foreign exchange, and provides the bulk of the products consumed by the population, although food imports are still substantial.

\subsubsection{AGRICULTURE SUBSECTOR}

Agriculture is a major contributor to the Comorian economy. This sector generates approximately 49 percent of the country's GDP, 80 percent of its jobs, and nearly 90 percent of its export revenue.

The agricultural sector is generally characterized by the following crops: subsistence crops (bananas, taro, cassava, and coconut), commercial vegetable crops (tomatoes, lettuce, potatoes, and onions), export crops (vanilla, cloves, ylang-ylang, coffee, and pepper), orchard production (citrus fruit, avocados, mangoes, jackfruit, and guava), and forestry.

Despite the country's diversified food production and agricultural potential, rice is still the basic food staple in the Comorian diet, and it is essentially imported. Almost all food, fruit, and 
commercial vegetable production is consumed locally. Storage and processing of agricultural products, which are high value-added activities, are still limited. Vanilla is still the main agricultural export product and constitutes the main source of foreign exchange in this sector. Over the years, the Union of the Comoros has become the world's leading producer of ylangylang essence.

\section{Sector performance and strengths}

There are several objective factors indicating that the agricultural sector can contribute substantially to restored growth and poverty reduction in the Comoros, if special efforts are made for its restructuring. This effort primarily involves:

- In the area of food and commercial vegetable crops, successful introduction of high-yield and disease-resistant varieties, and an increasing number of farmers who have mastered the technical production routes (itinéraires techniques de production);

- An established, operational supply network for agricultural inputs;

- The government's willingness to resume investments in the agricultural sector through medium-term public investment programs (PIP);

- Establishment of development funds (for development of food crops, fishing, etc.);

- Existence of growing domestic demand;

- Potential for diversification of cash crops;

- Small-scale spice and fruit processing and preservation;

- Fine species (spices and perfume) combined with existing crops on the same plot of land.

Food crops represent 80 percent of agricultural production and account for approximately 47 percent of value added in the agricultural sector. They are grown on small family farms and production substantially covers household food security.

Fruit crops are highly diverse and are harvested year round. These exceptional conditions make it possible to offer fresh fruit throughout the year. It would be a simple matter to increase fruit production to supply inputs to a fresh fruit juice or concentrate processing enterprise.

The contribution of commercial vegetable crops to national consumption could be strengthened with (i) broad dissemination of proven technical solutions; (ii) improved preservation methods; (iii) diversified forms of consumption; and (vi) a more effective marketing structure to limit distribution costs and irregular supplies. 
An organization movement has emerged and taken over certain basic functions in agricultural development: (i) organizations responsible for the supply of agricultural goods and services at the grassroots level: distribution of agricultural inputs, advisory support, etc.; (ii) organizations responsible for promoting activities to gain community support, education activities, and pooled development and management of the community equipment at the village level; (iii) rural financial institutions: village banks and savings and loans; and (iv) organizations primarily devoted to representing producers and defending their interests with the outside world, a farmers' union and a fishermen's union.

\section{Sector weaknesses and constraints}

Efforts to develop the Comorian agricultural sector must address certain major constraints to be eliminated and a series of problems to be corrected. The most important of these issues are listed below:

- Food, commercial vegetable, and fruit crops: water management; property access and security; isolation of production areas; insufficient marketing, processing, preservation, and supply structures; insufficient access to credit, and lack of appropriate resources for extension units;

- Export crops: isolation and fragmentation leading to high production and labor costs, which affect the competitiveness of Comorian products on the international market; insufficient diversification and absence of raw materials upgrading and marketing policies.

In addition to these specific constraints, we should add problems in active population renewal (rural flight of young people; absence of attractive, immediate income; absence of appropriate mechanization to make the work less strenuous).

Farmers' organizations are in the early development stages and lack the means and human resources to meet the rural community's needs in light of the government's divestiture of service, management, production, and marketing functions.

Despite these constraints, the sector offers real potential to grow and have a significant impact on poverty reduction, as the country's number one contributor to GDP and job creation.

In this context, the following activities must be targeted as priorities:

- Definition and implementation of an appropriate land reform;

- Capacity building for farm and professional organizations;

- Intensification of agricultural production (investments in irrigation, mechanization, secure supplies of inputs, fertilizers, access to credit, extension, training, research, etc.);

- Promotion of the agrofood industry; 
- Development of Comorian products through a Comoros brand;

- Establishment of an institutional framework to promote balanced development of the agricultural sector;

- Promotion of an agricultural entrepreneur class.

\subsubsection{STOCKBREEDING SUBSECTOR}

Stockbreeding is of minor importance in the agrofood subsector as it represented only 11 percent of the sector value added in 2007, far behind agriculture (49 percent), fishing (31 percent), and forestry (9 percent) (National Accounts, 2008). In terms of its contribution to poverty reduction, this subsector represents an essential factor as it gives poor farmers a means of saving (small ruminants and poultry) that can be quickly liquidated in case of emergency. It is also a subsector that represents substantial development potential as shown by the progress registered during the past 20 years in the intensification of cattle and goat dairy production.

In the Comoros, the stockbreeding sector is comprised primarily of ruminants and poultry. Other species are only found in insignificant levels.

\section{Ruminant breeding}

The situation can be described as follows for ruminants:

- Number of species: small numbers, in total and per capita terms, dominated by goats and cattle. The numbers are higher in Nzwani than Ngazidja (there were substantial herd losses in 2003-2004 as a result of the epizootic theileriosis);

- Herds are highly dispersed to rearing practices, mainly stall breeding (to prevent crop destruction). The animals are owned by the farmers themselves and it is uncommon for them to be supervised by herdsmen;

- Few pastures and those that do exist are poor in quality. Accordingly, feeding is predominantly grass fodder and harvested tree leaves; fodder crop areas are small, except in Nioumakélé; watering is often not provided and is difficult even when waterways exist, as the water must be transported to the animals;

- Insufficient production owing to low productivity in local breeds, hence the deficit in meeting the population's requirements. The country must import approximately 80 percent of its red meat requirements;

- The health situation has clearly been on the decline for the past five years; imports of cattle and goats on the hoof have introduced new tick-borne and viral diseases into the three islands, particularly Ngazidja; 
- Rehabilitation of the national livestock laboratory and two regional laboratories in Nzwani and Mwali, and establishment of a quarantine site in Moroni;

- Insufficient technical and health extension; only veterinary, animal production, and advisory NGOs are servicing this subsector;

- Existence of a dairy in Nzwani (a group of livestock farmers affiliated with the National Union of Comorian Farmers_-SNAC) although with operating difficulties;

- Trading in animals is a one-way activity from Mwali and Nzwani to Ngazidja; in both directions between Nzwani to Mwali; and curds are transported from Nzwani to Ngazidja.

\section{Poultry breeding}

Poultry breeding is characterized substantially by:

- Numbers and types of stock: a low total number of animals and number of head per capita, dominated by village and semi-intensive poultry farming; the latter has declined substantially during the past 10 years as a result of chick and fodder supply problems;

- Imported feed and chicks for semi-intensive poultry farming;

- Low production levels as local breeds are an insufficiently productive and semi-intensive poultry farms are small. Accordingly, there is a shortfall in meeting population demand, requiring the country to import approximately 80 percent of its white meat consumption;

- Health situation dominated only by losses owing to Newcastle disease;

- Insufficient technical and health extension; only veterinary, animal production, and advisory NGOs service this subsector;

- Farmers' groups present in Ngazidja (SNAC member) and Nzwani, although they are insufficiently organized.

\section{Subsector performance and strengths}

Much progress has been made during the past five years in ruminant and poultry farming. The stockbreeding subsector has certain strengths in development of dairy production and attempts to produce livestock feed.

\section{Ruminant breeding}

- Increase in cow's milk production per animal (from 2 liters to more than 10 liters per day) and in total production with crosses by natural covering and artificial insemination using highly productive foreign blood in Nzwani, and through the introduction of purebred dairy cows (from Tanzania) in Ngazidja; 
- Increase in goat meat production through crosses with Boer bucks in Mwali and Nzwani;

- Development of fodder crops in dairy production development centers;

- Local breeds well adapted and responding well to genetic improvement;

- Farmers highly receptive to technical changes;

- Attractive meat and milk market;

- Existence of NGOs capable of covering veterinary care, artificial insemination, and advisory services.

\section{Poultry breeding}

- Attempt to implement animal feed production in Nzwani;

- Attempt to establish a one-day-old chick production unit in Ngazidja;

- Existence of a nursery with highly motivated professional poultry farmers;

- Attractive market for white meat.

\section{Subsector weaknesses and constraints}

The weaknesses in the stockbreeding subsector and the constraints it faces are similar for both ruminants and poultry.

\section{Ruminant breeding}

- Insufficient health control at the borders;

- There is no organized dairy marketing;

- Insufficient production credit;

- Insufficient extension activities;

- Insufficient support for veterinary inputs, and in particular, vaccines are not subsidized by the state (theileriosis and Rift Valley fever).

- Very high production costs in light of competition from ruminants imported from neighboring countries such as Tanzania or Madagascar. 


\section{Poultry breeding}

- Chick and feed supply problems;

- Insufficient production credit;

- Insufficient extension activities;

- Very high production costs owing to competition from imported chicken wings and thighs.

\section{Stockbreeding sector outlook}

- Intensification of milk cow breeding by natural covering and artificial insemination with highly productive, easily adaptable blood;

- Intensification of goat breeding for meat through natural covering and artificial insemination with highly productive and adaptable blood;

- Support for semi-industrial poultry farming;

- Enhanced health controls at the borders and strengthened legislation governing imports of live animals;

- Support for players in the livestock subsector;

- Human resource capacity building.

\subsubsection{FISHING SUBSECTOR}

Despite the importance of sea products as a source of animal protein for the population and as a potential source of income, including through exports, fishing in the Comoros remained purely traditional until 1985, characterized primarily by boats that were archaic and highly risky. In the framework of fishing agreements with Japan and the European Union, efforts were made to improve the fleet, fishing techniques, to develop the fishing school, implement conservation units, etc.

The country's fishing territory encompasses an estimated maritime zone of more than 160,000 square kilometers, covering 900 square kilometers of continental shelf and 427 kilometers of coastline. This area is packed with potential resources estimated at 33,000 tons per annum, 64 percent of which is now exploited. This sector employs 6 percent of the population (equivalent to 8,500 direct jobs and 24,000 indirect jobs) and accounted for 12 percent of GDP in 2008 and 5 percent of foreign exchange revenue through exports. 


\section{Subsector performance and strengths}

- Existence of professional artisan fishing operations;

- Extensive motorization (30 percent of a fleet of 5,000 boats);

- More or less functional support and advisory agencies;

- Possibility of increasing catches by expanding the fishing zone;

- Strong demand for fishing products on the national, regional, and international markets;

- An international context for fishing characterized by full exploitation of existing fish reserves;

- Existence of unexploited niches (octopuses and squids [cephalopods], lobster, and shrimp);

- Existence of fishing development strategies (Food and Agriculture Organization of the United Nations - FAO, Arab Authority for Agricultural Development and InvestmentAAIDA, European Union-EU).

Although these resources are under-exploited, we observe an increase in national fish production from 6,000 tons in 1985 to 16,200 tons in 2004, leading to a discontinuation of fish imports for normal consumption.

\section{Subsector weaknesses and constraints}

The discontinuation of support programs in recent years has revealed human, technical, material, and commercial weaknesses:

- Weak support services and management and planning skills in the sector;

- Lack of data and information on resources;

- Low private participation in fishing activities;

- Lack of access to credit;

- Absence of a maritime safety system;

- Production capacity constraints;

- Overfishing off the coast;

- Absence of unloading facilities; 
- Lack of electricity and water at fishery sites;

- Absence of an organized marketing system;

- Failure to upgrade fishing products destined for external markets.

\section{Outlook for the subsector}

The fishing subsector in the Comoros can contribute much to economic growth and poverty reduction through an improved technical and economic environment (improved port infrastructure, land processing, subsidies, and other similar facilities) and through the implementation of fishing development plans. The objective is to increase the current level of production by more than 50 percent, to create more than 5,000 new jobs, and to achieve a substantial increase in the sector's contribution to GDP (approximately 16 percent) by 2014 .

\subsection{TOURISM SECTOR}

The tourism sector is acknowledged to have substantial economic growth and employment potential. As a sector that is closely correlated with the key areas of development, it has an impact on sectors directly related to its activities, such as transportation, hotels, and relevant agencies, but also on trade, building and public works enterprises, energy, agriculture, fishing, artisanal industry, telecommunications, and cultural events.

The hotel supply now consists of approximately 472 beds, which is far short of the supply in other countries of the region: more than 14,000 beds in Mauritius and approximately 4,600 beds in the Seychelles. The quality of the lodging supply is also not the same, varying between international hospitality standards and basic comfort found in the majority of establishments managed by nonprofessionals, with untrained staff. An estimated 490 persons are employed in the tourism sector.

While the Comoros has no hotel training facilities, the Indian Ocean Commission (COI)/EU regional tourism program has given more than 100 hotel sector employees the opportunity to attend specialized seminars in this sector. At the national level, the Tourism Directorate supported training for 150 young persons during the last four years of secondary school.

Prior to 1989, tourism visits primarily involved business tourism, missions, and visits by Comorian expatriates living in France. Pleasure tourism came of age in 1989 with the opening of Galawa, leading to a rapid increase in hotel visits. A substantial decline in incoming tourism began in 2000, with visits falling from 27,474 in 1998 to approximately 18,900 in 2003. This decline is largely attributable to the closing of Galawa in 2000.

The hotel clientele came primarily from South Africa, France, Germany, and England. The increase was attributed to the reliability of Emirates airline that provided service between the Comoros and South Africa and between the Comoros and Europe; as well as to the Galawa 
complex's marketing and promotion efforts. Further, the regional COI tourism program financed by the EU contributed by enabling the Comoros to participate in various international tourism events.

The sudden discontinuation of Emirates service, the closure of Galawa, and political instability led to a decline in arrivals. Accordingly, revenue declined from more than CF 5 billion in 2000 to less than CF 3 billion in 2003.

While the tourism sector of the Union of the Comoros has several strengths, it suffers from many weaknesses, some of which are inherent in the sector, while others are more cross-cutting and structural.

\section{Sector strengths}

The natural and cultural resources, substantial potential for adventure and sports activities, and village activities are part of the very attractive tourism fare the national territory offers. Among the strengths, we observe:

- Forty-five sites of tourism interest already surveyed;

- Abundant natural species;

- Flora including more than one hundred species of orchids;

- Remarkable marine fauna species (coelacanths, sea turtles, and dugongs);

- Rich, varied historical resources: archeological sites, religious buildings, ancient sultans' buildings, fortifications and tombs;

- Rich and developing craft industries — primarily wood carving, traditional jewelry, and above all, substantial skilled labor potential in cabinet making, wicker work, and embroidery;

- Cultural wealth extending to other areas such as grand wedding ceremonies, songs, dances, Comorian cuisine, the National Center for Documentation and Scientific Research (CNDRS) museum in Moroni, traditional medicine, games, and village activities;

- Sport activities highlighting the natural environment: diving, deep-sea fishing, and mountain hiking;

- An attractive investment code. 


\section{Sector weaknesses and constraints}

Several constraints are impeding the development of tourism activities:

- Insufficient basic infrastructure (roads, ports, airports, energy supplies, etc.);

- Insufficient city and village sanitation;

- Insufficient regional and international air service and very high ticket prices;

- Prohibitive rates for water, energy, and telecommunications, interest rates, and deficient air, sea, and land transportation;

- Insufficient hotel capacities;

- Insufficient national and international investments;

- Insufficient port and airport accommodation facilities;

- Virtually nonexistent legal framework to protect investments;

- Lack of transparency in granting national heritage concessions to the private sector;

- Very high cost of visas to enter the country;

- Insufficient promotion of Comorian crafts;

- Insufficient hotel, restaurant, and guide training;

- Absence of a tourism office;

- No marketing or promotion of the Comoros as a destination.

\section{Sector performance}

The Comoros has had good tourism periods: tourism arrivals amounted to 22,838 in 1995 and peaked at 27,474 in 1998. Today, after the closure of Galawa and a number of political crises, the country registers 14,000 arrivals, equivalent to 45 percent of the residual hotel capacity.

Tourism revenue varied during the same period from CF 5 billion (4.1 percent of GDP) in 2000 to CF 3 billion in 2005. Jobs declined from 960 to the present level of 490 . 


\section{Outlook for the tourism sector}

Based on these strengths, the government adopted a sector development strategy in 2005 that was updated in 2008. The strategy aims to preserve the country's natural and cultural resources, to engage the local populations, and to reduce poverty. This form of tourism is commonly known as ecotourism. The strategy, which requires support from donors and lenders and the interest of domestic and international investors, will be reflected by the:

- Creation of ecotourism relays and heritage centers of tourism interest;

- Marking of hiking paths;

- Upgrading of maritime links between the islands;

- Improvement in basic infrastructure;

- Human resource training;

- Promotion and marketing of tourism products;

- Creation of a tourism data observatory;

- Development of combined regional systems.

In cooperation with sector players, the government decided to revitalize the tourism sector and to designate it as one of the key growth sectors in the coming years. In fact, the sector could contribute substantially to:

1. Improve the population's living conditions through:

- $\quad$ Direct local job creation (lodging, restaurants, and guides);

- Indirect local job creation (transportation, crafts, agriculture, and fishing);

- Development and diversification of training in the trades;

- Creation of a market to stimulate local production such as commercial vegetable growing, stockbreeding, fishing, and crafts;

- Increased passenger and commercial connections between the islands through the establishment of reliable, rapid, and frequent connections;

- Making the national tourism area accessible;

- Access for the Comorian public to tourism accommodations and leisure activities. 
2. Activities respectful of the natural and cultural environment through:

- Preservation and development of natural sites;

- Organization of cultural activities such as: (1) restoration and development of the country's cultural and historical resources; (2) development of traditional shows; and (3) development of craft activities.

The Comoros is endowed with rich cultural and natural resources. These resources can constitute a powerful factor in the development of ecotourism. It is important for the government that its development partners support the restoration of the tourism sector in connection with the PRGS. Accordingly, village organization movements, local receiving agencies, hotel and restaurant operators, diving clubs, craftspersons, rural communities, fishermen, and natural essence distillers will be the main beneficiaries of tourism development.

With new investment projects to increase the hotel capacity to 2,000 beds by 2014 , tourism can make a significant contribution to improve national GDP with the intention of creating 2,500 direct jobs.

\subsection{ECONOMIC AND COMMUNICATIONS INFRASTRUCTURE}

Economic and communications infrastructure is a determinant factor in the process of economic development. Economic infrastructure includes roads, telecommunications, ports, and airports. The lack of economic infrastructure is one of the main obstacles to private sector recovery and poverty reduction.

\subsubsection{ECONOMIC INFRASTRUCTURE}

\section{Road infrastructure}

Road infrastructure clearly contributes to economic growth and poverty reduction by facilitating the circulation of goods and persons, and by promoting the creation of new economic activities.

The national and regional road system in the Comoros includes a total of $849 \mathrm{~km}, 665 \mathrm{~km}$ of which are asphalted and $184 \mathrm{~km}$ are unpaved. The system is distributed as follows: 58.3 percent in Ngazidja (495 km), 33.2 percent in Ndzouani $(256 \mathrm{~km})$ and 11.5 percent in Mwali $(98 \mathrm{~km})$. The road system is now characterized by the following:

- Deterioration as a result of insufficient maintenance;

- Uncontrolled increases in heavy truck traffic, primarily in Ngazidja;

- An insufficient structure to accommodate use;

- A need to make the agricultural and fishing production areas more accessible; 
- Unpaved roads that cannot be used for substantial periods during the year;

- Absence of signing.

\section{Performance and strengths of the road infrastructure subsector}

The country can rely on the following to promote road infrastructure:

- Programmed implementation of a toll to support the road fund to replace the fee now charged under the current law;

- Resources generated under the convention on economic citizenship;

- Recent establishment of new road companies;

- Technical studies and documentation on past consultations carried out involving the construction and/or rehabilitation of priority road sections. Financing has already been obtained for some of these works.

\section{Weaknesses and constraints of the road infrastructure}

The main constraint to the development of the subsector is clearly insufficient national capacity to manage and control road maintenance, implementation of which is fundamental. We also observe:

- Delays in implementing coordination of new administrative structures (governoratesUnion);

- Lack of maintenance in the road system;

- Failure to comply with road legislation;

- Ongoing deterioration in roads as a result of ageing, uncontrolled traffic, and insufficient drainage;

- Lack of load controls on the road per axle;

- Lack of a road database;

- Lack of appropriate logistics for the execution of maintenance works.

\section{Outlook for the road infrastructure subsector}

Road construction and maintenance represent a substantial source of job creation, particularly for the least favored sectors, if labor intensive technologies, which should be emphasized whenever possible, are used. 
Improved access and reduction of transportation costs will impact production costs and prices of consumer goods, as these factors tend to increase the circulation of goods and persons and intensify economic activity.

In addition, a well-maintained road system enhances the population's access to government services, health centers, schools, etc., and promotes the development of industries such as tourism.

The public authorities of the Comoros intend to undertake the improvement, expansion, and upgrading of platforms and roadways compatible with traffic and safety, as well as village bypasses.

Rehabilitation and extension of the national road system should promote:

- Improved circulation of goods and persons;

- Enhanced tourism development;

- Reduced maintenance costs for the current fleet of automobiles;

- Improved safety conditions;

- Access to the markets for agricultural and food products;

- Job creation.

\subsubsection{PORT INFRASTRUCTURE}

Port infrastructure facilitates foreign trade and commerce between the islands. Occupation rate for berths and docks are substantial if we consider the time spent at the dock by ships coming from the islands and the substantial increase in inter-island traffic. The country is now underequipped with port infrastructure.

The situation can be described as follows:

- Ngazidja is the focus of 80 percent of the country's commercial activities, but has only one deepwater port. Similarly, processing of sea products is the core issue in private sector rehabilitation. The Union of the Comoros signed fishing agreements with the European Union approximately 12 years ago. The absence of an adequate port structure and a stable energy supply are preventing the country from benefiting from the advantages provided under this agreement.

- In Ndzuwani, the deepwater port of Mutsamudu, built in 1982, is used as a transshipment port. Its activities have increased in recent years despite the problem of silting up that 
occurs as the river empties into the port basin. Port traffic could be developed if these port facilities were improved.

- In Mwali, a maritime access was established in 1999-2001 in Bwangoma in connection with the Sixth, Seventh, and Eighth European Development Fund (EDF). The project failed to reach its specific objective. Transferring of passengers by canoe is dangerous in rough seas. Maritime access use varies in the range of 50-70 percent during the year. Corrective measures to optimize use of this access would involve protecting the works with a seawall in deep water.

The port facilities are now operated by private handling companies such as Golf Com (Port of Moroni) and ASC (Port of Mutsamudu).

\section{Weaknesses and constraints of the port infrastructure subsector}

The main weaknesses and constraints of the subsector are:

- Insufficient organization of the harbormaster's office for the Port of Mwali;

- Lack of marking for all ports in the country;

- Insufficient draft in the Port of Moroni, which requires anchorage for most international coastal navigation;

- Silting of the Port of Mutsamudu with sediment carried by the river emptying into the basin;

- Lack of protection for the Mwali maritime access dock;

- Absence of offloading and lifting equipment in Mwali;

- Flooding of docks and platforms;

- Inability of ports to supply high-quality services to reduce lags in providing the country with supplies of inputs, spare parts, and raw materials for various economic sectors;

- Numerous breakdowns in the maritime traffic system between the islands, including the absence of designated secondary ports;

- Security problems for goods stored in warehouses;

- Deficient the maritime security system. 


\section{Outlook for port infrastructure}

The government plans to re-examine the role of the various participants to encourage all of them to honor their contractual commitments, which will reduce the cost of port services.

Further, in light of the growing volume of commercial activities in Ngazidja and the loss of time at anchorage for large ships to offload merchandise, the government of the Union of the Comoros intends to equip Ngazidja with a deepwater port comprising:

- A commercial dock;

- A transshipment dock for fish, including appropriate refrigeration facilities.

In Ndzuwani, to enable the Port of Mutsamudu to effectively serve as a port of entry and transshipment, the public authorities should carry out the following works:

- Construction of a dam upstream from the city of Mutsamudu to retain most of the sediments and materials carried by the river;

- Dredging to restore the original drafts;

- The bypass of the Mutsamudu river from a point upstream from the south platform access dock to the outside of the basin.

In Mwali, to ensure that maritime access is profitable and to enhance access conditions to meet the appropriate safety standards as provided for maritime navigation, the government intends to make maritime access similar to port access and to reduce swells that would make approaches difficult. This would involve protecting the breakwater from swells exceeding 0.5 meter and as much as 6 meters or more reaching the bay delta.

\subsubsection{AIRPORT INFRASTRUCTURE}

Infrastructure in this area comprises of the Moroni Prince Said Ibrahim Airport (AIMPSI) located in Hahaya, Ngazidja, and the secondary airports Ouani in Ndzuani and Bandar-Salama in Mwali. These airports service international and inter-island air links. Traffic, however, is fairly limited.

The secondary airport infrastructure is characterized by deteriorated runways, absence of safety (fire and rescue) equipment and lack of fences in all three airports. These problems compromise the security of inter-island air transport.

\section{Performance and strengths of the airport infrastructure subsector}

- The Comoros's membership in the Air Navigation Safety Agency (ASECNA) makes it possible to improve air safety and navigation; 
- The construction of a new AIMPSI air terminal, rehabilitation of the runway and extension of gates.

Weaknesses and constraints of the airport infrastructure subsector

- The ageing landing strip at the international airport can compromise air safety for large aircraft;

- Limited space in the passenger arrival hall;

- Insufficient organizational system;

- Secondary airports are characterized by the following weaknesses:

- Limited accommodation capacity for planes and passengers;

- Insufficient air navigation equipment (weather and radio communication);

- Absence of runway markings;

- Insufficient fences to protect the runways and hangar;

- Absence of a fire safety system.

\section{Outlook for the airport infrastructure subsector}

The outlook for air transportation in the context of a country such as the Comoros no longer remains to be proven. Efficient, secure airports are required for the tourism sector to offer attractive growth prospects. The same applies for air freight development.

\subsubsection{Telecommunication infrastructure}

Telecommunications in the Comoros became diversified in 2004. The national post and telecommunication company (SNPT) established a mobile telephone network to supplement the longstanding fixed system. In 2005, as a result of the split of the SNPT into Comores Télécom and Société Nationale des Postes et des Services Financiers (SNPSF), other services (networks) were created: CDMA, ADSL, and the extension of the GSM network.

\section{Performance and strengths of the telecommunication subsector}

- The main strengths of the subsector are rapid growth in installed lines owing to demand from new customers;

- Installation of telephone booths in rural areas; 
- Gradual improvement in telephone coverage with the installation of micro-centers in the islands;

- Improvement and reinforcement of the institutional framework;

- Existence of a sectoral information and communication technology (ICT) policy.

\section{Weaknesses and constraints in telecommunications}

- Accidented relief, making telephone coverage difficult in certain regions;

- An obsolete wiring system;

- Inefficient telecommunication services at costs deemed to be quite high;

- An institutional and legal framework for the subsector that is not observed;

- Nonconformity with public contracting regulations;

- Excessive maintenance intervention time (faults).

\section{Outlook for the subsector}

Development of this sector requires rehabilitation of the existing fixed telephone system to enhance access to telecommunication services. The government intends to focus its efforts on increasing the capacity of the networks to ensure:

- Greater access to services at reasonable prices for all islands;

- More fluid connections with the rest of the world to gain access to economic opportunities;

- Effective promotion of the tourism sector, enabling operators to advertise through websites;

- Easier communications within the Comoros and with the Comorian expatriate community;

- Liberalization of the telecommunication sector. 


\subsection{ENERGY, WATER, AND SANITATION SECTOR}

\subsection{ENERGY SUBSECTOR}

Energy plays a particularly important role in socioeconomic development. It is a determinant in the operation of enterprises and makes it possible to improve household living conditions.

The Comoros's energy balance shows wood as the main energy source ( 78 percent of energy requirements) followed by hydrocarbons (20 percent). Other energy sources (electricity, butane gas, etc.) occupy a negligible share (approximately 2 percent) of Comorian household consumption. Expansion of the existing electricity network in the Comoros and improved management and service quality could have a significant impact on growth and contribute to household well-being with a reduction in the harvesting of wood materials.

\section{The energy subsector is characterized by:}

- Low levels of energy consumption in general (122 ktep in 2001, equivalent to 0.2 tep per capita), and conventional energy, particularly indicative of a low level of economic development;

- Substantial dependence on wood fuels, and exploitation of this resource is negatively impacting the environment (massive deforestation, erosion, etc.);

- A substantial increase in petroleum product consumption (gasoline, diesel oil, kerosene, and lubricants) all of which are imported, partially explaining the high cost of energy;

- Limited use of butane gas, essentially in urban centers. A reduction in import duty may lead to increased consumption;

- Insufficient use of new and renewable energy sources despite real potential (hydroelectricity in Ndzuani and Mwali, geothermal power in Ngazidja; and biomass, solar, wind, and tidal sources on all three islands);

- Electricity production based essentially on the operation of thermal power plants having a total installed power of $24 \mathrm{MW}$;

- Production stock requiring adequate maintenance to ensure sustainable and effective energy production;

- Low overall efficiency in the electrical system of less than 45 percent for the overall country;

- Electricity production capacity losses of approximately 55 percent attributable to fraud, illegal hook-ups, technical network deficiencies, and low recovery rates. 


\section{Energy sector performance and strengths}

- Community participation in the completion of village electrification projects;

- The government's policy makes the energy sector a national priority;

- Substantial demand for electricity in rural and urban areas;

- A willingness of the strategic partners to accompany the Comoros in development of the energy sector;

- Execution of studies to expand capacities to store petroleum products, development studies for the electrical network, and preliminary production studies for hydroelectric, thermal, and geothermal energy;

- Real potential in the area of renewable energy, and specifically hydroelectric, solar, biomass, wind, and geothermal sources are unexplored.

\section{Main weaknesses and constraints of the energy sector}

- Absence of a sectoral energy policy and strategy;

- Failure to clarify the institutional and regulatory framework for the energy sector;

- Absence of a sectoral master plan for energy;

- The narrowness of the energy market limits economies of scale;

- Lack of financing to increase production capacity and rehabilitate power plants;

- Difficulties experienced by state companies in public service;

- Ongoing recovery problems;

- Low levels of energy autonomy: supply problems and insufficient storage capacities for hydrocarbons;

- Very high costs per kilowatt hour as compared with current rates;

- The most recent rate study dates back more than 20 years;

- Inability to meet energy demand (the available power of $7 \mathrm{MW}$ falls short of the balance of $15 \mathrm{MW}$ );

- Very high consumer prices; 
- Failure to exploit new and renewable energy sources;

- Insufficient capacity building for human resources and technology transfer;

- Lack of energy response in emergency situations;

- Disorganized biomass exploitation (wood - energy).

\section{Outlook for the energy sector}

- Devise an energy sector policy and strategy for the country;

- Clarify the institutional and regulatory framework for the energy sector;

- Prepare a master plan for the energy sector;

- Establish an energy control program (control consumption of wood fuels for environmental conservation);

- Strengthen and secure energy production and distribution (increase electricity access rates by extension);

- Update existing studies;

- Promote substitute energy sources.

In the near future, the upgrading of renewable energy sources should lead to an increase from less than 1 percent to approximately 20 percent of produced energy or installed power. The goal is to:

- Use energy resources other than diesel fuel;

- Build human capacities and strengthen technology transfers.

\subsubsection{DRINKING WATER SUBSECTOR}

Access to water is essential for the proper operation of the social sectors, economic activity, and individual well-being. In the Comoros, there are essentially three water sources: (1) surface water; (2) groundwater; and (3) rainwater collection.

The source varies depending on the island and location. In general, Nzwani and Mwali depend on surface flows from springs or rivers, while the population of Ngazidja obtains its supply primarily from the collection of rainwater and groundwater.

The first water systems were established in Nzwani and Mwali during the 1960s. It would take another 15 years for Ngazidja to have its first water system in Moroni from a well located six 
kilometers south of the capital. During the 1980s, a UNDP project equipped the island with 22 exploitable wells on the island belt. The government, with the support of its partners (UNICEF and the World Bank, in particular), non-governmental organizations, and above all, community participation, established several water supply systems drawing from these wells.

According to the 2004 comprehensive survey on household living conditions in the Comoros, households most commonly use the following drinking water sources: public standpipes (30.6 percent), and collection of rainwater in cisterns (24.2 percent). Only 15 percent of households have home hook-ups.

More than half of the households in Ngazidja use rainwater collected in cisterns. This option is quite vulnerable in terms of quality and quantity. The country does not have a national water quality policy. Sources are often unhealthy and constitute a potential health risk for those who consume the water. This situation is reflected primarily in the prevalence of waterborne diseases such as diarrhea and typhoid.

\section{Performance and strengths of the water subsector}

The main advantages for the development of the subsector are:

- Existence of wells from the UNDP project on the coast of Ngazidja, that can be used to increase the population's access to water;

- Rainfall levels are still favorable for the country as a whole;

- Existence of permanent rivers and waterways in Nzwani and Mwali;

- Willingness of the communities to help finance and materially support the execution of their projects in this area;

- Availability of technical expertise at the national water and electricity company to accompany implementation of water projects;

- Existence of studies on the expansion of water networks countrywide;

- Beneficiary communities are prepared or made aware of the issues involved, to take charge of their water systems gradually;

- Availability of development partners and NGOs to support progress in the water sector.

\section{Weaknesses and constraints of the water supply sector}

- Absence of a sectoral water policy and strategy;

- Failure to clarify the institutional and regulatory framework for the water sector; 
- Absence of a sectoral master plan for water;

- Lack of databases on water access;

- High costs of groundwater projects requiring substantial modern technologies;

- Lack of coordination and communication between the different players involved in sector promotion and development;

- Insufficient technical capacities in management of water systems;

- Lack of equipment and support mechanisms for water systems;

- Water from different networks is not systematically treated;

- Lack of adequate maintenance for water systems;

- Water is free and water system operating costs are not recovered.

\section{Outlook for the water subsector}

Water access for the Comoros is a basic objective for economic and social development. The main challenges in this area are:

- Preparing a master plan for water should be made an absolute priority for the recovery of the subsector;

- Redefining the institutional and regulatory framework for the water subsector;

- Institutionalizing the sectoral approach to water in the Comoros;

- Promoting human resource capacity building and technology transfer;

- Regulating water treatment and making it compulsory in the Comoros;

- Strengthening water production, transportation, and distribution infrastructure;

- Upgrading existing sources;

- Making water users increasingly aware of the issues and warning them that water system operating costs must be recovered;

\subsubsection{SANITATION SUBSECTOR}

With accelerated demographic growth and urban development, we observe a significant increase in production of household waste (approximately 1 cubic meter per person), an increase in 
untreated hospital waste, and an increase in waste related to transportation activities (drained motor oil, vehicle bodies, etc). Waste production is currently not covered by any appropriate organized collection or treatment system. In general, the absence of a waste management and sanitation system is a major public health problem.

Wastewater and rain management was found to be a major concern in both urban and rural areas. The problem is still unsolved in most cities, which have not been able to devote the necessary resources to address the problems resulting from this type of pollution. In the city centers, rubbish piles are also a form of visual pollution, and produce fetid odors extremely unpleasant for the local residents.

\section{Performance and strengths of the sanitation subsector}

We observe substantial community involvement in rehabilitation works for wastewater drainage pipes and gutters. These efforts show the importance the communities associate with sanitation problems and their determination to improve the standard of living.

\section{Weaknesses and constraints of the sanitation subsector}

The main weaknesses and constraints impeding the development of the subsector are:

- Uncontrolled growth of conurbations and proliferation of informal dwellings;

- Absence of an urban development plan and urban planning scheme;

- Absence of a regulatory framework for solid and liquid waste management;

- Lack of latrines in community areas;

- Lack of waste management and available landfill sites;

- Absence of sanitation policy and tools;

- Increasing production of natural and human waste materials;

- Intense degradation of ecosystems;

- Nonexistence of waste management systems.

\section{Outlook for the sanitation subsector}

The stakes consist in improving the quality of life and hygiene in urban areas and ending the runaway development of conurbations. The aim will be to develop technical, material, and organizational capacities required to implement a waste collection and disposal system. Meeting the basic requirements of urban populations is a social stake highly dependent on urban planning. The establishment of a planning policy in conurbations should ensure pleasant, stable living 
conditions for present and future generations. These concerns in fact consist in promoting and implementing tools for the sustainable planning of conurbations while protecting resources and limiting environmental pollution (contamination, household waste, health hazards, neighborhood conflicts, etc.).

Mobilization of resources and means is essential for the implementation of the national policy on environment and the environmental action plan. This approach will subsequently make the following activities possible:

- To complete the master plan for development of urban areas;

- To provide effective sanitation in residential areas;

- To implement a system to improve waste management;

- To assign priority to the establishment of landfill sites for solid waste materials;

- To plan construction of appropriate latrines in community and urban areas.

\subsection{ENVIRONMENT}

In the Comoros perhaps more than anywhere else, the environment emerges as the focus of key economic sectors for the production of commercial goods and services. Recent studies have found that resumed growth in the Comoros relies heavily on the development of tourism, while the country's tourism potential is contingent on the quality of life and the natural environment. The environment is an issue that must gain the support of all development players.

During recent years, we have unfortunately observed intensified environmental degradation overall, which affects all natural resources and undermines the production base. This can be observed in the form of land degradation ( 57 percent of agricultural land), deforestation (500 hectares per year), and poor natural resource management. The country also lacks suitable management tools for urban areas and coastal zones, and integrated policies to reflect the crosscutting dimension of environmental issues. The observed erosion of biological diversity in marine and coastal areas, as well as in the forests, seriously reduces the natural self-renewal capacities of the land and water ecosystems. This situation affects vital ecological processes such as the water cycle, fighting pollution from the silting up of coastal and marine areas, as well as the dynamics of buffer zones to protect against natural disasters. In terms of the effects related to climate irregularities, potential impacts involve accelerated losses of coastal land strips, reduction of agricultural and fish production, contamination of coastal water tables with seawater, and displacement of more than 10 percent of the coastal population.

We should also note that most environmental constraints are similar to those identified for Small Island Developing States (SIDS) under Agenda 21 and the Barbados Plan of Action: ecological and economic fragility, substantial vulnerability to climate change and natural disasters, insufficient response and management capacity, narrow resource base, and high energy costs. 
Environmental deterioration also risks intensifying competition and the risks of conflicts over access to shared resources such as fish and groundwater. These challenges are inevitably linked to broader issues of governance and economic and social vulnerability-hence the scope and complexity of the challenge. Environmental issues have become an intense topic as a result of the multiple challenges they entail, as well as the substantial opportunities intrinsically related to environmental management and sustainable development in the Comoros.

\section{Main strengths and opportunities in the environmental sector}

The archipelago of the Comoros and its territorial waters house ecosystems of remarkable scientific and esthetic value. In particular, we observe high levels of endemism within different groups of flora and fauna and the presence of emblematic or charismatic species. Further, the Comoros ranks high on the priority list for biodiversity conservation on a world scale. The country is also classified as a "Hot Spot" for world diversity.

The country also has substantial genetic resources in the form of medicinal, aromatic, fodder, and farming species. The genotypic characteristics of the varieties present in the Comoros have been preserved, particularly as a result of plant reproduction practices used for vanilla and the absence of programs to introduce new varieties of these species. The conservation and sustainable use of the species and varieties cultivated in the Comoros therefore provide substantial benefits at the regional and world scale by ensuring the perpetuity of genotype material unique to the country or to the subregion and the preservation of the potential to adapt cash crops at the regional scale. This context makes the country eligible for international and regional fair trade networks as a mechanism to ensure a level of income for the farmers, who have suffered tremendously from export price deterioration.

Traditional agroforestry practices in the Comoros are also a source of numerous strengths in terms of conservation (soil, water, habitat for species of flora and fauna), and production (food, fodder, and wood for working and for energy). This stable system provides permanent soil cover, reducing erosion, promoting surface water supplies, and optimizing the use of space through the staggering of production cycles.

This system also helps sustain biodiversity through the wide variety of plant species it harbors, and the habitats it provides that are conducive to productivity in numerous plant and animal species. These factors position the Comoros effectively as a major player in regional and international scientific research programs.

The Comoros provides opportunities in the area of eco-services as a result of its abundant rainfall, renewable energy source potential, and the availability of fertile, unpolluted land in certain areas. The country's classification as a Carbon Sink also opens interesting avenues to access sustainable financing sources under global environmental and sustainable development financing facilities. In addition to these strengths, the Karthala Volcano offers geothermal and ecotourism potential.

These natural resources offer vast opportunities to diversify the sources of national wealth and credible income alternatives to benefit a substantial sector of the population, whose survival depends on the exploitation of natural resources. Sustainable management of environmental 
resources is therefore still an essential lever for sustainable growth and poverty reduction, in light of its potential for development, in connection with natural resources, the quality of the atmosphere, and rich biodiversity.

\section{Key challenges and obstacles in the environmental sector}

The Comoros is now facing a number of environmental challenges, specifically in terms of adaptation to climate change; preservation of biodiversity; biological security; integrated coastal management; access to basic sanitation and urban environmental management services; sustainable natural resource management; and preparation, prevention, and response to disaster risks.

The challenges related to the ecosystems (marine, coastal, lake, and land) reflect insufficient practical action to promote efficient management. These constraints involve (i) clearing or deforestation; (ii) lack of land regulation and security policies and mechanisms; (iii) absence of mechanisms to update and implement the regulatory texts on management of ecosystems; (iv) ongoing confusion of responsibilities as the terms of reference and missions of the institutions responsible for environmental management are not clearly specified; (v) extraction of coastal resources (sand, pebbles, coral, and mangroves); (vi) inappropriate occupation of arable land; (vii) use of unsustainable fishing practices (dynamite, small mesh nets, coral-based fishing, toxic and/or chemical substances); and (viii) absence of sanitation and integrated waste management systems.

It was also found that tensions created by overexploitation and poor management of natural resources are the results, above all, of the failure to define clear natural resource ownership rights and to assess ecological services properly.

\section{Challenges related to climate disturbances}

It is also clear that climate disturbances are accentuating the pressure and tensions already affecting the natural resources such as soils, forests, and other ecosystems, particularly in the coastal and sea environments. Similarly, these manifestations (elevated sea levels, floods, storms, tidal waves, and accentuated seasonal phenomena) can be expected to make the water supply less secure and increase the vulnerability of agricultural resources and risks of disaster. Climate disturbances lead to (i) coastal erosion, which in turn destroys socioeconomic infrastructure (roads, seawalls, coastal habitats, loss of land); (ii) reduced agricultural and fishing production; (iii) contamination of coastal water tables with seawater; (iv) increased risks of pandemics (malaria, cholera, typhoid, etc.); and (v) displacement of 10 percent of the coastal population.

\section{Challenges related to disasters}

The Union of the Comoros is part of the group of poor, vulnerable countries subject to many risks, including cyclones, drought, epidemics, tornadoes, brush fires, tidal waves, floods, major accidents, landslides, volcano eruptions, and risks related to the presence of an active volcano (earthquakes). This vulnerability might be aggravated by an insufficient capacity to prepare for, prevent, and respond appropriately to risks and disasters. 


\section{Key stakes}

With regard to the challenges and opportunities underlying promotion of the environment in the Comoros, we observe three general stakes:

- To include environmental protection measures in the scope of adaptive, regulated development, emphasizing the necessary symbiosis between economy and ecology;

- To use environmental solutions to contribute to poverty reduction by finding sustainable solutions to the problems caused by inappropriate development that are affecting the public well-being;

- To confirm the cross-cutting, multidimensional nature of environmental problems in a context where the dominant view is highly sectoral.

The environmental promotion outlook is guided by the aim of providing the country with essential capacities to design and implement, with relative autonomy, a policy, strategies, and practical initiatives for environmental management to help meet the challenges of sustainable development existing in the Comoros.

\section{Premises for action}

The design of priority action programs and the relevant activities are guided by the following principles:

- To reconcile poverty reduction and respect for the environment;

- To support the rational use of natural resources and development of alternative solutions;

- To promote sustainable management and reconstitution of forest resources and degraded land;

- To promote decentralized management of natural resources and voluntary community involvement.

\subsection{GOVERNANCE AND SOCIAL COHESION}

Governance is the system of values, policies, and institutions through which a society manages its economic, political, and social affairs through interactions within the government, civil society, and the private sector, and between these entities. The political instability observed since the country gained independence has not supported good governance, social dialog, or the reinforcement of the rule of law. This situation has led to weakened government authority, dysfunctional institutions and administrations, undermined national cohesion, nonobservance of the legal and regulatory texts, and the entrenchment of poverty. 
Recurrent political unrest leading to a weakening of the state has created a difficult economic situation, particularly for the poorest sectors of the population, specifically women and children. The negative effects induced by successive economic policies and failed social programs have had serious consequences for the well-being of individuals and households. Substantial segments of the population live below the poverty line and do not have access to basic social services.

To compensate for these government failings, the public relies on the principle of solidarity and being part of a village, region, or island, rather than on being a member of the Union. This feeling is also strengthened by the perception that the state's scarce resources are unevenly distributed, decentralization is incomplete, political and social dialog mechanisms are insufficient, and young people are offered few opportunities.

As one of the many weaknesses of public institutions, the social security system is virtually nonexistent. Collective provident schemes, which enable the most vulnerable individuals or households to cope with social risks, are rudimentary. A report by the International Labour Office $^{1}$ (ILO) indicates that in 2003 there were less than 5,000 beneficiaries, representing under 1 percent of the country's total population. Further, there has been little change in the legal framework for social security, which dates back to the colonial era. There are several types of problems: the scope of actual application of social security is limited and government employees and their lawful claimants have no coverage against occupational risks, illness, disability, death, or family support. Systems providing health insurance and indemnification in case of illness are undeveloped. The scope in terms of personnel is also quite limited and little revenue is distributed. Last, management agencies are experiencing tremendous organizational problems.

The job market is still dominated by the informal sector. The informal agricultural economy (essentially subsistence) is predominant; and the non-agricultural informal economy accounts for approximately 16.2 percent of national employment (EIM 2004). Employment and underemployment levels are also substantial as a result of insufficient economic growth in recent years (the unemployment rate increased from 10.4 percent in 1995 to 13.5 percent in 2004).

Unemployment is widespread and there is essentially no difference between urban unemployment (14.7 percent) and rural unemployment (13.1 percent). Unemployment, however, more acutely affects young people (with 44.6 percent unemployment for workers 15-24 years of age) and women, for which the unemployment rate is twice as high as it is for men, regardless of the education level (19.2 percent, as against 9.2 percent for men).

The job supply is limited and the Comorian government is still the country's leading employer. However, this administration faces many problems: a bloated work force and delays in wage and professional service payments, leading to reduced purchasing power for civil servants, and thus absenteeism, permissiveness, corruption, saturation of the civil service, and abusive recruitment in flagrant violation of the texts governing the civil service. Owing to the wage bill, which absorbs more than 70 percent of real revenue ( 85 percent according to the IMF mission estimates), the state is unable to cover most of its expenses, and can address only the most urgent ones. In addition, the Comorian government is highly centralized in the capital, meaning that it is

\footnotetext{
${ }^{1}$ ILO, Note au Gouvernement sur la situation de la protection sociale (Memorandum to the Government on the status of the Social Security System), J. Audibert, 2001.
} 
far from most users or beneficiaries. This centralization penalizes people who live in the peripheral areas and regions of the country, thus the importance of completing the process of decentralization initiated by the Constitution of December 23, 2001. In fact, in 2001 the country adopted a new institutional framework that generalizes the principle of subsidiarity and provides four levels of power: federal, island, regional, and local. In operational terms, this approach should lead to new institutional management mechanisms, particularly at the local and regional levels. While these local development dynamics have focused on development of the municipalities, the latter do not exercise all of their prerogatives, specifically in vital statistics management.

The vital statistics system in the Comoros is characterized by insufficient use of vital statistics services, incomplete and unsatisfactory data, insufficient recording of data on vital statistics events, and is overshadowed with suspected fraud. Last, there is virtually no information on Comorian expatriate communities throughout the world registered in the vital statistics system.

These problems characterizing the Comorian vital statistics system are derived in part from the substantial prevalence of poverty, leading to survival strategies at the individual and community levels, supported with fraudulent vital statistics documents and poor governance. Moreover, the national statistics system cannot adequately reflect vital statistics as a source of core data for development and poverty reduction.

In terms of the substance of the law, the Comorian system is a combination of several legal systems in which a French legal system coexists with ancestral customs and Islamic law. This combination of legal origins leads to juridical uncertainties that may be the source of the numerous legal contradictions observed. In addition, Comorian law does not always observe the numerous conventions the country has ratified.

The National Assembly undertook the tasks to reform and modernize Comorian legislation to comply with the country's international commitments. However, this institution cannot operate effectively owing to insufficient material and human resources.

The judicial system today is characterized by multiple dysfunctions that make it a difficult matter to access justice services and that seriously impede its internal operations. Problems include insufficient institutional organization; a substantial shortage of qualified, specialized, and experienced human resources; and a lack of operating resources. The judiciary organization process is still incomplete. The basic courts, primarily the local Islamic courts (Cadi Courts), labor courts, trade courts, administrative courts, juvenile courts for minors, and the Supreme Court, which includes three sections (judiciary, administrative, and an accounting section) are not in place. The judiciary lacks both magistrates and associate personnel (justice assistants and administrative support staff). Clerks, bailiffs and judicial police officers are often inefficiently supervised and lack motivation owing to insufficient resources and management procedures. The attorney function, albeit a professional activity, is also the subject of major concern. There are few attorneys and the legislation governing them is out of date.

Execution of court decisions is a source of problems to the extent that there is currently no executive body to perform this function. Whether the government or individuals are involved, this situation will inevitably result in cases of impunity weakening the enforceability of court 
decisions, the authority of the judicial officers who made them, ultimately undermining the overall judiciary institution.

Problems related to the execution of court decisions also shed light on the penitentiary system as the country lacks penitentiaries worthy of the name. Existing remand homes are in a particularly difficult situation, in an advanced state of disrepair, and do not comply with international human rights legislation.

Outdated and run-down buildings, inhumane detention conditions, and degrading treatment of prisoners encourage escapes. There are no separate quarters for women and juveniles. Penitentiary staff are in short supply, untrained, and ill-equipped. Prisoners' families must provide food and medical care. These conditions are at odds with the principles of basic human rights.

In fact, human rights issues are not high on the agenda in the Comoros, despite the existence of legislation acknowledging the key international instruments. There is in fact a real gap between the legislation and day-to-day reality. Many human rights violations are perpetrated by those who are supposed to uphold them. Children's and women's rights are not always respected. Juveniles are often subject to sexual exploitation, physical violence, neglect, and mistreatment. Such violence is committed within the family, at home, in the schools, in the street, and in the workplace. The country has few schemes providing care, accompaniment, or psychological/psychosocial support for victims of violence. Further, although the legal age for marriage was established at 18 years of age for boys and girls under the new family code, early marriages are still common.

There is little participation of women in making decisions concerning the management of public affairs. While women participate actively in economic development and poverty reduction, they are victims of inequalities in terms of workload and limited access to knowledge and production factors. As a result of these inequalities, women are concentrated in the informal sectors of the economy (17 percent in trade and 49.9 percent in agriculture), they are insufficiently represented in certain "masculine" trades, and accordingly they enjoy little decision-making power in household and community circles.

To address this situation, the government drafted a number of documents to improve living conditions for women and children and to enhance the gender equity. These strategic documents specifically entail ratification of the key international instruments, adoption of the Family Code, the national policy on gender equity and equality, and the national strategy to protect the most vulnerable children. Further, national and island organizations have been established to promote and defend human rights. A law establishing the national commission on human rights and liberties was passed in 2006, but has yet to be promulgated.

Free, transparent elections are regularly organized. An electoral law defining precise rules designed to govern all operations and modalities specifically for each election was adopted and amended in January 2007. This law establishes an ad hoc body known as the Independent Electoral Commission of the Comoros (CENI), Island Election Commissions (CIE) assisted by standing administrative secretariats (SAP) and at the union level (SNAP) and at the island level (SIAP). 
Despite substantial progress registered in the organization of elections, these structures have insufficient technical capacities and lack financial, material, and logistic resources. Moreover, the electors have an insufficient knowledge of their rights and obligations.

The various elections that have been held since 2004 have been overseen by the Constitutional Court established in 2004. The latter judges the constitutionality of the laws of the Union and the Islands and oversees the regularity of electoral operations at the island and Union levels, including referendums. It oversees the distribution of power between the Union and the Islands. It judges electoral disputes and guarantees fundamental human rights and civil liberties.

Respect for civil liberties, safety of goods and persons, and measures against terrorism and transnational crime are inevitable global stakes for all countries. The events of

September 11, 2001 in fact changed the global perspective of peace and security. Security Council Resolution 1373 (September 28, 2001) denotes the linkage between international terrorism and organized crime, weapons and drug trafficking, money laundering, and smuggling of hazardous materials. Resolution 1373 is binding on all countries and has profound implications on the legal system, control of financial flows, and administration of justice. Although the Comoros is a relatively secure country, we observe an increase in criminal activity and a need to strengthen national security.

\section{Performance and strengths in the area of governance and social cohesion}

- Introduction by the Constitutions of the Union and the Islands of direct universal suffrage as the only means to accede to political power at all levels, making it possible for the public to choose its own leaders;

- Establishment of the Constitutional Court is a substantial contribution to the observance and enforcement of the Constitution, as well as to the operation of the existing institutions;

- Ratification of several international conventions on human rights and business law;

- Adoption of national laws and acts in respect of social security, decent work, gender, family, vulnerable children, judiciary organization, national statistics system, and emergency preparation and response;

- Compilation of legislative and regulatory texts on civil rights and business law;

- Compilation of national and international texts in respect of the protection of women and children;

- Availability of a vital statistics rehabilitation project, a national statistics development strategy; a paper on the demographic and health survey project; a national policy on gender equity and equality and the relevant action plan; and a national disaster preparation and response plan; 
- Existence and involvement of public agencies and non-governmental organizations in the defense and promotion of human rights under development programs.

\section{Subsector weaknesses and constraints}

- Political instability preventing the preparation and adoption of relevant legislative and regulatory texts to enhance governance, justice, and security;

- Conflicts of authority impeding the proper functioning of the existing institutions;

- Execution of certain revenue and expenditure outside of all budget and control procedures;

- Abuses in overbilling, acquisition of assets at high prices, and transfers of assets at nominal prices;

- Absence of parliamentary control of budget execution (a posteriori control);

- The state's inability to honor its commitments (irregular payment of wages to government employees, and of debts with the private sector);

- Inappropriate civil service recruitment which is a burden on the wage bill;

- Failure to complete decentralization processes;

- An inefficient vital statistics system;

- A dysfunctional national statistics system;

- Endemic corruption;

- Rudimentary social security mechanisms;

- A very limited supply of jobs;

- A dysfunctional judiciary system;

- Failure to take into account the higher interests of the child in policies and programs;

- Discrimination against women;

- Insufficient emergency preparation and response mechanisms;

- Failure to enforce judgments and orders of the tribunals and courts; 
- Insufficient human and material resources for the tribunals and courts;

- Difficulty in accessing the legislative and regulatory texts;

- Failure to comply with the current texts;

- Failure to promulgate the law on the national human rights and liberties commission.

\section{Outlook}

Several prior conditions must be met to enable governance and social coherence to play effective roles in the PRGS. Putting an end to poverty requires resolute action to strengthen social cohesion, consolidate peace, establish social security, fight corruption, respect human rights, and establish a sound justice system to preserve peace and social stability. The process of decentralization should also become a reality. The process should be completed and the government should be brought closer to the people.

Justice and security are in fact the key instruments to ensure the fundamental liberties that go hand in hand with development, to enhance the public well-being and reduce poverty. The government should therefore protect, promote, and guarantee individual rights and security.

A necessary part of anticorruption measures is the establishment of a transparent system at different levels and the comprehensive application of the law and regulations (independent audits, involvement of civil society, the media, and the competent jurisdictions).

The government should integrate the promotion of human rights into the process of implementing all development and poverty reduction programs. This strategy should rely on corporate, political, and legal tools, and the establishment of a National Commission on Human Rights and Liberties.

The PRGS should be based on the knowledge gained from positive developments in the new institutional framework of the Union of the Comoros, to propose adequate mechanisms to restore good governance. These mechanisms will make it possible to strengthen the political, economic, and social dimensions that characterize governance and social cohesion with the objective of restoring economic growth and reducing poverty.

\subsection{EDUCATION SECTOR}

Education has a direct impact on the future well-being of individuals. It is essential for the socioeconomic development of a country because it helps improve the living conditions of individuals by giving them access to more economic opportunities. At the macro level, a well educated and informed population is more productive and capable of mastering modern productive technology. It can generate value-added and considerable income. At the micro level, education greatly increases the chances of a person finding a job and, in a context of 
globalization, makes individuals more competitive and attractive to employers, therefore placing them in a better position to take advantage of the available opportunities.

The Comorian education sector comprises a formal and an informal education system.

\section{The formal education system includes the following levels:}

- Preschool education;

- Elementary education;

- Secondary education;

- Technical education and occupational training;

- Higher education and research.

\section{The informal education system includes:}

- Education for young people and adults;

- Trade apprenticeship and literacy.

We should emphasize that the fundamental difference between these two systems is now based on sector organization and financing. In the formal sector, the government largely covers the supply of services; while, in the informal system, the resources do not necessary derive from sector policy.

The education system must now envisage new approaches to enable the range of education service providers to contribute effectively to produce a high-quality education and reduce poverty.

\section{Presentation of the education sector}

The formal education system is structured by the national scholastic charter, and is divided into 18 regional academic inspection districts (CIPR) distributed as follows: two in Mwali, five in Ndzouani, and 10 in Ngazidja. Each CIPR is managed by a primary school education inspector assisted by a number of academic advisors (the number depends on the size of the district).

At the elementary level, the Union of the Comoros has a total of 308 public elementary schools (24 in Mwali, 111 in Ndzouani, and 183 in Ngazidja) and 85 private elementary schools. At the lower secondary level, the country has 53 public colleges (including six Islamic colleges), including six in Mwali, 14 in Ndzouani, and 27 in Ngazidja, plus 89 private colleges distributed as follows: four in Mwali, 27 in Ndzouani, and 58 in Ngazidja. At the upper secondary level, there are 10 public secondary schools (including one in Mwali, five in Ndzouani, and four in Ngazidja); and 62 private institutions, including two in Mwali, 17 in Ndzouani, and 43 in 
Ngazidja). Last, since the start of the 2006-2007 academic year, following the merger of the existing higher education institutions (the Patsy School of Higher Education-EESP-in Ndzouani was incorporated into the University of the Comoros in 2008), higher education has been provided by the University of the Comoros through the following constituent Faculties, Institutes, and Schools:

- Faculty of Arts and Humanities;

- Faculty of Law and Economics;

- Faculty of Science and Technology;

- Imam Chafiou Faculty;

- Teacher Training and Education Research Institute (IFERE);

- University Institute of Technology (IUT);

- $\quad$ School of Medicine and Public Health (EMSP).

A number of private higher education establishments and institutes are beginning to develop throughout the country.

\section{Analysis of performance in education}

For the 2006-2007 school and university year, the population enrolled in all public and private higher education institutions was estimated at 151,335 students, up 0.9 percent from 2003 . The distribution by level is provided in the table below.

Distribution of school enrollment by level

\begin{tabular}{|c|c|c|c|c|c|}
\hline Education level & $\begin{array}{l}2003 \\
\text { Persons } \\
\end{array}$ & $\%$ & $\begin{array}{l}2007 \\
\text { Persons }\end{array}$ & $\%$ & Increase \\
\hline Pre-elementary education (community and private) ${ }^{(1)}$ & 1,618 & 1.1 & 2,720 & 1.8 & 13.9 \\
\hline Elementary education, public and private & 104,274 & 71.4 & 104,418 & 69.0 & 0.0 \\
\hline Lower secondary education, public and private & 25,689 & 17.6 & 27,256 & 18.0 & 1.5 \\
\hline Upper secondary education, public and private & 11,962 & 8.2 & 13,862 & 9.2 & 3.8 \\
\hline Higher and technical education, public & 2,426 & 1.7 & 3,079 & 2.0 & 6.1 \\
\hline Total & 145,969 & 100 & 151,335 & 100.0 & 0.9 \\
\hline
\end{tabular}

Source: Ministry of National Education, Management Indicators 2002/2003, 2004, and 2006/2007.

(1) The latest school census conducted in 1999 registered 2,500 Koranic schools (Palashio) comprising 96,752 students, all ages combined.

At the preschool level, the large number of Koranic schools in the Comoros is a major advantage, particularly as each locality has at least one such school. In addition to a few mostly essentially 
private nursery schools mostly located in urban areas, early childhood education is covered largely by traditional schools. The Ministry of National Education undertook a restructuring policy for this type of education in 2003 in 12 pilot schools in rural areas and one reference school. As a result of this pilot experiment, the schools were integrated into the formal education system in May 2009. This led to an increase in school enrollment from 1,618 children in 2003 to 2,720 children in 2007, equivalent to an average increase of 13.9 percent per annum. The share of school enrollment in community schools in recent years is 53.2 percent.

At the elementary level, during 2003-2007, the number of children enrolled in primary school (public and private) held steady at approximately 104,000. Enrollment for girls increased slightly from 46,225 to 48,582 , equivalent to an increase of 1.3 percent at the national level.

The proportion of girls in the system followed this trend, increasing from 44 percent in 2003 to 47 percent in 2007. This expansion in enrollment continued at approximately the same rate as demographic growth, i.e., approximately 2.4 percent per annum during the period. The share of the private sector in compulsory free primary education remained stable at 10 percent.

The gross school enrollment rate registered a decline of approximately 6.7 points between 2003 and 2007 (94.8 percent in 2007, as compared with 101.5 percent in 2003) at the national level. School enrollment for girls, however, evolved more quickly than for boys, with an average respective growth rate of 1.3 percent per annum, leading to an increase in the enrollment rate from 66.4 percent in 2003 to 70.9 percent in 2007 . Recently we have observed, particularly in Ndzuani, a trend toward equal gross admission rates between boys and girls. The elimination of school enrollment fees for both girls and boys therefore seems to be yielding results.

The gap between the primary school enrollment rate for boys and girls declined substantially at the national level, from 13.24 to 4.07 points during the aforementioned period. The gap remained wide in Ngazidja and Mwali but narrowed in Ndzuani. The differences are more pronounced in rural areas and in poor households.

During the 2002-2003 school year, the primary subsector acquired new textbooks (one textbook for each student) covering the three core disciplines (French, mathematics, and science). However, the textbooks were not managed in such a way that the initiative could be continued. The policy for renting textbooks at an affordable price led to the following consequences:

- Payment problems leading to dropouts;

- Poor management by the school board of funds collected, leading to operating problems in certain schools.

In terms of supervision, all CIPRs have educational advisors and inspectors. The purpose of this system is to help improve training and continuing education for teachers, with the knock-on effect of improving the quality of education and learning. While coverage has been maintained, the teacher trainers rehired did not have the proper profiles. The sector subsequently encountered resource problems (shortages of teaching materials and logistical resources).

During the same period, enrollment in lower and upper secondary schools increased rapidly, from a total of 37,651 to 41,118 students, equivalent to a 2.2 percent increase per year, with 45 percent 
girls. We should note, however, that upper secondary school registered a slight increase in the proportion of girls (46.7 percent in 2007, as compared with 44.1 percent in 2003). By contrast, the share of the private sector in secondary education declined slightly from 41.1 percent to 36.8 percent during the period. The gross admission rate observed in 2007 was 34.9 percent, as against 40.5 percent in 2003.

Most institutions, particularly at the secondary level, are in an advanced state of disrepair. Accommodation capacities are quite limited and some schools, particularly at the primary and secondary levels, are forced to turn enrollment-aged children away. Nearly 78 percent of the 1,735 existing classrooms are used in double shifts. This situation has led to an increasing number of children, particularly from poor households and less favored areas, who are deprived of education and who are increasingly populating the category of dropouts or children not, or no longer, enrolled in school.

Technical education and vocational training remain the least attended subsectors owing to insufficient facilities. This area benefits from little investment, despite its clear importance in the country's economic development, its evident role in integrating young people into the labor market, and in reducing unemployment and poverty.

At all levels of general education, substantial efforts have been made to recruit teachers to supplement the existing work force. At the primary level, the number of teachers increased from 2,488 to 3,069 between 2003 and 2007, equivalent to an increase of 5.4 percent. At the secondary level, the number of teachers in public schools increased substantially, by approximately 6.0 percent per year (equivalent to 1,184 in 2007, as compared with 938 in 2003). This increase made it possible to cover the chronic deficits that were impeding operations during the school year, and to reduce the teacher-student ratio. During the period 2003-2007, the ratio of students per teacher decreased from 37.7 to 30.2 at the primary level and from 23.6 to 21.9 at the secondary level, all levels combined.

We should also highlight the problem of insufficient motivation for supervisors (status), insufficient training time (particularly at the primary level), limited access to textbooks for students, and the lack of educational and didactic support for teachers. These are some of the factors explaining the poor performance of the education system, and particularly explaining lowquality education and training.

The internal rate of return is also quite low. Promotion rates between the various levels of education are very low, and the repeater and dropout rates are still quite high at all levels. At the primary level, for example, the repeater rate varies between 22 percent and 29 percent between the islands, while the dropout rate is in the range of 2-15 percent. Many children leave primary school without acquiring essential knowledge and skills for day-to-day life.

At the structural level, the country faces substantial demand for education while the available resources are clearly insufficient. Despite the financial efforts the government has made to develop the education system, the results still fall short of expectations. While the budget allocated to education occupies a substantial share of the state budget, it does not meet the requirements of the system, as more than 80 percent of this budget is devoted to wages. Management and administration of education services register insufficient human, technical, and 
financial resources. These problems are compounded by school management in the context of decentralization since 2002.

In the informal system, education for young people who have dropped out or not attended school, and adults (with an estimated total illiteracy rate of 40.9 percent per the MICS 2000/GCP 2001) is an area of the education sector that has been neglected in the past. There is no policy and very few programs targeting these groups. In addition, there are truly no literacy and training centers. Last, the country lacks suitable teaching and educational materials and competent instructors.

The economic crisis that has affected the country in recent years and the resulting fiscal difficulties have dealt a hard blow to the education sector, particularly the subsectors targeting young people who have dropped our or not attended school, as well as adults, technical education, and vocational training. The institutions still in operation are facing multiple problems including very limited facilities, inappropriate school environments, obsolete infrastructure and equipment, insufficient qualified teaching staff, and inadequate employment training.

\section{Weaknesses and constraints in the education sector}

The main constraints the education system is facing are described below:

- There is a mismatch between demand for enrollment and the public supply of education. The accommodation capacities are in fact quite limited, forcing some schools to turn away enrollment age children, particularly in rural areas. This is a common situation in elementary education, despite the introduction of double (and even triple) shifts;

- A school environment that is not motivating for teachers and unattractive for students, and thus not conducive to child school enrollment, particularly for girls. Many schools, particularly in rural areas, are dilapidated (sometimes in an advanced state of decay), which can pose a health and security threat to the children. Most schools have no water or latrines, and this situation does not encourage children to attend school, nor does it provide incentives for girls to stay in school;

- The formal education system has no organizations to cover and protect early childhood education. Koranic schools that accommodate most children three to five years of age operate at the margin of the education system and are not subject to any administrative or educational control. Private nursery schools now only serve a small proportion of children in this age group;

- Most teaching staff, especially at the primary level, do not have the required qualifications or educational training for effective education of young children;

- Insufficient knowledge of the teaching languages, and particularly French, which is the first language of teaching in the education system, on the part of teachers and students at all levels, constitutes a true quality impediment in the education system; 
- The absence of initial training, as well as continuing education for secondary level teachers means that students are not receiving efficient instruction;

- Teachers do not receive effective initial or ongoing training as a result of weaknesses in the training institutions;

- Insufficient current resources for education at the primary level (despite the training of new education supervisors), and virtually no inspections at the secondary level: the few educational inspectors trained at this level are employed in education administrations or are seconded to other sectors;

- In recent years, we observe an increase in private institutions, particularly at the secondary and higher education levels, without accompaniment or supervision measures;

- The absence of an active, adequate technical education and occupational training network capable of offering young people new opportunities or of producing labor required for the country's economic development;

- Persistent enrollment disparities between boys and girls, urban and rural areas, and wealthy and poor households;

- Non-diversified higher education in which the supply and quality are limited;

- Nonexistence of an appropriate structure and policy to cover education for youth dropouts, persons not enrolled, and for illiterate adults;

- Insufficient steering of the education system, at the central and decentralized levels, in terms of design, planning, and management, monitoring and assessment, and resource mobilization and management;

- The school charter is not observed, leading to an imbalance between school supply and demand, and inefficient use of resources;

- The absence of specialized child school health monitoring services is a factor in frequent absenteeism and dropping out;

- A decline in the annual time schedule as a result of frequent strikes;

- Insufficient coverage of education in emergency situations.

\section{Outlook for the education system}

For better coverage of early childhood education, an appropriate environment must be created to foster its development. This approach would involve restructuring the subsector, and harmonizing the programs and methods for teacher training and education. The aim is to generalize the introduction of discovery and play activities and to promote active learning 
mechanisms in all Koranic schools, reflecting the lessons learned during the pilot phase initiated by the Ministry of National Education in collaboration with UNICEF. Against this backdrop, the subsector will become integrated into the formal education system. This approach will draw from the national strategy for comprehensive early childhood development (DIJEC).

Efforts must, in any case, be intensified to maintain these trends and, in the long term, to reach the Education for All (EFA) objectives at the horizon 2015, in accordance with the National Education for All Plan (NAP/EFA), and particularly envisaging to:

- Develop and innovate in early childhood education and protection;

- Ensure free, universal, compulsory school enrollment, providing quality education, at the primary level;

- Eliminate all forms of inequalities in primary and secondary school enrollment, particularly strengthening education for girls;

- Strengthen access to and quality of secondary education and diversify the education supply to give all young people equal opportunities to succeed;

- Promote technical education and occupational training for young people and offer them the opportunity to acquire the skills they need for day-to-day life, and for more effective socio-professional integration;

- Improve the literacy level of young people and adults to enable them to acquire the knowledge and skills they require to improve their living conditions;

- Develop, diversify, and strengthen quality higher education at the University of the Comoros to meet demand to educate the young generations and to meet the country's development requirements.

Last, it is essential to strengthen capacities in planning, administration, and management of the education system and to establish an efficient strategy to optimize and rationalize the use and allocation of human, material, and financial resources.

\subsection{HEALTH SECTOR}

The health status of individuals is a key indicator of both the population's well-being and poverty. Substandard health and sanitation conditions, particularly for the poor, derive from the complex relationship between health and poverty. Poverty is reflected in this sector through: (i) insufficient access to quality health services; (ii) prevalence of certain priority diseases; (iii) insufficient infrastructure for health, hygiene, sanitation, etc.; and (iv) a resurgence of malnutrition and a poor quality diet. Not only does poverty lead to poor health owing to a lack of adequate health care; a poor state of health also perpetuates poverty.

Under the National Health Plan (PNS), the National Health Development Plan (PNDS) - 2015 Outlook is the benchmark for the country in the area of health development. It emphasizes 
community participation as an ongoing strategy to ensure health for all, and considers health districts to be the cornerstone of health development. In light of the institutional changes, PNS implementation should be accompanied by legal clarification.

Heath system reform in fact introduced a pyramid structure to the sector with three levels of organizational competence (central, intermediary, and peripheral). The central level (Union level) is comprised of the following institutions: (i) Minister's Cabinet; (ii) Secretariat General; General Heath Inspectorate; (iii) National Health Directorate; (iv) central directorates and units responsible for program coordination; (v) National Reference Hospital; and (vi) National Autonomous Pharmacy of the Comoros (PNAC). At the island level, we observe the health administration and Regional Hospital Centers (CHR). The final level is comprised of the Health Districts (seven in Ngazidja, seven in Ndzouani, and three in Mwali), covered by two medicalsurgical centers in Ngazidja and Ndzouani and three urban medical centers for the three islands. These three levels are supplemented with a network of clinics (Armed Forces, Catholic agency for overseas aid and development-CARITAS, private sector, and 49 peripheral community health units). This framework should enable effective implementation of national health policy. While it can be receptive to change, the framework should reflect PNDS standards as well as the current health charter.

The fundamental law of the Union of the Comoros stipulates that the system must aim for a broad, dense network of basic health units (geographic accessibility to a health center in a 5kilometer radius is estimated at 63 percent). Major efforts should be made in the areas of staff training, rehabilitation, and re-equipment of certain health units, and the low-cost availability of essential medicines. These efforts should lead to higher levels of use.

Despite the efforts that have been made, particularly in training and capital expenditure, the quality and quantity of health services have deteriorated during recent years as a result of: (i) insufficient technology level, obsolete biomedical and medical technology equipment, and inadequate equipment maintenance; (ii) inadequate performance of the pharmaceutical sector; (iii) shortage of qualified personnel; (iv) weakness of the partnership with NGOs and civil society; (v) poor management and lack of motivation in health personnel; (vi) disorganized construction of health infrastructure by the communities, and facilities not operating to the required quality standards; (vii) insufficient quality of health services and care; and (viii) partial application of the health development plan and insufficient coordination and steering of activities.

In addition, there is the factor of the population's increasing impoverishment, insufficient public awareness of health problems, high costs of health services, inadequate accommodation in health units, shortage or even absence of doctors in health centers, and unavailability of medical technicians and other types of health workers. In addition, the absence of appropriate regulations and anarchic development of the private sector have undermined the quality and accessibility of care and have contributed to high-cost, inconsistent health services.

These well-known problems, combined with poor hygiene and sanitation conditions and the population's insufficient access to drinking water and a healthy environment, explain much of the persistence of certain diseases such as malaria (the number one cause of morbidity and mortality in children under five years of age), intestinal parasites, lymphatic filariasis, acute 
respiratory infections, and diarrhea. They are also the source of certain potentially epidemic diseases such as arboviroses (dengue fever and Chikungunya virosis).

Morbidity and mortality related to certain noncommunicable diseases, and in particular, mental illness, blindness, cancer, sugar diabetes, cardiovascular disease, and hypertension continue to be concerns. The data on these diseases are to all intents and purposes nonexistent.

Immunization coverage for the six preventable illnesses in the Expanded Program on Immunization (EPI) declined from 90 percent during the 1990s to less than 70 percent in 2004. This decline places the Comoros below the subregional average. By contrast, the life expectancy at birth increased from 55 years of age in 1991 to 63 in 2002. An examination of certain monitoring objectives for the Millennium Development Goals in the area of mother and child health, as indicated in the table below, clearly shows the insufficient performance of the Comorian health system, particularly as we know that improved mother and child health, by reducing mother and child mortality rates, is the focus of concerns among the public authorities as indicated in the national health plan.

This still-high maternal mortality rate ( 381 per 100,000 live births) is explained by poor quality care and services, lack of pregnancy care, and absence of appropriate responses to obstetric and neo-natal emergencies, and, despite the efforts that have been made, late referrals to health units, home births, poverty, ignorance, and illiteracy.

Table of reproductive health monitoring indicators in connection with the Millennium Development Goals

\begin{tabular}{|c|c|c|c|c|}
\hline Indicator & 1991 & 1996 & 2000 & 2003 \\
\hline $\begin{array}{l}\text { Mortality rate of children less than five years old } \\
\text { (per } 1,000 \text { live births) }\end{array}$ & 130 & 104 & 74 & \\
\hline $\begin{array}{l}\text { Infant mortality rate } \\
\text { (per } 1,000 \text { live births) }\end{array}$ & 86.3 & 77.3 & 59 & 79.3 \\
\hline $\begin{array}{l}\text { One year-old children effectively immunized } \\
\text { against measles (percent) }\end{array}$ & $(--)$ & 48 & 56.3 & 71.08 \\
\hline $\begin{array}{l}\text { Maternal mortality rate } \\
\text { (per } 100,000 \text { live births) }\end{array}$ & 570 & $(--)$ & 517 & 381 \\
\hline $\begin{array}{l}\text { Proportion of births assisted by qualified personnel } \\
\text { (percent) }\end{array}$ & $(--)$ & 52 & 62 & \\
\hline
\end{tabular}

Source: Ministry of Health.

AIDS has become a great concern, in the area of public health as well as development. Even if the prevalence rate for HIV infection in 2003 was still low ( 0.025 percent), an explosion is possible and preparations must be made now.

Surveys show little knowledge of how HIV is transmitted and appropriate preventative methods, which makes certain groups particularly vulnerable. Moreover, we observe that the frequency of other sexually-transmitted infections (STIs) in symptomatic men and sex workers might contribute to the spread of HIV, under certain circumstances. 
Despite the substantial progress that has been made, the country must intensify its efforts to perpetuate the activities to fight this disease, particularly by identifying more partners, such as the World Fund, Indian Ocean Commission (COI), the Joint United Nations Programme on HIV/AIDS (UNAIDS), the World Health Organization (WHO), the United Nations Population Fund (UNFPA), the United Nations Children's Fund (UNICEF), the United Nations Development Programme (UNDP), etc.

The health system registers poor facilities and services in public sector health units. Development in the private sector is anarchic, and services are costly and can be questionable. As a result of this situation, combined with other sociocultural factors inherent in the health system, people must make often costly journeys to obtain medical care, in the private sector or abroad. The poor have insufficient incomes to access quality health care commensurate with their health situation. They often resort to traditional methods that can be harmful. There is no national policy to care for indigents. By contrast, a network of mutual health associations is being developed in the islands.

\section{Performance and strengths of the health system}

The main strengths of the health system are:

- There is a national health program (PNS);

- A national plan to develop the health information system (PNDSIS) is being prepared;

- Decision-making agencies have been established for health development (CNS, CTNS, CCM, National Committee against HIV/AIDS and STIs - CNLS, etc.);

- An Office of the Inspector General for Health has been established;

- A new health code has been adopted;

- The authorities have expressed their willingness to harmonize state institutions under the new Fundamental Law of May 17, 2009;

- Primary and secondary health facilities are geographically accessible;

- The community is involved in health activities;

- A Master Plan for the Health Information Sector has been adopted;

- Capacity building is in progress for health workers in connection with PNDRH program implementation;

- A National Order of Physicians, Pharmacists, and Medical Biologists exists;

- An essential drug purchasing center (PNAC) exists; 
- Development partners show clear interest and willingness to collaborate;

- Associative dynamics and community solidarity are present;

- Comorians expatriates are involved in health financing.

\section{Weaknesses and constraints of the health system}

The development of the health system faces the following weaknesses and constraints:

- Absence of clarification in the official texts defining the functional relations between the central government and the autonomous islands following the adoption of the new fundamental law of May 17, 2009;

- An insufficient financial contribution from the state, which is below the recommended 15 percent;

- Absence of innovative mechanisms in the health system;

- Insufficient technical level from all standpoints, despite the efforts that have been made;

- Qualitative and quantitative shortage of health personnel;

- Absence of care for indigents;

- No generalized social security policy for the whole population and particularly for indigents;

- Human resource problems related to the lack of career plans;

- Limited number of managers for certain personnel categories, poor distribution, high degree of mobility, and low level of motivation;

- Insufficient health information system;

- Inadequate use of health services by the population;

- Frequent conflicts between the community management bodies and health personnel;

- Insufficient dissemination and application of current regulatory texts;

- Frequent depletion of essential drug supplies;

- High cost of medicines; 
- The failure of the National Order of Physicians, Pharmacists, and Medical Biologists to function as it should;

- District pharmacies are not operational;

- The brain drain has increased;

- Personnel are insufficiently motivated owing to irregular wage payments and poor working conditions.

\subsection{PRIVATE SECTOR AND MICROFINANCE}

\subsubsection{PRIVATE SUBSECTOR}

The Comorian private sector is comprised of different sized enterprises, although predominantly micro and small-scale enterprises. Businesses are generally labor-intensive, generating revenue with a substantial number of personnel. The economic fabric, however, remains thin and is dominated at the top by four large parastatal enterprises. Based on the available documentation and expert opinions, there are an estimated 49,000 private enterprises in the Comoros, including the formal and informal sectors. More than 93 percent of these are microenterprises, approximately 6 percent small and medium-scale enterprises, and less than 1 percent are large enterprises. The agrofood sector represents 63 percent of the number of private enterprises, fishing accounts for 18 percent, and trade 11 percent. By contrast, industry represents only 0.1 percent and tourism 0.4 percent of the total number of private enterprises.

The increasing share of trade activity (distribution, which is now tending to inflate the tertiary sector in the Comoros) is noteworthy. By contrast, there are few small-scale enterprises and industries (SME-SMI) in the manufacturing sector and processing and industry. There are more of such enterprises in the informal sector, particularly in the grocery trade.

The modern, organized private sector employs approximately 8,000 persons, according to the best estimates, equivalent to 30 percent fewer persons than the public sector.

The private sector has historically been largely dominated by a few cash crop processing and import-export companies. It was not until the 1980s that we observed a new generation of modern enterprises keen to make locally-produced goods available on the market to substitute for imports.

Accordingly, the Comorian private sector is still unstructured, despite some recent progress in foreign direct investment and the re-opening of Banque de Développement des Comores (BDC), which enabled some entrepreneurs to resume production activities or to expand existing commercial concerns.

From the standpoint of its structuring, the private sector has been attempting to become organized for a number of years. In 2007, The Comoros Employers' Organization (OPACO) undertook a 
reorganization with more professional management and by offering more services to its members. The transfer of the Chamber of Commerce to private transactors also gives the private sector a new outlook. New organizations aiming to participate in private sector development (the Comorian private sector federation and the national federation of Comorian farmers, in particular) have also emerged. Last, in 2009, there are plans for the Chamber of Commerce, Industry, and Agriculture of Ngazidja to implement the Professional Organizations House with support from the trade services capacity building program.

While the private sector is gradually becoming organized, the dialog with the public sector is still insufficient. The public sector is engaged in activities that are not always compatible with private sector promotion and development. The clear absence of a cooperation framework to define a true economic strategy, and the suspicion targeting the private sector are factors that limit the willingness and capacities of Comorian enterprises to invest and perform.

The public-private partnerships, that were a source of great hope, did not materialize. By contrast, recent experiences of the National Agency for Investment (ANPI) show some encouraging signs. For example, Comorian private enterprises could form joint ventures with major international groups to carry out major works and property investments.

\section{Sector performance and strengths}

The main strengths for private sector promotion are:

- The Comoros' membership in the euro/franc area ensures that the Comorian currency is relatively stable;

- Membership in a number of subregional groups (Indian Ocean Commission-COI, Common Market for Eastern and Southern Africa-COMESA, Community of SahelSaharan States - CEN-SAD, Greater Arab Free Trade Area - GAFTA, Organization of the Islamic Conference-OCI, Islamic Development Bank-IsDB, Union of Chambers of Commerce and Industry of the Indian Ocean-UCCIOI) entails trade development advantages;

- The future economic partnership agreement between the EU and COMESA, under the Cotonou agreements binding the Comoros with the European Union, will offer opportunities in terms of access to the European market and the free trade area (ZLE);

- The African Growth and Opportunity Framework (AGOA), the Uniform Acts of OHADA, the Multilateral Investment Guarantee Agency (MIGA) Convention; SID and SIASE (IsDB investment insurance), the Integrated Framework;

- The Comoros's membership in the League of Arab Nations is providing, inter alia, an opportunity to gain access to the Arab market and to make the Comoros a platform to access the Gulf States;

- Membership has been undertaken in the World Traded Organization; 
- Enlargement of Saïd Ibrahim International Airport and its alignment with international standards;

- Integration into the world globalization and liberalization process (liberalization and opening of the telecommunication market);

- Implementation of the submarine fiber optics cable in connection with the East Africa Submarine Cable System (EASSY) Project;

- The government's commitment to implement a framework favorable to private sector expansion through the state's divestiture from the trade sector to concentrate on customary public service activities;

- Strengthening of employment and social security policies;

- Existence of a new, modern, and attractive investment code based on performanceoriented incentives and the operation of the ANPI;

- The program to strengthen trade services and the existence of sectoral studies (vanilla, ylang ylang, and other spices).

\section{Private sector weaknesses and constraints}

Private sector development faces the following weaknesses and constraints:

- The absence of follow-up on commitments undertaken reduces investor visibility;

- An inflated tertiary sector dominated by the informal sector;

- A virtually nonexistent secondary sector limited to a few small and medium-scale enterprises;

- Limited opportunities for bank financing;

- Absence of foreign trade promotion structures;

- Insufficient commercial representative offices abroad;

- Absence of a clear policy on enterprises;

- The legal system does not provide effective support to the private sector in rapid processing of litigation and the elimination of arbitrary practices in certain tax services;

- Insufficient skilled labor; 
- Absence of corporate and management culture.

\section{Outlook for the private sector}

Since the 1980s, successive governments have become aware of the role the private sector must play as a partner in the country's development. Private sector support programs should promote the development of entrepreneurial capacities and make financing available for productive investment. Moreover, enterprise creation procedures must be streamlined and certain incentives established to promote investment. The government should take steps to enable the private sector to progress and to play a more important role in development programs.

\subsubsection{FINANCIAL AND MICROFINANCE SUBSECTOR}

The Comorian financial sector has registered substantial growth during the past five years. In 2007 , the banking system had only one commercial bank. Today, the banking landscape has changed with the opening of new banks and microfinance institutions.

The financial sector comprises:

- Banque pour l'Industrie et le Commerce (BIC), which accounts for more than 60 percent of the savings and credit market;

- Banque de Développement des Comores (BDC), which serves a limited number of small and medium-scale entrepreneurs owing to substantial transaction procedures and costs, which constitute a barrier to access for this type of service. It does not take deposits, but draws borrowing resources from foreign institutions. When the BDC resumed operations in 2008, it began to focus on microfinance activities. New enterprise financing activities were suspended to strengthen existing enterprises, and to finance their development;

- The National Postal and Financial Services Company (SNPSF), established in 2005, developed a new service with the introduction of postal checks in 2006;

- The two microfinance institution networks (Sanduk and Meck) are developing quickly. Meck was licensed by the BCC in November 2005;

- In 2009, we observe the establishment of two new commercial banks. Exim Bank, which now operates as a representative office, and Banque Fédérale du Commerce; and two offices of the postal services were opened in France to facilitate transfers from Comorian expatriates throughout the world;

- The Western Union monopoly on fund transfers is now facing competition with the establishment of Travelex, and Money Gram since 2008.

Where nonbanking services are concerned, the UNDP micro and small-scale enterprise support project (AMIE) works directly with those who have project ideas by helping them formalize their projects and providing access to microcredit in the range of CF 50,000-500,000. Financing is 
based on a credit facility provided initially by UNDP. AMIE is now an independent association that works closely with the Mecks network.

The formal financial sector is characterized by ineffective financial intermediation where some savings are reinjected into the economy through loans and productive investments, which register a sharply declining trend. Formal financial institutions in fact mainly finance commercial activities and seasonal cash crop activities, which are short-term operations.

The financial system has long been in a position of excess liquidity, although the economic cycle has led to a tightening of credit. However, the financial system is now facing a liquidity shortage. Savings must therefore be stimulated to ensure that civil service wages can be paid.

In general, banks are no longer investing in the productive sector. This situation can be explained by several factors, including the perception of substantial risks in investment projects and the fairly pessimistic outlook for enterprise profitability in the current economic and political climate.

To offset this lack of access by the poor to formal financial services, microfinance institutions (MFIs) appeared during the late 1990s: Caisses Sanduk (a network of 55 banks covering all of the islands) and Mutuelle d'Épargne et de Crédit des Komor (Meck), which has 13 branches located in the three islands, although its operations are more dense than Sanduk's

Established in 1993 with support form the Agence française de développement (AFD), the Sanduk bank network aims to give rural people access to grassroots banking services. Meck was established in 1996 with support from the International Fund for Agricultural Development (IFAD) and the Comorian government. While these decentralized financial institutions (DFIs) grant loans to the less affluent population, they apply credit policies similar to banks, providing financing for vanilla production and trade activities.

These two networks have gained popularity and their market share is constantly growing, indicating that they meet an existing requirement. The share of savings increased from 15 percent in 2001 to 27 percent in 2004, and the share of credit from 12 percent in 2001 to 28 percent in 2004. These developments are promoted through an estimated CF 35 billion in transfers from the Comorian emigrant community, which are used for savings and repayment of loans arranged by the households involved. AFD is now financing programs to support the Sanduk and Meck networks with a view to rehabilitating the institutions and consolidating the system.

\section{Performance and strengths of the financial and microfinance sector}

The Comoros's membership in the euro area is a factor in the stability of the financial system and in investor security. This membership protects against risks of tight credit policy, despite the unfortunate presence of excessively prudent commercial bank policies, which are impeding credit development.

During recent years, we observe substantial growth in DFI activities, as reflected by an increase in outstanding deposits, loans, and membership numbers: 
- At December 31, 2004, the Meck network registered 25,351 members, as against 19,105 in December 2003, outstanding savings of more than CF 5 billion, up 13 percent; and outstanding loans of CF 2.5 billion, as against CF 1.7 billion in December 2003;

- Sanduk network activity, with three autonomous regional unions, grew slightly in 2004, with 22,070 members, as compared with 20,355 in December 2003; while deposits increased from FC 2 billion to CF 2.4 billion and outstanding credit from CF 1.2 billion to CF 1.4 billion during the same period.

The existence of a regulatory framework governing the DFIs, enabling the central bank to exercise its supervision authority, is a positive factor that can be expected to support the sustainability of the system.

\section{Weaknesses and constraints of the financial and microfinance sector}

The financial and microfinance sector faces the following major weaknesses and constraints:

- A lack of real competition in the credit market;

- An absence of diversification in microfinance products and agencies;

- Substantial dependence on credit from donors and lenders;

- Insufficient follow-up of credit cases in certain institutions;

- Difficulty in effectively channeling savings from Comorian expatriates;

- Low level of remuneration on savings;

- The judiciary system is not efficient or organized enough to provide valid support for the financial sector;

- Confusion of supervision and financing roles;

- The supply of financial services is not adapted to the specific features of certain activities;

- DFI management lacks sufficient professional standing, which can have severe consequences for some organizations;

- There are insufficient financial instruments that would permit more effective risk management;

- Interest rates are often deemed to be excessive as compared with returns on investments;

- Microfinance institutions reach an insufficient proportion of the population in rural areas. 


\section{Outlook for the financial and microfinance sector}

Initiatives are in progress for Banque de l'Habitat, an investment a bank, and a bank for emigrants. With the celebration of the international year for microfinance, Comorian DFIs have become aware of the preponderant role they must play in local economic development and efforts and to fight instability in their communities. Support to enhance the professional standing of DFIs is essential. The changes we observe in the composition of the Comorian expatriate community could lead to a drastic reduction in transfers in the medium term. 


\section{CHAPTER IV}

\section{CORE STRATEGIES AND PRIORITY PROGRAMS}




\subsection{INTRODUCTION}

The poverty reduction and growth strategy was developed according to three basic principles. The stakeholders are convinced that poverty can be reduced substantially in the Comoros with (i) robust economic growth; (ii) human and institutional capacity building; and (iii) strengthened governance and public management, with, inter alia, a clarification of roles, responsibilities, and scope of authority between the Union and the islands, combined with a reorganization of the civil service.

\section{Robust economic growth is essential for poverty reduction}

The experience of the Comoros and many developing countries shows that economic growth is a necessary condition for sustainable poverty reduction. To improve the population's living conditions, production and productivity must be increased, jobs created, and revenue generated. The scope of the impact depends on sector performance, the political and institutional environment, macroeconomic and sectoral policies, and the level of inequality prevailing between the socioeconomic categories and environments. Numerous studies also show that economic growth can be accompanied with an increase or reduction in inequalities depending on the sector in which the growth is concentrated. When we observe a substantial concentration of poor households in a given sector, we can expect substantial growth in the sector to have a more substantial impact on poverty reduction than if growth were induced in a sector encompassing fewer poor households. By contrast, growth deriving from a sector where few poor people are concentrated can also contribute indirectly to reduce poverty and inequalities, provided that the government establishes effective redistribution policies.

There are therefore two major options in terms of sectoral priorities to reduce poverty through growth: promote growth in the most promising growth sectors where the country has comparative advantages, and ensure that some benefits of this growth are redistributed through redistribution policies; or adopt a "pro-poor policy" aiming to boost the income of the poor in the sectors where they are concentrated, which will also lead to an increase in GDP.

The government of the Comoros intends to use a combined approach, by targeting the sectors where the poor are concentrated, to directly and quickly increase their income, and by stimulating medium-term development of new growth sectors, the benefits of which can be redistributed through taxation and through equitable, incentive-based public expenditure policies. In a shortterm framework, there was a special focus on the micro and small-scale enterprise sector and the agro-food sector (agriculture, fishing, and stockbreeding) in general, as these sectors typically register a significant proportion of households, a poverty incidence exceeding the national average, and therefore individuals likely to respond quickly to incentives (EIM, 2004).

Comorian agriculture has lost substantial domestic market share during recent years. Increasing amounts of fruit, vegetables, and food products are imported from the African continent. As a result of substantial increases in sea transportation costs, and international rice prices, which doubled in one year, local products are now more competitive and offer opportunities to regain market share, provided that the trade circuits in the marketing scheme are organized to reduce production and transaction costs, to support farmers, ensure that inputs are available, and promote 
consumption of local products. The authorities are convinced that promoting growth in the agriculture and fishing sectors will contribute directly to job creation in the poorest sectors.

In the framework of a medium and long-term outlook for the agricultural sector, the government intends to promote private sector development in the Comoros in certain targeted export-oriented niches of the agrofood sector. The aim is to stabilize, and if possible to improve current production of the traditional cash crops of vanilla, cloves, and ylang ylang, while developing new crops and positioning the country in export niches. Potential candidates would include tropical fruits such as lychees, algae growing, lobster and shrimp farming, cultured pearl production, etc.

Tourism development, however, will be the country's medium-term economic engine. This option is the centerpiece of a government development strategy. To date, despite the country's evident tourism potential, the Comoros has not been able to develop this sector as other islands of the Indian Ocean. This situation could change, however, in the coming years. Financing agreements have been signed for over US\$250 million with international tourism groups to develop high-end seaside beach complexes. Work has also begun on the old Galawa hotel site.

Tourism is a particularly interesting sector in poverty reduction as it is job-intensive and can create knock-on effects in a number of economic sectors. In addition, most of the skilled jobs created in the sector will require a relatively short training period (from a few months to a few years). Further, if effectively managed, this sector represents a sustainable source of income and can contribute to environmental conservation. The challenge for the Comoros is to optimize revenue and benefits from growth in tourism by developing multiple services related to this sector, including the supply of fishing, stockbreeding, and agricultural products. In the least favorable scenario, these products will all be imported, which will reduce the knock-on effects throughout the economy. By contrast, if the Comoros follows the examples of the Seychelles and Mauritius, there will be numerous, dynamic linkages between tourism and other economic sectors. The government is aware of both the problems and the opportunities involved. To ensure coherent synergies between the sectors, the concepts of tourism development and public private partnership (PPP) poles will be implemented. The conditions for a win-win situation must be defined in which Comorians will gradually gain the skills required and invest alongside international investors.

In addition to questions related to the type of sector to be given priority in poverty reduction and growth, the type of growth will also affect poverty reduction. Unskilled labor-intensive growth will be much more effective in poverty reduction than capital-intensive growth. Accordingly, labor-intensive technologies, primarily those requiring unskilled labor such as road construction and maintenance, construction, agrofood, etc. should be given priority.

Whether this effort involves identifying growth niches in the agrofood or tourism sector, serious studies should be conducted to assess technical feasibility, market potential, the comparative advantages of the Comoros, and possible strategic niche market positioning. Similarly, studies must be conducted to identify labor-intensive technologies to be promoted in different sectors to ensure product quality, returns on economic activities, and the competitiveness of Comorian goods and services. 


\section{Improving human capital is at the core of the development and poverty reduction process}

Poverty is not only a result of low income. It is also caused by insufficient access to different forms of capital, and particularly human capital. The government intends for all Comorians to be healthy, well educated, and able to reach their personal and professional potential. To that end, individuals must be able to take the economic opportunities made available to them to earn their living and ensure the well-being of their families. The education sector plays a strategic role in this connection as it is the best mechanism to convey social values and develop skills to enable individuals to find the means and motivation to build a country where the quality of life is good.

Against this backdrop, the PRGS places special emphasis on vocational training activities in addition to those directly targeting the formal education sector. It is an important matter to allocate resources to occupational training and functional literacy for young persons and adults. These are effective mechanisms to promote their occupational integration, particularly in key employment sectors. The aim will be to promote short-term training activities, such as agrofood technology institutes and hotel and tourism schools, to provide specialized labor required to develop these identified growth niches.

Strong demographic growth is a constraint for the country's development. The demographic growth rate was approximately 2.1 percent according to the $2003 \mathrm{RGPH}$, and there is no reason to believe it has declined in recent years. Clearly, this growth rate should be reduced in order to reduce poverty significantly. Demographic growth in fact accentuates demand for basic social services, while available financial and human resources are quite limited. The government intends to attack this problem directly through strengthened family planning programs. The introduction of relevant training modules into training curricula, in the public and private sectors, is a priority. Last, we know that broad education is required to reduce the demographic growth rate, with a focus on education for girls and adult literacy. Activities in these two areas will receive special attention.

\section{Sharing of responsibilities through responsible governance ensures sustainable development}

Good governance is a necessary condition for poverty reduction in the Comoros. The government of the Union of the Comoros intends to continue the process of national reconciliation, democratization, and decentralization so that the Islands can be more autonomous and to enable civil society organizations gain increasing responsibility and involvement in the development management process.

Insufficient governance and political instability have been factors in increasing poverty and blocking the economic and social development process. The danger of secessionism will be present as long as the power sharing between the Union and the islands is not anchored in democratic practices. The basic texts must be understood by all citizens and for civil society and citizens' organizations to ensure such understanding through the daily exercise of power at the community level and through institutions at the island level. This change in attitude will be supported by the schools, which will begin at the primary level to provide civic training in the principles of democracy. In this connection, public communications and media development should receive more attention. A well-informed society is generally more democratic and better 
positioned to understand the stakes and difficult choices that must be made, and will contribute more effectively to the development process.

At the same time, rapid progress is also essential on the issue of sharing authority between the different levels of government at the sectoral and inter-sectoral levels. The Constitution of 2001 and the promulgation of the Organic Laws of 2005 clearly established a constitutional framework. Now, the responsibilities of the different parties must be clarified and the appropriate instruments established for each of them to exercise their rights. Too often, in recent years, Union and island government activities have been blocked by a lack of clarity and consensus on the each participant's prerogatives. Issues that are initially technical rapidly to take on political undertones, making problem solving a difficult matter.

It is therefore quite normal for good governance to be at the center of the concerns in the poverty reduction strategy. The government of the Union intends to attack this issue in partnership with the island governments as quickly as possible so that all Comorians can meet the challenges of poverty reduction. Rapid progress in improving living conditions will be sought, as in the past, the great poverty that still affects many Comorians has been a factor in vulnerability to unproductive distractions. Good economic governance is also a central issue in the national reorganization effort. Not only will the authorities aim at sound management of fiscal resources, but they will ensure that the markets operate efficiently and that distortions and sources of illegal enrichment - factors of public discouragement - will be removed.

\subsection{PRGS CORE STRATEGIES}

According to the adopted principles and orientations, the 2010-2014 PRGS adopted six core strategies and 32 priority programs to be implemented during the next five years (Table 1 ).

Table 1. 2010-2014 PRGS: Core strategies and priority programs

\begin{tabular}{|c|c|}
\hline Core strategy & Priority program \\
\hline \multirow{5}{*}{$\begin{array}{l}\text { Core strategy 1: Stabilize } \\
\text { the economy and lay the } \\
\text { groundwork for strong and } \\
\text { equitable growth }\end{array}$} & Program 1.1. Enhance government and fiscal operations \\
\hline & $\begin{array}{l}\text { Program 1.2. Integrate and facilitate domestic and } \\
\text { international trade }\end{array}$ \\
\hline & Program 1.3. Improve the energy supply at a low cost \\
\hline & $\begin{array}{l}\text { Program 1.4. Improve basic economic infrastructure and } \\
\text { communication services }\end{array}$ \\
\hline & $\begin{array}{l}\text { Program 1.5. Increase access to drinking water, sanitation, } \\
\text { and sustainable resource management }\end{array}$ \\
\hline \multirow{8}{*}{$\begin{array}{l}\text { Core strategy 2: Strengthen } \\
\text { key sectors by focusing on } \\
\text { institution building and } \\
\text { ensuring a broader role for } \\
\text { the private sector }\end{array}$} & I. Strengthening the private sector \\
\hline & Program 2.1. Support private sector organization \\
\hline & Program 2.2. Financial intermediation and microcredit \\
\hline & II. Restore growth through key sectors \\
\hline & - Agriculture and stockbreeding subsector \\
\hline & Program 2.3. Enhance security of property resources \\
\hline & $\begin{array}{l}\text { Program 2.4. Support the creation of a favorable } \\
\text { environment for agriculture sector development }\end{array}$ \\
\hline & Program 2.5. Restore agricultural and agrofood production \\
\hline
\end{tabular}




\begin{tabular}{|c|c|}
\hline Core strategy & Priority program \\
\hline & $\begin{array}{l}\text { Program 2.6. Protect livestock against exotic infectious } \\
\text { diseases and intensify the animal production sector }\end{array}$ \\
\hline & - Fishing subsector \\
\hline & $\begin{array}{l}\text { Program 2.7. Create an environment favorable to the } \\
\text { balanced development of the sector }\end{array}$ \\
\hline & $\begin{array}{l}\text { Program 2.8. Develop a conservation, processing, and } \\
\text { marketing system for fish products }\end{array}$ \\
\hline & - $\quad$ Tourism subsector \\
\hline & Program 2.9. Support tourism development \\
\hline \multirow{4}{*}{$\begin{array}{l}\text { Core strategy 3: Strengthen } \\
\text { governance and social } \\
\text { cohesion }\end{array}$} & $\begin{array}{l}\text { Program 3.1. Promote good governance, social cohesion, } \\
\text { solidarity, and consolidation of peace }\end{array}$ \\
\hline & $\begin{array}{l}\text { Program 3.2. Improve the legal framework, promote } \\
\text { anticorruption measures, and strengthen transparency in } \\
\text { fiscal management }\end{array}$ \\
\hline & $\begin{array}{l}\text { Program 3.3. Strengthen the capacities of the judiciary } \\
\text { institution }\end{array}$ \\
\hline & $\begin{array}{l}\text { Program: } 3.4 \text {. Fight terrorism and transnational crime, and } \\
\text { strengthen civil security }\end{array}$ \\
\hline \multirow{4}{*}{$\begin{array}{l}\text { Core strategy } 4: \text { Improve } \\
\text { the health status of the } \\
\text { general public }\end{array}$} & Program 4.1. Fight malaria and priority diseases \\
\hline & $\begin{array}{l}\text { Program 4.2. Integrated sexual and reproductive health } \\
\text { development }\end{array}$ \\
\hline & $\begin{array}{l}\text { Program 4.3. Fight HIV/AIDS and sexually transmissible } \\
\text { infections }\end{array}$ \\
\hline & $\begin{array}{l}\text { Program 4.4. Strengthen the efficacy of all aspects of the } \\
\text { health system }\end{array}$ \\
\hline \multirow{4}{*}{$\begin{array}{l}\text { Core strategy 5: Promote } \\
\text { education and vocational } \\
\text { training with the aim of } \\
\text { developing human capital }\end{array}$} & $\begin{array}{l}\text { Program 5.1. Develop education, technical instruction, and } \\
\text { occupational training, to reflect the requirements of the job } \\
\text { market }\end{array}$ \\
\hline & $\begin{array}{l}\text { Program 5.2. Improve access to and quality of basic } \\
\text { (preschool and elementary) and secondary education }\end{array}$ \\
\hline & $\begin{array}{l}\text { Program 5.3. Develop competent human resources and the } \\
\text { sectoral (SWAP) approach in education }\end{array}$ \\
\hline & $\begin{array}{l}\text { Program 5.4. Promote literacy, sports, and cultural } \\
\text { activities }\end{array}$ \\
\hline \multirow{6}{*}{$\begin{array}{l}\text { Core strategy 6: Promote } \\
\text { environmental } \\
\text { sustainability } \\
\text { and civilian security }\end{array}$} & $\begin{array}{l}\text { Program 6.1. Conserve biodiversity and equitably share its } \\
\text { advantages }\end{array}$ \\
\hline & Program 6.2. Conserve and upgrade agro-biodiversity \\
\hline & Program 6.3. Adapt to climate change \\
\hline & Program 6.4. Fiscal rehabilitation with an ecological focus \\
\hline & $\begin{array}{l}\text { Program 6.5. Capacity building for multisector } \\
\text { environmental management and coordination }\end{array}$ \\
\hline & $\begin{array}{l}\text { Program 6.6. Establish prevention and management } \\
\text { mechanisms for risks related to natural and climate } \\
\text { disasters }\end{array}$ \\
\hline
\end{tabular}




\section{Core Strategy 1: Stabilize the economy and lay the groundwork for strong and equitable growth}

This strategy involves conducting major fiscal reforms, reorganizing the administration, adopting incentive commercial policies to promote the integration of the Comoros into the regional and world economies; implementing measures to make the Comorian economy more competitive, particularly in the key sectors of agrofood and tourism; executing reforms and investments to guarantee a regular energy supply at a reasonable costs; and building and improving basic economic infrastructure (roads, ports, airports, and telecommunications) to support external trade as well as to enable Comorian economic players and producers to take optimal advantage of the opportunities available to them on the domestic market. Last, this core strategy involves access to drinking water and sanitation services.

\section{Core strategy 2. Strengthen key sectors by focusing on institution building and ensuring a broader role for the private sector}

This core strategy involves implementation of priority programs aiming to develop and increase productivity in key economic growth sectors and to help achieve a sustainable reduction in poverty. This strategy primarily involves agriculture, stockbreeding, fishing, and tourism. While the traditional components of the agrofood sector are better known, and their contribution to economic development and food security no longer remain to be proven, the tourism sector offers great potential that has never truly been tapped.

The measures under this strategy aim at institutional support and the regulatory framework governing growth sectors; support for the intensification, improved productivity, strengthened competitiveness, and capacity building for commercial activities and marketing circuits. This strategy also covers accompanying measures to strengthen the financial intermediation system and access to microcredit facilities, support for nonfinancial services to promote private sector development, and an improved business climate. These activities constitute essential measures for the country and the underprivileged sectors to become integrated into the modern economy and to consolidate the development of micro and small-scale enterprises, which are often highly vulnerable to economic shocks.

\section{Core strategy 3: Strengthen governance and social cohesion}

This strategy aims to consolidate good governance and social cohesion by constructing the democratic and administrative institutions of the Union and the islands. It aims primarily to strengthen the regulatory framework by clarifying the responsibilities, roles, and scope of authority of the national institutions with a view to a renewed, constructive social dialog.

Through implementation of the adopted priority programs, this strategy will make it possible to improve governance and the efficacy of public institutions, to implement a true decentralization policy at the rural community and municipality levels, to renew a constructive social dialog to provide citizens with greater peace and security, to give all citizens access to transparent, equitable justice, and to fight transnational crime and strengthen civilian security. 


\section{Core strategy 4. Improve the health status of the general public}

Core strategy 4 aims to give the public better access to quality health service, targeting the most vulnerable groups and rural populations, and to give priority to the measures to reduce anemic diseases and to improve all areas of the health system.

In this connection, the government will focus its efforts on implementation of programs aimed at reducing malaria and priority diseases, improving mother and child health, preventing HIV/AIDS, improving health system management with a view to more efficient, effective health services, and improving the hospital environment.

\section{Core strategy 5. Promote education and vocational training with the aim of developing human capital}

The education sector in the Comoros should produce a socially-responsible, educated population capable of taking advantage of economic opportunities. It is a powerful vehicle for change in behaviors that must also help citizens reach goals and give them better governance and improved health. The government intends to focus its efforts and to direct those of its partners to meet these major challenges.

Core strategy 5 emphasizes better access to quality education at all levels, a shift of the ministry's efforts to technical and vocational training, and further support for informal training through literacy activities targeting young people and adults.

\section{Core strategy 6. Promote environmental sustainability and civilian security}

We note that most of the environmental constraints the Comoros faces are similar to those fond in Small Island Developing States (SIDS) under Agenda 21 and the Barbados Plan of Action: ecological and economic fragility, substantial vulnerability to climate change and natural disasters, insufficient response and management capacity, narrow resource base, and high energy costs.

In the Comoros, perhaps more than anywhere else, the environment is the focal point of the key economic sectors to produce commercial goods and services. Recent studies have shown that growth in the Comoros is still highly contingent on development in the agrofood and tourism sectors, both of which are highly dependent on the natural surroundings, the quality of the environment, and its conservation. The government therefore chose to make the environment a central issue in the PRGS. Several ambitious priority programs will be implemented to protect the environment and ensure its regeneration, conservation, and rational, sustainable exploitation, while being mindful of the well-being of current and future generations.

The Union of the Comoros is a poor, vulnerable country with many risks, including cyclones, droughts, epidemics, tornadoes, brush fires, tidal waves, floods, major accidents, landslides, volcanic eruptions, and risks related to the presence of an active volcano (earthquakes). This vulnerability might be aggravated by an insufficient capacity to prepare, prevent, and respond appropriately to risks and disasters. The government takes this issue very seriously as it intends to 
establish risk and disaster prevention and management mechanisms in connection with global warming.

\subsection{CROSS-CUTTING STAKES}

To supplement the core strategies described above, the government also believes it is important for the following cross-cutting issues to be considered in the formulation of all priority programs and in the conduct of reforms involving public sector institutions.

\section{Improved production and access to statistical information deemed to be essential in the preparation and monitoring of development programs}

Problems in the area of statistical information and the requirement to improve socioeconomic databases are a cross-cutting concern that we find in all the core strategies. A national statistical development strategy (SNDS) was validated in 2007. This ambitious strategy calls for substantial resources. Its implementation is a priority, particularly in terms of the computerized public expenditure system and a more powerful information system linking the central and island levels in the strategic sectors of the economy. This information is essential for PRGS monitoring and evaluation, as well as for the strategies deriving from it.

In fact, it was learned in the preparatory work for the PRGS that it is important to strengthen the formulation and steering of sectoral policies. As is true in the sectors where the work is already in progress, such as road infrastructure policy, for which the validation workshop was held in July 2008, a systematic effort must be undertaken during the implementation of this PRGS to ensure that the sectors have the planning tools, competence, and information required to prepare valid sectoral strategies.

While the sectoral strategies are derived from the Union, they must also be prepared in cooperation with the autonomous islands. Now, the mechanisms for this coordination pose problems as the islands, rightly or wrongly, tend to consider that their needs are not sufficiently taken into account. In this connection, the absence of disaggregated data by island poses a problem. The information system is imprecise, and sometimes nonexistent, between the central level and the islands. The required clarification therefore involves relations between the Union and the islands within each sector.

In the same capacity as planning, monitoring of public program execution and evaluation requires access to reliable statistical information and data. These functions should be reinforced in the context of modernized, results-based public management. Implementation of a coordinated monitoring and evaluation system requires a profound change of attitudes and the adoption of new public management practices. Institutional capacity building (at the Union and island levels) will be required to implement more effective, efficient fiscal management.

Development of and access to new production and communication technologies is a major challenge to make the Comoros more attractive, productive, and competitive at the regional and world levels. 
Economic growth and improved living conditions for the population in the Comoros are based, as in the rest of the world, on the use of new technologies available in all sectors. The government, private sector, producers in the primary sector, and players in civil society must have access to modern technologies to increase their productivity and develop new economic activities that can meet the needs of the population and external demand.

Access to such technologies is particularly important in the agrofood sector, where the majority of the poor are concentrated. It is a sector where technological innovations are required to increase productivity, to maintain the country's world market share, and to develop new incomegenerating business sectors. It is essential for Comorian higher education and research institutions to join forces with the relevant government and private sector institutions in this effort.

Moreover, better access to new information technologies is essential to place the Comoros in a better position on the tourism market, which is a substantial growth market, and the highly dynamic business process outsourcing (BPO) sector. Progress under way in the area of connectivity must be pursued and operating costs reduced. It is a favorable sign that investors in the region recently contacted the authorities for more information on BPO opportunities in the Comoros.

The government intends to develop a rigorous institutional incentive framework for investment in this sector. The National Investment Promotion Agency (ANPI) which is being established will study the conditions for successful BPO activities based primarily on the experiences of Madagascar and Mauritius, will inform national operators on existing opportunities, and identify external partners.

\section{It is a priority to incorporate gender and human rights issues into the implementation of all programs, to ensure peace and security and to promote a renewed, constructive social dialog.}

The contribution of women to the development process has long been underestimated in the Comoros, despite their essential contributions to food production, marketing of agriculture and fishing products, income generation, home management, and child education. Gender equity studies were conducted in 2007 and substantial recommendations were subsequently validated at a national workshop. The government intends to restore women to their rightful place in the decision-making and development processes. Women and girls will be the priority target groups for access to social services (education, health, and family planning), economic services (financial services and microenterprise development), and justice. Strengthening of the woman's place at senior levels of the public sector and in decentralized decision-making centers will be encouraged.

The government would like to enrich and expand the country's development strategy through an approach that reflects human rights. Two consultations were held in 2007 to prepare to incorporate human rights into the PRGS. Recommendations were adopted during a validation workshop, primarily involving the: (i) identification of vulnerable groups; (ii) need for capacity building in civil society so that it can serve as a countervailing power and influence the implementation of a human rights-based approach in PRGS implementation; (iii) expansion of the participative approach (principle of inclusion) by involving vulnerable persons in the 
planning authorities and defining objectively verifiable indicators; (iv) adoption of legislation respectful of vulnerable persons; (v) capacity building for lawful claimants to enable them to assert their rights and capacity building for obligated parties to respond to justified claims made against them by such claimants; (vi) adoption of legislative texts to establish an obligatory accountability mechanism.

\section{Integration of trade into the PRGS is a necessary condition for growth, wealth creation, and socioeconomic development in the Comoros.}

Within the framework of its membership in the Integrated Framework (CI), the Comoros in 2007 prepared its diagnostic study on integration of trade into development and poverty reduction policies. This study laid the groundwork for a cross-cutting approach to international trade, which highlighted (i) the organizational weaknesses in the private sector and deficiencies in the business and investment climate; (ii) the need to strengthen the country's competitiveness, including tax reforms, improvement of basic infrastructure, and production of energy to reduce excessive factor costs; (iii) strengthening of the rule of law and the legal system; (iv) strengthening of trade and investment institutions; (v) improved operation of domestic markets (adoption of implementing decrees for the public contracting code, establishment of legislation on competition, and creation of a contracting surveillance agency); (vi) reforms required to participate in the Common Market for Eastern and Southern Africa (COMESA) agreements and to align the country's institutions and enterprises with a view to the Economic Partnership Agreement (EPA) and entry into the WTO; and (vii) targeted actions to remove the bottlenecks in the productive sectors. This study also highlighted the importance of reducing inter-island transportation costs.

A matrix of priority actions to remove the bottlenecks and strengthen the institutions responsible for trade and investment was prepared and validated. The trade diagnostics and its priority action matrix were endorsed by the Council of Ministers in January 2008 and a project implementation unit has recently been established.

\section{Operations to reach the Millennium Development Goals (MDG) must receive priority as unifying stakes to improve the socioeconomic situation of the general public.}

In 2006, the government requested support to study the country's status in respect of the MDGs. Although the Comoros registered social indicators higher than those in most African countries, it would seem that without massive support from the international community, it will be impossible to reach the goals established for 2015. Substantial efforts, however, have been made and we observe a budget reallocation to benefit the social sectors. It is also very important to be aware the issue is deficient policies, which can be addressed. Through greater attention, the authorities have reduced both mother and child mortality; small girls are attending school, even if there are still differences in favor of boys; the school enrollment rate for girls has increased and their retention rate in the school system has improved.

The cost of reaching the MDGs by 2015 was estimated in June 2008. The total cost is approximately US\$29 billion during an eight-year period, more than half of which is earmarked for improved access to energy, infrastructure construction, and transportation.

\subsection{PRIORITY PROGRAMS BY CORE STRATEGY}


The PRGS adopted a total of 32 priority programs. These programs are organized according to the six core strategies of the PRGS. This section presents the context of each program. More detailed plans will be presented in an action plan covering the period 2010-2014. Implementation of priority programs and reforms will essentially follow a sectoral approach subject to coordination and oversight by the relevant ministerial departments. By contrast, some programs should be implemented with an inter-sectoral approach as they involve a number of different sectors.

\subsubsection{CORE STRATEGY 1. STABILIZE THE ECONOMY AND LAY THE GROUNDWORK FOR STRONG AND EQUITABLE GROWTH}

Four priority programs were identified to set the stage for sustainable economic development. Their priority aim is to improve macroeconomic management, to implement structural reforms, and to enhance the competitiveness of the Comorian economy by reducing factor costs and through investment in basic infrastructure and communications. The following programs were adopted:

$\begin{array}{ll}\text { Program 1.1 } & \text { Enhance government and fiscal operations; } \\ \text { Program 1.2 } & \begin{array}{l}\text { Integrate and facilitate domestic and international trade; } \\ \text { Program 1.3 }\end{array} \\ \text { Improve the energy supply at a low cost; } \\ \text { Program 1.4 } & \begin{array}{l}\text { Improve basic economic infrastructure and communication } \\ \text { services; }\end{array} \\ \text { Program 1.5 } & \begin{array}{l}\text { Increase access to drinking water, sanitation, and sustainable } \\ \text { resource management. }\end{array}\end{array}$

\section{Programme 1.1: Improve government and fiscal operations}

The past few years have been particularly difficult ones for the government, as it has had had to face a threefold challenge: (1) an unprecedented economic crisis at the world and national levels; (2) alarming fiscal and public sector deterioration; and (3) the persistent political and institutional crisis.

The Public Expenditure and Financial Accountability (PEFA) report prepared in 2008 entailed a comprehensive fiscal analysis. The report brought to light a number of weaknesses, insufficiencies, and dysfunctions characterizing fiscal management. During recent years, the fiscal deterioration has accelerated and the distortions in good governance and public management have multiplied. As a result, the government now faces a major fiscal crisis and a disorganized, unmotivated administration. The time has therefore come for reconstruction and return to budget orthodoxy. 
In this particularly difficult context, the international community once again showed its support to the government through the IMF'S October 2008 approval of EPCA ${ }^{2}$. Subject to effective economic and financial management, the country could become eligible in 2009 for the HeavilyIndebted Poor Country (HIPC) Initiative and ultimately for the MDRI. ${ }^{3}$ While these objectives are within reach, they will require substantial budget discipline in the short term, as well as a reorganization of general government in the medium term.

Improved financial and budget management will be facilitated through the adoption of new instruments. The government intends to promote a results-based public management approach and to introduce tools under the medium-term expenditure framework (MTEF) and program budgets. Along with the adoption of these reforms and new instruments, it will be essential to strengthen the capacities of the government and to review the national system for planning, management, and monitoring and evaluation of public programs. It will also be essential to strengthen information flows between the Union and the islands, and the quality and regularity of statistics. Without these efforts to build capacities and strengthen the information system, it will be a difficult matter for the authorities to steer macroeconomic and sectoral policies.

Fiscal recovery goes hand in hand with institutional improvement. The deterioration in government operating conditions, as its size far exceeds the country's financing capacities, is not only a source of negative motivation for the existing civil servants, it also leads to a flight of the best trained and most dynamic personnel. Moreover, the financial crisis has led to the pure and simple disappearance of operating resources and to deterioration in capital goods. The absence of any consistent capital management system (annual inventories, equipment maintenance contracts, etc.) leads to substantial waste. The shortage of operating resources and equipment leads to further lethargy and dependency on development partners.

In addition to the government's efficacy and sound fiscal management, the question of privatization of state enterprises and companies is a focus for the government's concern and must be continued. The state's gradual divestiture from the productive sectors and commercial activities to benefit the private sector is vital. This divestiture will be pursued through voluntary policy based on comprehensive structural reform measures. The need for these reforms is strengthened through the establishment of the Comoros in COMESA, which requires implementation of customs and fiscal reforms to ensure that administrative practices and regulations are more broadly harmonized.

While the government is aware of structural and recurrent problems, it is also aware of the difficult decisions that must be made to correct the fiscal and overall administrative situation. It intends to meet these challenges in the context of PRGS implementation. Fiscal rehabilitation, improved government operation, and the reorganization of the civil service are conditions for restoring the macroeconomic fundamentals to equilibrium, which is required for robust economic growth sufficient to reduce poverty.

The objectives during the period are to contain public deficits, reduce the size of government, ensure a better allocation of public resources to the priority sectors and programs to reduce

\footnotetext{
${ }^{2}$ Emergency Post Conflict Assistance.

${ }^{3}$ Multilateral Debt Relief Initiative.
} 
poverty, and to review the role of government in the context of a liberalized economy that recognizes the place and importance of the private sector in the process of growth, job creation, improved household living conditions, and poverty reduction.

\section{Program 1.2. Integrate and facilitate domestic and international trade}

Commercial policy based on the multilateral trade framework and the process of regional economic integration adopted by the government will help give new impetus to the economy while reducing rent-seeking behaviors, reducing factor costs, facilitating trade, and improving the business and investment climate. The multilateral trade system and agreements with COMESA will help stabilize commercial policy through firm anchoring in a market economy. One of these goals includes an accelerated growth rate and reduced poverty. Accompanying measures (training, strengthened professional organizations and associations, and access to information and financing), however, are required to enable the most disadvantaged to profit from this growth and to enjoy its benefits.

At the same time, the government intends to stimulate domestic trade in local goods to provide a better supply for the general public. Reforms will be undertaken to remove the barriers that impede the circulation of goods and increase their prices, which are harmful to the least favored sectors. These measures should promote inter-island trade flows and guarantee more regular supplies.

\section{Program 1.3. Improve the energy supply at a low cost}

Access to energy is a key factor in economic recovery. The energy problems the country has been experiencing for a decade require a strategic medium and long-term outlook. The energy sector diagnostics brought to light the need for rational biomass management, greater autonomy in terms of imported petroleum products, more effective production and distribution systems, diversification of the energy supply with new energy sources such as solar, hydraulic, aeolian, and geothermal energy. Owing to the narrowness of the market, high electricity production costs explained by high petroleum prices are leading to major problems in the country's development. These problems are accentuated by the absence of a sectoral strategy, an unclear institutional framework, and insufficient human resources to ensure effective management of the sector.

To meet these challenges, the PRGS has adopted a priority program whose objectives are to (i) clarify and strengthen the institutional and organizational framework and provide the country with a national strategy to improve energy management; (ii) strengthen energy storage, production, and distribution infrastructure; and (iii) reduce technical and non-technical losses related to production, distribution, and marketing of energy through a national energy management and efficiency program.

This approach should lead to lower energy costs and improve accessibility of energy services. This program will also aim to promote the substitution of firewood by introducing new cooking technologies, and particularly, improved heating facilities and the use of modern fuels. Last, diversification of energy sources will be stressed to improve the country's energy autonomy and promote clean energy sources to preserve the environment. The expected impact of these 
measures will be to meet human requirements for access to energy, to effect social improvements, and to facilitate economic activities, particularly for women.

\section{Program 1.4. Improve basic economic infrastructure and communication services}

The cost of production factors in the Comoros is high - much higher than observed in other countries in the region. Insularity and the small size of the market, aggravated by the division of the territory into several islands, partially explain why the costs of energy, water, and transportation are higher than the average in neighboring countries. However, there are other factors explaining the situation. In addition to the tensions and disputes that have prevented normal operation of the administration's technical services during the past 10 years, we observe that most infrastructure built approximately 20 years ago has not been upgraded, and that they are inadequate to cope with the increase in domestic demand and the introduction of new marketing and production processes.

Significant investments are necessary to create the conditions for restored growth. The insufficiency, poor quality, and deficient management of infrastructure (such as roads, ports, and airports) has led to increased costs of trade between the islands and have buoyed up the cost of imported inputs, making enterprises less competitive. This situation leads to higher costs of imported consumer goods and reduces household purchasing power, particularly for the most disadvantaged.

Roads. A study to establish a sectoral road transportation policy at the horizon 2030 was conducted in 2007 and validated in July 2008. The study was financed by the European Commission, one of the main sources of financing for the implementation of the adopted program. This program provides for maintenance, repairs, and expansion of national roads. Works on secondary roads to make production centers more accessible are also programmed. Training will be provided to enhance management and oversight of the works.

Moreover, the 2007 Budget Law created a special public treasury account known as the Road Maintenance Fund (FER). This account will receive 15 percent of the proceeds from the single tax on petroleum products [taxe unique sur les produits pétroliers-TUPP]. A road maintenance fund existed in the past and should have been funded directly from a fee levied on fuel use. This mechanism, however, became ineffective in 2004 as a result of tensions between the islands, and payments to the fund were discontinued. The government's challenge will be to ensure that FER resources are effectively transferred and used only for road system maintenance and repairs.

Ports. There are plans to dredge the port of Mutsamudu and to build a floating pier at the Port of Moroni as an interim solution pending a decision on the location of a deepwater port. In the context of the PRGS, an appropriate site will be identified and a preliminary feasibility study will be conducted. The container storage area in Moroni should also be expanded. Development work on the Port of Mwali is also programmed and its management should be improved. Merchandise shipped to Mwali first arrives in Ngazidja or Nzwani and is then dispatched to Mwali, entailing a sequence of transshipments leading to higher prices for all imports. The option of a transportation price subsidy might be considered. 
The construction of small fishing ports with minimum cold chain and storage facilities on the three islands will continue in connection with PRGS implementation. This effort will reduce transportation costs from fishing areas to the urban centers and will initiate the organization of the fish trade. These activities should lead to a more regular supply of fish products and can also be expected to reduce prices.

Measures will also be implemented to improve port management (computer equipment), strengthen security (port entry markings, communication equipment, and radar) and will facilitate use of the facilities (removal of irreparable equipment from the docks, maintenance of water and power outlets, drainage channels, etc.). The government will strengthen the functions and missions of the Comoros Port Authority, which now only operates in the Port of Moroni.

Airports. Substantial work has been carried out in recent years: construction of a new terminal in Moroni and improved airport security. The airport's partial fence must be converted into a full one and the airport must be equipped with a freight scanner, as international airlines refuse to load merchandise that has not been scanned.

The Mwali and Nzwani airports have similar requirements: runways must be resurfaced, minimum markers must be installed, terminals must be built or existing ones developed, and fire protection equipment must be installed.

In the area of management and coordination of various airport services, much remains to be done and the government wishes to rationalize and enhance coordination between the services.

There are also plans to improve coordination between the road, port, and airport infrastructure and to build gangways for fast, easy freight and passenger transfers between the different means of transportation.

Telecommunications. In recent years, the Comoros has entered into the mobile telephone era. In less than five years, the number of mobile telephones has surpassed the number of fixed units. At the same time, appreciable market shares have been gained through the introduction of the Internet, and more recently, high-speed ADSL connections. Access to information and fluid communications have become substantially easier, even in rural areas. Each village now in fact has at least one telephone booth, which has provided greater access to information technologies. Of course, the price of communications is still high compared with rates in Madagascar. The recent decision to liberalize the sector and open it up to a second mobile telephone operator will introduce competition, and will probably reduce prices per communication unit. The government is determined to pursue its efforts to enhance the accessibility and quality of communication services.

\section{Program 1.5. Increase access to drinking water, sanitation, and sustainable resource management}

Access to high-quality drinking water is a fundamental requirement that must be met as a priority. This factor is identified in the MDGs and is included in the PRGS priorities. The relationship between drinking water and public health is well known. In general, the least favored groups are more vulnerable to diseases related to poor water quality. The risks of waterborne 
diseases and pollution are quite high in the Comoros, particularly because there is no protection for wells or pumping facilities, nor are there any water quality monitoring or control mechanisms. Only a few salinity analyses are performed on an ad hoc, partial basis. Health hazards are observed primarily through the prevalence of water-borne diseases such as diarrhea and typhoid. Studies have shown that the use of poor quality water for consumption is a source of infectious and parasitic diseases that are still the number one cause of mortality and morbidity in the Comoros today.

Similarly, individuals' quality of life and health depends directly on the environment in which they live. A healthy, improved environment is a determinant factor in the health of individuals, and particularly children, who are much more vulnerable to diseases related to an unhealthy environment. With accelerating demographic growth and urban development, we observe a significant increase in production of household waste and wastewater, untreated hospital waste, and waste related to transportation activities (motor oil drainage, automobile bodies, etc.). The absence of a system to manage household waste, wastewater, and sanitation is a major public health problem. Wastewater and rainwater management is a major concern in both urban and rural areas.

In the Comoros, access to high-quality water is still a luxury for the majority of the population. Less than 15 percent of the population reportedly has access to drinking water according to accepted standards. Moreover, the country has virtually no sanitation system. Wastewater and solid waste are discharged into the sea in the population's immediate living environment.

The country has no national water strategy or master plan. Activities in the water and sanitation sector are conducted essentially in the absence of any institutional or regulatory framework, which reduces the efficacy and performance.

\subsubsection{CORE STRATEGY II. STRENGTHEN KEY SECTORS BY FOCUSING ON INSTITUTION BUILDING AND ENSURING A BROADER ROLE FOR THE PRIVATE SECTOR}

A total of nine priority programs were identified under Core Strategy II. They are included in two major subgroups: (i) strengthening the private sector (two programs); and (ii) restoring growth through key sectors (seven programs).

\section{Strengthening the private sector}

Program 2.1. Support private sector organization

Program 2.2. Financial intermediation and microcredit.

\section{Restoring growth through key sectors}

Key sectors involve agriculture and stockbreeding, fishing, and tourism. Priority programs are organized in the following three subcategories:

\section{- Agriculture and stockbreeding subsector}

Program 2.3. Enhance security of property resources; 
Program 2.4. Support the creation of a favorable environment for agriculture sector development;

Program 2.5. Restore agricultural and agrofood production;

Program 2.6. Protect livestock against exotic infectious diseases and intensify animal production sectors.

\section{- Fishing sector}

Program 2.7. Establish an environment favorable to the balanced development of the sector;

Program 2.8. Develop the system for conservation, processing, and marketing of fish products.

\section{- Tourism sector}

Program 2.9. Support tourism development.

\subsubsection{Strengthen the private sector}

The private sector is poorly organized. The Chambers of Commerce, Industry, and Agriculture have recently come through a lengthy crisis resulting from disputes with the government, which decided to place them under its supervision. In September 2007, consular elections were held and a new leadership team for the Union of Chambers of Commerce was elected by the members. Professional organizations do little for their members. Aside from the structured sector comprised essentially of small and medium-scale enterprises, there is a substantial informal sector that engages in unfair competition.

Enterprises require skills in areas not directly within their field of expertise, but that are essential for their development. Such services include legal counsel, accounting, management, quality control, information technology services, market research, marketing, selection of production technologies, processing, marketing, packaging, storage, information management, after-sale services, etc. The consulting sector is undeveloped and is based on a few projects involving assistance in enterprise creation, involving a few new enterprises with limited resources that sell their services to existing enterprises. To implement a sustainable, competitive supply, it is important to strengthen private consulting firms, thereby contributing to the gradual establishment of the entrepreneurial fabric essential for private sector development.

The Comorian private sector also includes the financial service sector. Until last year, there was only one general private bank, BIC, plus two decentralized financial institutions (IFD) - the Meck and Sanduck networks. In 2008, two new banks, Eximbank of Tanzania and a Kuwaiti bank, were licensed by the central bank to open branches in the Comoros. Banque de Développement des Comores was also recapitalized and has recently returned to the market. It has opened a microfinance window and emerged as a competitor for Meck and Sanduck. Although the system registers excess liquidity, credit is still costly and does not meet the requirements of a developing country. We can, however, expect new banks to introduce more competition, leading to the introduction of new financial instruments (venture capital companies, for example), and a gradual decline in interest rates. 
Two priority programs were defined to meet the challenge of strengthening the private sector.

\section{Program 2.1. Support private sector organization}

Targeted actions will be taken to strengthen the human and institutional capacities of the Chambers of Commerce and professional associations so that they can provide useful services to their members. These actions will be included in a program of operations designed to improve the investment climate, make enterprises more competitive, reduce rent-seeking economies and taxes, primarily for large enterprises, strengthen the judiciary institutions with magistrates specialized in financial and commercial matters, establish the Supreme Court, and implement the Organization for the Harmonization of Business Law in Africa (OHADA) chart of accounts, which the Comoros adopted a few years ago. There are also plans to develop arbitration assistance for disputes that could be filed with the Chamber of Commerce. Last, the adoption of implementing decrees for the new investment code and the 2008 establishment of "Invest in Comores", the national investment promotion agency completed this scheme. In connection with this program, there are plans for this autonomous public institution to pursue its work to harmonize and simplify the administrative procedures for creating enterprises, and to strengthen cooperation with the external partners to stimulate foreign investment.

\section{Program 2.2. Financial intermediation and microcredit}

There are plans to implement organizations for elected officials and employees of decentralized financial institutions (DFIs), and to build the internal audit and supervision capacities of the institutions involved. Efforts will be made to obtain a license from the central bank for the Union régionale des Sanduck de Mohéli et de Ngazidja. In terms of developing new financial instruments, consultations will take place with the public and transactors to better define the desired targets and instruments. Strengthened prudential measures will be adopted and a compulsory savings insurance scheme will be implemented for decentralized financial institutions.

Women already constitute more than 50 percent of DFI clients, and efforts will be made to increase this rate as many poor women would like to arrange small loans to support their trading activities. There are currently no financial instruments that meet this need. Efforts will be made to develop specific activities targeting this population group.

\subsubsection{Restore growth through key sectors}

Restored growth and sustainable poverty reduction require development of and expansion in key growth sectors likely to create income and wealth. In the Comoros, these sectors are found where a significant proportion of the population is located, and have traditionally been the driving sectors of the Comorian economy (agriculture, stockbreeding, and fishing), or a largely underdeveloped sector that nonetheless offers substantial indirect growth potential through its potential knock-on effects on the rest of the economy (tourism). The seven priority programs in this subgroup of Core Strategy 2 are therefore presented according to the four growth sectors. 


\section{Agriculture and stockbreeding sector}

In the Comoros, agriculture and stockbreeding are traditionally combined within the same farm. Farms are small and the livestock (cows, sheep, and goats) are tethered. Stockbreeding aims primarily to cover the household meat and milk requirements, and to provide fertilizer for the farmland. It also provides supplementary income and serves as a savings mechanism. Four priority programs have been identified to meet the challenges in the agricultural and stockbreeding sector.

\section{Program 2.3. Enhance security of property resources}

The property problem is both physical, in terms of access to land; and legal, in terms of ownership rights. These two dimensions are interdependent. In physical terms, the property problem is basically one of village land management, and planning to maintain it and restore its fertility; the size of farms as a result of the extreme demographic density, and parceling, to the extent that the land is divided into very small plots. Legal issues include the absence of laws or the failure to apply poorly defined, unknown property law.

In 2007, a financing arrangement was executed with AFD to establish a property registry. Work is in progress and will continue during PRGSP program implementation. The government will concurrently take steps to encourage property registration. The cost of registration, which is now quite high, will be reduced drastically to enable the more modest sectors to register their properties. The law on land ownership, sharecropping, and the rights and obligations of the different parties involved must also be clarified. This effort will provide greater security and transparency, and in the long term will make it possible to organize the real property market.

\section{Program 2.4. Support the creation of a favorable environment for agriculture sector development}

In the context of shared responsibilities between the state and civil society, organizations for farmers, professionals, and private transactors must intensify their role in the rural economic development process. They must help in the definition of strategic guidelines, their implementation, and the monitoring and evaluation of the activities undertaken.

Insufficient performance in the agricultural sector is explained by an insufficient involvement of economic transactors in the decision-making mechanisms, planning of activities, and ownership of key rural development functions.

To restore growth in the agricultural sector, participative, community development must be reinforced, placing special emphasis on productive activities and organizational factors related to the technical, administrative, and financial management of farmers' organizations, and the coordination of all parties involved.

\section{Program 2.5. Restore agricultural and agrofood production}

Food and local consumption goods. The Comorian population is essentially rural ( 70 percent) and earns its living from agriculture. Food and commercial vegetable production have been 
subject to several pilot projects during the past 10 years. Technical itineraries are effectively in use to intensify production. Disease tolerant high-yield varieties have been identified and tested with success in rural areas, although their generalized use has not truly begun. Local production in fact is still insufficient to cover domestic market demand. In addition to being an importer of exotic food products (rice, wheat flour, oil, sugar, milk, and powdered milk), the country buys large quantities of food and commercial vegetables from neighboring countries (Madagascar,

Tanzania, and South Africa). These imports hurt the Comoros as they tend to replace local production, where certain products and regions are concerned.

Insufficient national agricultural production is explained by a number of factors, including: (i) small family farms that focus primarily on household food security rather than commercial production; (ii) insufficient investments to increase output; (iii) food and commercial vegetable circuits insufficiently organized to market the products; (iv) low productivity; and (v) an exchange rate making imports more attractive than local products.

Cash crops have traditionally played an important role in the economic development of the Comoros. These sectors now face substantial price fluctuations on the world market with a particularly strong Comorian franc against the currencies of countries in the subregion and the U.S. dollar. Moreover, the lack of investment has led to a decline in crop quality and productivity. Despite these difficulties, the fact remains that these crops offer substantial potential. They might help significantly increase revenue of producers, processers, and the government.

This program aims to support the intensification and improvement of agricultural productivity through better access to inputs and production technologies, organization and structuring of the sectors, and investments designed to facilitate agricultural product marketing and exporting.

\section{Program 2.6. Protect livestock against exotic infectious diseases and intensify animal production sectors}

Poverty reduction in rural areas also involves development of stockbreeding, and small-scale stockbreeding in particular, to meet the basic food requirements of vulnerable populations, as well as to generate additional monetary income. As pasture land is limited, productivity must be increased in animal production, through diversification and support for small-scale stockbreeding, which is easier to control and which requires less space and fewer resources. Small-scale stockbreeding is also a major income generating activity for women. In recent years, problems with imports of diseased animals (primarily cattle) have led to epidemics that decimated the herd.

Actions will be taken to promote more effective health inspections of imported animals. There are also plans to establish an advisory service to support small-scale producers, and specifically women who engage in small-scale stockbreeding.

\section{Fishing sector}

The Comoros has considerable fishery potential, which could contribute substantially to growth, poverty reduction, and provide higher-quality food for most of the population. However, the 
scope of the resource is not fully understood and is based on estimates that date back approximately 30 years. The top priority is therefore to establish a solid knowledge base on growth in resources that can be exploited under renewable conditions. Two priority programs have been identified to meet the challenges in the fishing sector.

\section{Program 2.7. Create an environment favorable to the development of the sector}

Development of the fishing sector is based on the establishment of an incentive environment conducive to increasing catches while respecting ecological balance and resource renewal.

The government would like to encourage organization of the sector, to learn about exploitable resources, and promote responsible management of fish resources to optimize economic efficiency in the sector. The structure of the sector requires strengthening of professional and fishermen's organizations, as well as support organizations and services.

\section{Program 2.8. Develop a conservation, processing, and marketing system for fish products}

During the past 20 years, the Comoros has succeeded in transforming traditional fishing into artisanal fishing using fiber glass boats with small motors. Fishing techniques have also developed. The result today is that artisanal fishing meets demand in the Comoros fairly well. This is a clear success story.

Future development of Comorian fishing requires the modernization of artisanal fishing, which calls for (i) introduction of new fishing techniques; (ii) use of larger boats capable of navigating in high seas; (iv) extension of fish preservation techniques; (v) development of the cold chain; and (vi) organization of marketing activities. Some Comorian operators are now interested in moving forward. The modernization of artisanal fishing will not only help to meet the requirements of the domestic market, but will also promote the gradual integration of Comorian fishing into the export markets.

With the participation of the sector players, the government intends to support efforts to upgrade and promote fishing products to increase job creation and income.

Expanded preservation and processing capacity for fish products will reduce losses, thus constituting an essential condition for development of the sector. The government intends to promote the expansion of preservation and processing capacities. Efforts must also be made to find new, more lucrative outlets to absorb increased catch volumes and develop new products.

Modernization of the fishing industry will require investments to develop small fishing ports, build storage facilities and cold chambers, and develop roads to access the national highway system for rapid transportation to consumer centers.

\section{Tourism sector}

While the Comoros has a clear comparative advantage in tourism, it has not been exploited in the same way as in the Indian Ocean islands, for which tourism has been a powerful engine for development. In 2007, Mauritius and the Seychelles respectively welcomed 906,000 and 161,000 
incoming tourists, as compared with just over 20,000 in the Comoros. The World Tourism Organization projected a growth rate of 6.3 percent per year in this sector for the period 19952020 in the Indian Ocean Region.

The main constraint for the Comoros is the lack of hotels. In 2005, the three islands in the archipelago had an accommodation capacity of 238 rooms, or 472 beds. The geographic distribution was very uneven, with 83 percent of the rooms in Ngazidja, 9 percent in Mwali, and 8 percent in Ndzouani. The level of comfort and amenities varied substantially, with only one third of the accommodations being situated at the three-star level. None of these establishments offers seaside tourism. The absence of international level tourism establishments ties in closely with the country's political problems that began in 1997.

The Comoros faces cross-cutting handicaps including (i) high costs of air transportation between the Comoros and source countries and between the islands of the archipelago. There are very few direct connections, which lengthens transportation time; (ii) high costs of credit and the amount of investment required to build hotel infrastructure.

In 2007, two major financing agreements were signed to develop the northern part of the island of Ngazidja; one with Dubai World involving the creation of a new tourism complex on the site of the old Galawa hotel, and the other with Comores Gulf Corporation to build a tourism village near the Lac Salé and the renovation of the Itsandra Hotel in Moroni.

A tourism development policy would thus seem to be possible today, and the knock-on effects on the economy and its diversification might be evident by 2010. The scope and quality of the effects across the economy will, however, vary substantially depending on its capacity to provide local products such as fruit and vegetables, meat and seafood, construction materials, services (from microenterprises), and employment. Noteworthy in the framework of poverty reduction policy are the scope of direct and indirect job creation, the potential to create many jobs requiring short or even on-the-job training periods, and the substantial percentage of jobs for women.

The target group is middle to upper middle class tourists. Seaside tourism essentially would be marketed, highlighting the country's magnificent beaches, with an ecotourism content focusing on the unique features the Comoros offers, like no other place in the world, such as hiking trails to the Karthala Volcano; discovery of the largest known fruit bat living in the virgin forest; cœlacanthe, a fish dating back several million years thought to have been extinct; and the extraordinary site of the Mwali national sea park where the whales come to breed.

The relationship between seaside tourism and ecotourism is often perceived as antagonistic. This view is inaccurate and is disproven by many examples throughout the world. The two forms of tourism are in fact complementary in many ways, rather than conflicting. For example, seaside tourism provides the critical mass to reduce transportation costs and improve the frequency and quality of international and national connections. This cost reduction will promote the development of ecotourism which in turn will provide opportunities for unique experiences to those who choose this type of seaside tourism. The Comoros will therefore opt for controlled seaside development highlighting the cultural and ecological opportunities the country offers.

One priority program was identified to meet the challenge of developing the tourism sector. 


\section{Program 2.9. Support tourism development}

The government will continue its current policy to look for international investors to implement large-scale tourism projects meeting international standards. The future projects should be located on the islands of Mwali and Nzwani to balance development between the islands. The current policy will be adapted to create tourism development centers that will include (i) a land improvement plan; (ii) actions to improve airports, ports, roads, and access to electricity; (iii) liberalization of the skies to introduce airline competition; (iv) execution of supply contracts between hotels and the rural communities; (v) support for the development of microenterprises and income-generating activities. To ensure maximum synergies, PPPs will be developed with economic transactors and local communities. Development of the business hotel trade in the cities will also be encouraged, along with micro-hospitality units in rural areas.

Comorian tourism will be promoted as a product on the Internet (with the creation of an interactive website); a CD-ROM, brochures, and prospectuses will be produced, and representatives from the hotel industry will participate in targeted tourism fairs. Where ecotourism developments are concerned, hiking paths will be developed and marked, monuments and historical sites will be rehabilitated, and traditional and artisanal production will be encouraged. Plant and animal wildlife preserves will be created on the three islands and additional resources will be provided to maintain the Mwali sea park and to stop poaching.

Substantial efforts will also be made to improve professional training in the hotel and restaurant trades. While the local training capacities are geared up, training will be organized in nearby countries to recycle existing hotel staff and to train young people. Language training, particularly Arabic and English, should also be provided.

To implement this ambitious program, the Tourism Directorate, which might ultimately become a ministry, must be reinforced. The authorities plan to establish a Tourism Office in the medium term. During the next two to three years, however, its functions can be covered with existing capacities until 2010/2011, when tourism effectively becomes operational, with the opening of two major tourism complexes now under construction in northern Ngazidja. Priority in the immediate future should be given to the establishment of a coordination mechanism encompassing the ministries involved, economic transactors, and municipalities.

\subsubsection{CORE STRATEGY III. STRENGTHEN GOVERNANCE AND SOCIAL COHESION}

The political instability that has prevailed in the Comoros since the country gained independence is not conducive to good governance, social dialog, or to strengthening the rule of law. This situation leads to weakened government authority, inefficient institutions and government, weakened national cohesion, and noncompliance with the legal and regulatory texts - all factors leading to increased poverty.

Good governance and social cohesion are therefore necessary conditions for poverty reduction in the Comoros. The government of the Union would like to consolidate the process of national reconciliation, social dialog, and democratization, and to implement the process of 
decentralization to ensure that the islands and civil society organizations gain increasing responsibility for and commitment to the development and management process.

Relations between the Union and the islands are difficult, and can be severely impeded by unclear coordination of responsibilities between the administrations. Institutions face ambiguities that make matters difficult and that lead to conflicts. A substantial need for clarification at all levels is registered among technical personnel. Progress has, however, been observed in some sectors such as education, which should be emulated in other areas. The government is aware of the problems and has decided to address them.

At the same time, program and policy implementation should systematically involve the island political and technical authorities, and the communities, so that more detailed programming can be prepared, reaching the municipal and community levels. This approach should be introduced gradually as disaggregated statistical information is collected and analyzed, and as capacities to implement these arrangements are developed in the municipalities and grassroots professional organizations. A participative approach in this area is essential at the community level. Its implementation will require substantial training and supervision efforts over several years focusing on local professionals.

Justice is another key element in the rule of law. It protects public peace by resolving conflicts among individuals. The "law" is considered to replace private vengeance with legal penalties, reducing social unrest as a result of crime through its decisions, and protecting individual liberties.

The government intends to use this core strategy to build individual and institutional capacities for democratic governance to consolidate social cohesion, provide a coherent legal framework, and civil and social security mechanisms based on the promotion of human rights and transparent management of public affairs.

The four priority programs listed below were identified to implement Core Strategy 3:

Program 3.1. Promote good governance, social cohesion, solidarity, and the consolidation of peace;

Program 3.2. Improve the legal framework, promote anticorruption measures, and strengthen transparency in the management of public affairs;

Program 3.3. Build the capacity of judicial institutions;

Program 3.4. Fight terrorism and transnational crime, and strengthen civil security.

\section{Program 3.1. Promote good governance, social cohesion, solidarity, and the consolidation of peace}

The political situation in the Comoros during recent years has been detrimental to national unity. In a context of national reconciliation, a new constitution was adopted to define an institutional framework. Owing to the complexity of this framework, special attention is required in implementing the relevant democratic institutions. This institutional framework gives more autonomy and responsibility to the islands, but represents a challenge in its implementation and 
practical operation. Decentralization will help ensure political stability required to restore development and poverty reduction. It is also a proven way to bring citizens and governments closer together. This approach will ensure more effective development management and higher quality public services, primarily through the involvement of the relevant populations.

Decentralization will also be pursued at the municipal level. Institutions will be established along with municipal structures to inform the public of its rights and duties. Assistance in this area is in place from the European Union.

Another important project under this program is the civil service reform, which will include containment of the work force and clarification of relations between the islands to reduce duplications, reorganize the ministries to reflect the tasks to be accomplished, training opportunities for civil servants to enhance the level of skill and services to the public, and procurement of operating resources and equipment. Large-scale computerization will enhance productivity while helping to disseminate good governance practices.

Last, measures are also planned to strengthen civil society organizations so that they can serve as countervailing powers in a democratic setting.

\section{Program 3.2. . Improve the legal framework, promote anticorruption measures, and strengthen transparency in the management of public affairs}

The state plays a central role in the development process, among other matters, by providing public goods and services and by coordinating development activities. Transparency and accountability in public management will ensure that all development players support the adopted priorities.

It is generally believed that corruption is widespread in the Comoros. This assertion is confirmed by audits on domestic debt and public enterprises. Such corruption has had adverse consequences on the country's development. It undermines the competitiveness of the national economy and makes investment less attractive owing to cost overruns and the uncertainty it engenders for economic transactors. It leads to higher costs of goods and services for consumers, particularly for the poor, who have few alternatives. Corruption also affects the incentive system by distorting the social advancement mechanism. In this connection, action against corruption is a major challenge that the country has decided to tackle.

\section{Program 3.3. Strengthen the capacity of judicial institutions}

Justice faces tremendous structural and functional problems in the Comoros, preventing its effective operation and damping its performance as defender of rights and liberties, particularly for the vulnerable populations. The sector registers limited access to justice owing to its distance from those under its jurisdiction, high costs of proceedings, legal assistance shortages, and ignorance of the law. Accordingly, some persons and communities apply parallel rules that do not necessarily guarantee social peace or support the principles of the law.

The sources of Comorian law have produced a legal system where Islamic law, texts passed by the Comorian legislator, and traditional law are superposed. It would be wise for this legislation 
to be adapted to the pacts, treaties, and conventions the Comoros has ratified at the regional and international levels, as the authorities have done with the implementation of the Convention on the Rights of the Child and the harmonization of business law with the texts of the Organization for the Harmonization of Business Law in Africa (OHADA).

The envisaged activities will make it possible to finalize the architecture of the judiciary system by taking the necessary steps to implement the approved laws, but that have yet to be implemented, such as the establishment of the Supreme Court, training and specialization of judges, capacity building for the entire judicial system (lawyers, clerks, judiciary police officers, etc.), promotion and dissemination of OHADA commercial law, and ratification of international conventions. Arbitration and conciliation instances are planned to accelerate procedures and help relieve the backlog in the courts. An effort will also be made to improve prison conditions.

\section{Program 3.4. Fight terrorism and transnational crime, and strengthen civil security}

The security of goods and persons and the fight against transnational crime and terrorism are essential global stakes for all countries. The events of September 11, 2001 in fact changed the global outlook on peace and security. Security Council Resolution 1373 (September 28, 2001) acknowledges the linkages between international terrorism and organized crime, weapons and drug trafficking, money laundering, and smuggling of hazardous materials. Resolution 1373 is binding on all countries and has profound implications on the legal system, control of financial flows, and administration of justice. Although the Comoros is a relatively secure country, we observe an increase in crime and a need to strengthen national security.

Like many countries, the Union of the Comoros is vulnerable to potential terrorist activities on its territory. The country's geographic features, with an exclusive maritime area of 240,000 square kilometers, and its insufficient technological capacities make it vulnerable to many security problems.

Specifically, there are plans to equip the airports with merchandise scanners and to provide the customs and police departments with two speedboats and communication equipment to cover security for the country's territorial waters.

\subsubsection{CORE STRATEGY IV. IMPROVE THE HEALTH STATUS OF THE GENERAL PUBLIC}

Health is an essential component of public well-being and an important factor in labor productivity. Unacceptable health conditions for the poor are the result of the complex relationship between health and poverty. Poverty is reflected in the health sector through:

(i) insufficient access to quality health care and services; (ii) insufficient health, hygiene, and sanitation infrastructure; and (iii) a resurgence of malnutrition and poor quality food. Not only does poverty lead to poor health owing to inadequate care, but poor health is a contributing factor to ongoing poverty.

The General Assembly on Health of 2001 took stock of the implementation of the National Health Development Plan (PNDS) and health system reform. Resolutions were adopted to prepare a national policy reflecting the new political and administrative configuration of the Union of the Comoros and the country's priority public health problems. This policy was adopted 
on April 8, 2005. The health administration is receiving support from the World Health Organization in conducting the PNDS update.

The following four priority programs were identified to implement Core Strategy 4:

Program 4.1. $\quad$ Fight malaria and priority diseases

Program 4.2. Integrated sexual and reproductive health development

Program 4.3. $\quad$ Fight HIV/AIDS and sexually transmissible infections

Program 4.4. Strengthen the efficacy and efficiency of all aspects of the health system.

\section{Program 4.1. Fight malaria and priority diseases}

Malaria is still one of the country's major public health problems. Despite encouraging results registered during the past three years, this disease is still the major reason for visits to and hospitalizations in medical facilities and is a factor in high absenteeism at school and at work. Although the disease affects people of all ages, children under five years of age and pregnant women are the most vulnerable groups. Malaria is more prevalent in rural than in urban areas, primarily as insecticide-impregnated mosquito nets are not as commonly used in rural areas. Other diseases such as tuberculosis, leprosy, neonatal tetanus, filariasis, and poliomyelitis affect the population, and particularly the poor.

Malaria. As in countries with endemic malarial disease in the African region, the Comorian government has included the reduction of malaria as one of its health objectives. The country has joined the "Roll Back Malaria" partnership in support of this effort. As a result of this commitment, the country developed the first strategic plan to fight malaria for 2001-2006, followed by a revised plan for the period 2007-2012. This plan reflects the objectives of the Abuja Declaration and the MDGs.

The plan aims to reduce malaria prevalence, mortality, and morbidity by at least 50 percent by 2012. The main activities are prevention through large-scale use of long-lasting insecticide impregnated bed nets, targeted use of intradomicile insecticide sprays (PID), intermittent preventive treatment (TPI) for pregnant women, artimisinin-based combination therapy (ACT) for malaria, and promotion of antilarval measures with larvivorous fish.

Development of national programs to fight noncommunicable diseases. The degradation in hygiene and sanitation conditions, deficiencies in the national epidemiological surveillance system, characterized by the absence of a national health laboratory and the absence of health inspection and control services also expose the country to outbreaks of vector-borne diseases such as arbovirus infection and yellow fever.

Other illnesses such as tuberculosis, leprosy, neonatal tetanus, filariasis, and poliomyelitis affect the population, and particularly the poor. Programs are in progress to fight these diseases or to eliminate or eradicate them. These programs will be supported and reinforced to target the poor more specifically. Actions such as (i) early detection and treatment of leprosy and tuberculosis; (ii) mass preventive treatment campaign for lymphatic filariasis; (iii) the expanded program on immunization for prevention of poliomyelitis, tetanus, and other diseases that can be controlled 
through immunization; and (iv) epidemic surveillance and alert services will be strengthened. The authorities also plan to adopt specific measures to address acute malnutrition.

Noncommunicable diseases, particularly sugar diabetes, cardiovascular disease, hypertension, cancer, blindness, and mental psychoses are concerns for health professionals as increasingly frequent source of deaths in the country. The relevant data are to all intents and purposes nonexistent. Research is therefore urgently needed to assess the prevalence of these diseases in the community and to develop appropriate programs. Steps will be taken to treat noncommunicable diseases.

\section{Program 4.2. Integrated sexual and reproductive health development}

The disadvantaged rural populations, in particular, do not have access to quality sexual and reproductive health $(\mathrm{SRH})$ services, which partially explains the high rates of fertility (5.1 children per woman), maternal mortality (381 per 100,000 live births), and child mortality (74 per 1,000).

The unavailability of SRH services is explained, inter alia, by operational insufficiencies in peripheral units which are understaffed with qualified personnel (almost exclusively staffed by nurses and medical assistants), run down buildings, and a shortage of adequate equipment. As a result, people are forced to travel to more distant health centers, which also do not provide quality services to meet the needs of these populations. This entails additional costs, limiting health care access for the poor.

In addition to the insufficiencies on the supply side, the insufficient use of reproductive health and family planning services is explained by the lack of interest shown by rural and disadvantaged households in these services. These people are generally not convinced that such services are important, particularly as the cost represents a major obstacle for low-income women with repeated pregnancies. To address this situation, the government has decided to focus on improving reproductive health services in peripheral health units. Staff training, equipment, and supplies of consumables will be reinforced. The services will be equipped with transportation means for obstetric emergencies. There are plans to rehabilitate 49 health units and 15 district health centers. Social communication activities will be subcontracted with rural radio services and NGOs to sensitize the populations, particularly young people.

\section{Program 4.3. Fight HIV/AIDS and sexually transmissible infections}

While HIV prevalence in the Comoros is still low, the risk of an explosion is possible owing to poverty as a contributing factor to AIDS, infrequent use of condoms, increasing prostitution (particularly clandestine activities), rapidly increasing exchange with countries heavily affected by this pandemic, massive returns of very young Comorian expatriates, and the substantial prevalence of sexually-transmitted infections. The public is also vulnerable to this problem owing to insufficient knowledge of HIV transmission mechanisms and appropriate preventive measures. 
Even if the rate of HIV positive prevalence was estimated at 0.09 in 1999 and 0.025 in 2003 with confirmed predominance in women and adults $15-49$ years of age ( 0.13 percent), an explosion is possible and preventative steps must be taken now.

Factors to promote the spread of the epidemic are present: (i) sexually transmissible infections are highly prevalent; (ii) the general public has insufficient knowledge of HIV transmission and prevention mechanisms; (iii) condoms are not frequently used in casual sexual relations; and (iv) persons living with HIV/AIDS are subject to discrimination.

This program aims to control the spread of HIV/AIDS and to reduce the incidence of STIs. The following measures are envisaged for that purpose: construction of two new diagnostic centers; construction and equipment of a national blood transfusion center; public awareness targeting young people and high-risk groups; and distribution of condoms. Clinics will also be supplied with anti-retroviral drugs and staff will be appropriately trained. Public communication activities will be launched in the schools to sensitize young people, who will be organized into mutual support groups. There are also plans to conduct a national survey to assess developments in the spread of the pandemic.

\section{Program 4.4. Strengthen the efficacy of all aspects of the health system}

Health care management directly affects the quality of health care services in the health facilities in general. It impacts the accessibility of care and containment of health expenditure through a more effective use of available financial, human, and material resources. Mindful of this pillar of the PRGSP, the February 2005 National Health Policy provided seven points for implementation. These points are still valid, as little progress has been made since 2005 . The actions described below were undertaken in connection with the present PRGS:

- The state's political commitment to increase the share of health in the national budget to 15 percent;

- Use of the "simulated participation" technique consisting in negotiating with the communities to make individuals aware of the advantage of contributing to health service management and financing. Health service users should be considered true partners;

- Equality and equity in heath facilities, leading to better, more effective and efficient management, more rigorous exercise of responsibilities to the public, more effective services, and higher-quality care;

- Training activities for health professionals, review of the human resource development plan, and establishment of a computerized system will be undertaken to make health services more efficient;

- Creation and management of an environment to promote good health: access to drinking water and sanitation, a healthy and safe environment, appropriate diets, and healthy lifestyles; 
- Contractual approach for health care workers, without the state's divestiture from health finance;

- Diversification of health finance mechanisms, specifically through: (i) reinforcement of the mutual system; (ii) creation of a health insurance system that would initially cover state-owned companies, large private companies, and civil servants (the systems should be improved as some companies such as SNPT, MAMWE, etc. have already begun to provide some staff health care coverage); and (iii) gradual implementation of insurance in the communities that would rely on Meck networks in urban centers and Sanduk networks in the villages.

\subsubsection{Core strategy V. Promote education and vocational training With the aim OF DEVELOPING HUMAN CAPITAL}

Poverty is not only the result of insufficient income. It is also the result of insufficient access to different forms of capital, and specifically human capital. The education sector plays a strategic role in this connection as it is the best way to transmit social values and to develop skills to enable individuals to find the means and motivation to build a country that offers a good quality of life.

Human resource training is essential in economic development, as in an increasingly integrated market economy, the competitiveness of the enterprises and the country's attractiveness to potential foreign investors depend largely on whether sufficient quantities of skilled labor are available in the appropriate areas. Specifically, there is substantial excess demand for technical and occupational education graduates.

The Ministry of National Education, Higher Education, and Research in 2005 established a master plan on education and training covering the five-year period 2005-2009. This plan derives primarily from the National Education for All plan and the Interim PRGSP. The share of education in total state expenditure increased from 19.6 percent in 2004 to 39 percent in 2007, according to the 2008 report by the Indian Ocean Child Rights Observatory (ODEROI). A substantial share of the state budget is therefore devoted to education, which is considered a highpriority sector. Total public education expenditure represented 3.1 percent of GDP in 2004. This level is insufficient as compared with the internationally-recommended target of 6 percent of GDP. In addition, wage payment delays of several months are undermining morale among teaching staff.

Although some progress has been made during the past 10 years, the Comorian education system still registers major shortcomings. These problems and their underlying causes were analyzed and acknowledged in the interim PRGSP, and the analyses are still valid. Under the 2010-2014 PRGS, the budget and personnel allocations to the highest priority sectors must be reviewed. The quality and efficacy of education must also be increased, which will involve supplementing and improving teacher training, a monitoring system for teachers, and gradual elimination of doubleshift schemes. Moreover, technical and occupational education are still the least attended subsectors owing to insufficient facilities. This sector receives very little investment, despite its clear importance in the country's economic development, its obvious role in incorporating young people into the labor market, and in reducing unemployment and poverty. This sector will receive 
special attention, along with higher education, to train professionals and managers to meet labor market requirements.

The following four priority programs were adopted under Core Strategy 5:

Program 5.1. Develop education, technical instruction, and occupational training, to reflect the requirements of the job market

Program 5.2. Improve access to and quality of basic (preschool and elementary) and secondary education

Program 5.3. Develop competent human resources and the sectoral (SWAP) approach in education

Program 5.4. Promote literacy, sports, and cultural activities.

\section{Program 5.1. Develop education, technical instruction, and occupational training, to reflect the requirements of the job market}

In the context of poverty reduction, technical education and occupational training are major tools in support of human capital development. Training of human resources, and primarily skilled, competent labor, is essential in the country's sustainable development and therefore in economic growth. It gives the beneficiaries a job to improve the living conditions of their households in a context of globalization where enterprises are becoming increasingly competitive; and helps attract potential foreign investors that require skilled labor in sufficient quantities.

Technical education should be promoted in lower secondary school and a voluntary occupational training program should be developed for young drop-outs, those who never attended school, and uneducated adults, who constitute a substantial proportion of the active population, to integrate them more effectively into the country's socioprofessional circles.

Technical and occupational training priorities will be to reorganize the subsector, rehabilitate the existing schools, build and adequately equip new facilities, diversify the available training, and train instructors. This option must reflect the country's development requirements.

In the context of national reconciliation, the university is an essential instrument in social cohesion and consolidation of national unity. In this connection, it must play a fundamental role in strengthening the national identity and promoting a new spirit of citizenship. To that end, the university requires an appropriate, attractive environment, and sufficient facilities to meet training demand for mid-level and senior managers in areas deemed to be priorities for the country's development.

The university must offer more diverse training with the twofold objective of meeting the expectations of young people, responding to their demand for training, while reflecting the stakes deriving from modernization. 


\section{Program 5.2. Improve access to and quality of basic (preschool and elementary) and secondary education}

Preschool education does not exist in the Comorian formal education system. Early childhood coverage and education are provided by the Koranic school (a well-established secular institution present throughout the Comoros), and with the recent introduction of western nurseries located primarily in urban areas serving only a fraction of the 3-5 year age bracket. Studies confirm, however, that a satisfactory early childhood education, within the family as well as within more structured programs, has a positive impact on child development and learning capacities. This program aims to build capacities to accommodate and educate children.

To reach the aim of providing quality education for all at the horizon 2015, the government must rehabilitate, build, and equip classrooms, update education programs and methods, strengthen scientific disciplines and teaching languages (particularly French), provide initial and ongoing training for education inspectors and teachers at the elementary and secondary levels, build capacities in training institutions, and facilitate availability and accessibility of textbooks to students and educational and didactic materials to teachers, to ensure effective learning and enhance the performance of the education system. Accompanying, accreditation, and control measures should make it possible to build a solid, constructive public-private sector partnership. This program aims to improve the supply and quality of academic training in the primary and secondary schools.

\section{Program 5.3. Develop competent human resources and the sectoral (SWAP) approach in education}

Building the capacities of professionals involved in the education sector in the area of planning, management, and monitoring and evaluation will streamline the use of resources allocated to the sector. Insufficient performance in the sector is now explained in part by a lack of capacity in the administrative structures and in monitoring and coordination units. It is an important matter to ensure that teachers are properly trained at all levels, beginning with trainer training.

Another negative factor is the absence of operating mechanisms and irregular wage payments for teachers, leading to frequent teacher strikes. The institutional strengthening of the education sector should be included in the broader framework of budget reform and improved fiscal management.

\section{Program 5.4. Promote literacy, sports, and cultural activities}

Illiteracy is one of the main obstacles to the country's social and economic development. Illiteracy is a major challenge to be met with the aim of achieving education for all at the horizon 2015 and to reach the Millennium Development Goals. To date, the Comoros has not had an education policy for young people not enrolled in school, or who have fallen back into illiteracy. Women, in particular, are most severely affected by illiteracy.

The total illiteracy rate is still quite high in the Comoros. It is estimated at 40.9 percent according to the MICS 2000 survey, and pertains especially to economically productive populations. This situation is at once an impediment to economic growth and a factor in vulnerability and 
impoverishment. Appropriate action should be taken in connection with poverty reduction to enable this important sector of the active population to acquire the knowledge and skills required to improve their living conditions and to participate effectively in the joint effort to reconstruct the national economy and thereby to improve the individual and collective standard of living.

\subsubsection{Core Strategy VI. Promote environmental Sustainability and Civilian SECURITY}

The constraints affecting the Comoros are similar to those identified for SIDS under Agenda 21 and the Barbados Plan of Action: ecological and economic instability; substantial vulnerability to climate change and natural disasters, insufficient response and management capacity, and a narrow base of energy resources at high costs. The national policy and action plan for the environment, which constitute the reference documents, revealed substantial, alarming environmental trends and threats. These include degradation of land and deforestation, absence of or poor natural resource management, deterioration of the environment, lack of appropriate management tools for urban and coastal areas, and an absence of integrated policies reflecting the cross-cutting dimension of the environment.

The political, economic, legal, and regulatory framework is not appropriate for the current context and must be revised or supplemented to reflect the autonomy that has been granted to the islands: (i) the organic framework as promulgated does not define the sharing between the Union and the Islands of authority for environmental management and protection; (ii) many implementing texts for the Framework Law in respect of the environment have yet to be drafted; (iii) the national legal framework has not been revised to constitute a framework to allow implementation of the conventions the Comoros has ratified; (iv) there is no institution responsible for drafting, revision, and harmonization of legal texts deriving from various sectors; (v) there is a mismatch between the human resources provided in the organic frameworks and the requirements for the institutions to meet the responsibilities incumbent on them. The financial resources required to equip and implement the directorates are to all intents and purposes nonexistent. As a result, these institutions are not capable of discharging their missions, particularly in the area of planning, coordination, promotion, management, and awareness. Six priority programs were identified to meet these challenges.

Program 6.1. Conserve biodiversity and equitably share its strengths

Program 6.2. Conserve and upgrade agro-biodiversity

Program 6.3. $\quad$ Adapt to climate change

Program 6.4. $\quad$ Fiscal rehabilitation with an ecological focus

Program 6.5. Capacity building for multisector environmental management and coordination

Program 6.6. $\quad$ Establish prevention and management mechanisms for risks related to natural and climate disasters

\section{Program 6.1. Conserve biodiversity and equitably share its strengths}

In the Comoros, virtually all of the population's subsistence activities are based on the direct exploitation of natural resources. Such resources are therefore the main source of income for the sectors of the population hardest hit by the drama of human and monetary poverty. Now, these 
related resources and ecosystems are threatened by uncontrolled exploitation activities, at the risk of permanently compromising their essential economic potential. The important issue is that the conservation of biodiversity contributes to the country's sustainable socioeconomic development, particularly for local communities, constituting the majority of the population that is dependent on natural resources for survival.

Sustainable exploitation and upgrading of natural resources are clearly essential levers to reverse the current trends marked by impoverishment and increasing marginalization of the people, and to improve their living conditions. In this connection, establishment and implementation of a network of protected areas, co-managed with the village communities, is considered an appropriate approach. Beyond the dimensions of environmental conservation and sustainable natural resource management in the areas to be protected, these areas will primarily be used as tools to attract interest and highlight the exceptional latent eco-tourism potential the Comoros has never managed to exploit, and to derive all the benefits the country can expect in support of its economic development and social progress.

\section{Program 6.2: Conserve and upgrade agro-biodiversity}

There is a type of agro-forestry practiced in the Comoros that has many advantages in terms of environmental conservation (soil, water, and habitat for flora and fauna species), and in terms of production (food, and wood for working and energy). This traditional growing method in the Comoros is very stable and provides permanent soil cover, reducing erosion, promoting distribution of surface water, and optimizing the use of parceled areas through the staggering of production cycles. There are several types of traditional agro-forestry systems depending on the ecological condition of the sites, their exposure, soils, and drainage.

The special features of Comorian products derive from traditional production methods consistent with the requirements of agro-biological crops, and from the presence of endemic varieties in the Comoros that are rare at the regional scale. The genotype features of the varieties present in the Comoros have been preserved, primarily as a result of the plant reproduction techniques used for vanilla and the absence of programs to introduce new varieties of these species. Conservation and sustainable use of the species and varieties cultivated in the Comoros have substantial benefits at the regional and world scale, conserving genotype material peculiar to the country or subregion, and preserving the potential to adapt these cash crops at the regional scale.

Improved productivity in and stabilization of this system should make it possible to limit deforestation and the extension of cultivated lands at the expense of the natural forests, supporting agro-biodiversity and conservation of the biological diversity in the forest ecosystems.

The aim at this level is therefore to preserve and upgrade agriculturally important varieties and species and traditional agro-forestry systems specific to the Comoros, and to promote their exploitation.

\section{Program 6.3. Adapt to climate change}

As in most fragile tropical environments, the Comoros islands are highly vulnerable and sensitive

to climate change. The known effects of climate changes on ecosystems, and thus on productive 
resources, plant and animal species, and the marine environment are great concerns for a small island country such as the Comoros. In addition to natural disasters, climate change can lead to permanent changes in the way of life and in production methods used by the population, and have the potential to compromise already unstable living conditions in many communities.

The effects of climate change include accelerated losses of coastal strips of land, reduced agricultural and fish production, contamination of coastal water tables with seawater, and displacement of more than 10 percent of the coastal population. As is true for the SIDS, ${ }^{4}$ the Comoros supports the objectives to reduce greenhouse gas emissions and the principle of anticipating and preparing for events related to climate change. Energy sources should be diversified to move towards energy autonomy and limit natural forest deforestation by developing pilot projects focusing on alternative sources of energy such as wind and solar energy, hydroelectricity, and community reforestation parcels for firewood.

Climate change will therefore have substantial impacts on health, food security, economic activity, water resources, and physical infrastructure. These impacts can be disruptive in this archipelago, whose economy and life are largely dependent on agriculture, tourism, and fishing, and where most the population lives on the coast. There is a risk, in particular, that climate change will eliminate the development efforts that have been made in connection with specific food security and poverty reduction strategies. Accordingly, climate change adds new difficulties to the progression towards sustainable development. The new challenge today is to address the current and future impacts of climate change and take the necessary steps to reduce their impacts.

\section{Program 6.4. Fiscal consolidation with an ecological focus}

Integration of the ecological dimension into the fiscal area and into the financing of economic activity is a completely new approach in the Comoros. The Comorian fiscal system does not reflect the conventional concerns of fighting pollution and conserving natural resources and ecosystems. The same applies to initiatives aimed at promoting positive activities for the environment. The public contracting code does not require environmental clauses to be incorporated into public tenders. The decree instituting impact studies has not been applied in practice owing to the absence of practical implementation provisions and a complete lack of understanding of the relevant legislative provisions.

The nascent network of decentralized financial institutions in the Comoros is not, at least in practice, designed to address the stakes underlying ethical finance, aside from the grassroots credit institution dimension. They use essentially the same conditions for operations and for extending credit as conventional financial institutions. To date, there are no institutional joint guarantee mechanisms or partnership structures to support and sustain ecologically and socially responsible loans. The $\mathrm{AMIE}^{5}$ project is now testing two initiatives, with the establishment of a joint guarantee system through women's associations in connection with specialized loans for disadvantaged women, and through $\mathrm{Meck}^{6}$ Moroni by granting joint loans in the agricultural

\footnotetext{
${ }^{4}$ Small Island Developing Countries.

${ }^{5}$ Micro and small-scale enterprise support project.

${ }^{6}$ Mutuelle d'Epargne et de Crédit ya Komor.
} 
sector, in partnership with the SNAC. ${ }^{7}$ The concept of ethical finance and the corresponding implementation tools, including socially and ecologically responsible investment and credit instruments constitute a new area for local players.

A UNDP-supported study conducted by the International Union for Conservation of Nature (IUCN) determined that it would be relevant to establish a trust fund for biodiversity conservation. Development of such a financial tool will involve alternative, innovative financing mechanisms, including external debt conversion mechanisms, through debt-for-nature swaps. The aim would be to integrate sustainability criteria into fiscal management instruments, and to develop financing mechanisms reflecting the essential need to preserve the country's natural resources and social equity.

\section{Program 6.5. Capacity building for multisector environmental management and coordination}

All of these mechanisms acknowledge that sustainable development in the Comoros is largely dependent on the capacity of the government and the public to ensure sustainable management of natural resources and ecosystems. The lack of capacity observed at all levels, however, is preventing effective implementation of environmental management, planning instruments and policies.

Accordingly, systemic, institutional strengthening of environmental management structures at the island and national levels should be considered a priority. Regional sustainable development planning should also be introduced to optimize the actions identified under each component. This approach is increasingly relevant in the current context in which the country is establishing a new institutional and administrative framework.

These activities are intended to give the country environmental knowledge and management tools, to establish a legislative and regulatory framework, and effective public services and institutions. Specialists must also be trained and the public must be informed in order to become more effective participants in environmental management. To achieve the goals described at this level, national and local capacities must be developed to incorporate the environment into development plans and programs, as well as their cross management.

\section{Program 6.6. Establish prevention and management mechanisms for risks related to natural and climate disasters.}

The major natural risks to which the Comoros islands are normally exposed include tropical cyclones, floods, tidal waves, and for Ngazidja, eruption of the Karthala Volcano, as well as other risks inherent in the presence of an active volcano.

Where climate change is concerned, the national report confirms that the populations in the coastal areas are exposed to exceptional events such as cyclones and violent winds potentially resulting in tidal waves. Abundant precipitation could cause landslides and fallen earth. These events could destroy strategic infrastructure and impede inter-island communications.

\footnotetext{
${ }^{7}$ National Comorian Famers' Union.
} 
The key issues in this case are the control and prevention of risks and natural and climate disasters. The underlying concerns focus on disaster risk preparation, response, and management schemes. 
CHAPTER V

ECONOMIC ENVIRONMENT AND MACROECONOMIC FRAMEWORK 2010 - 2014 


\subsection{INTRODUCTION}

The government's economic policies have substantial impacts on economic growth and poverty reduction. They either directly or indirectly affect the conditions under which enterprises and households make their decisions in terms of resource allocation, creation of value added, distribution of income from production, processing, marketing, and consumption of goods and services. At the aggregate level, they affect the major macroeconomic equilibria, price levels, and economic growth rates.

The government acknowledges that a stable macroeconomic environment is a necessary condition for economic growth and poverty reduction. This environment directly affects enterprise performance, individual purchasing power, and the government's capacity to offer essential public goods such as an accessible, quality basic education and primary health care for everyone.

The government's macroeconomic objective in connection with the PRGS involve observance of major economic equilibria, particularly the level of state expenditure and the public deficit, balance of payments, and general price level; and on the other hand, establishment of an environment conducive to robust, sustainable growth through promotion of the private sector and particularly growth sectors such as tourism, agriculture, fishing, and stockbreeding. Economic policies that will make it possible to create these conditions involve budget and fiscal policies, trade policy, monetary policy, and legal and institutional reform.

This chapter first presents recent developments in the economic environment in the Comoros and the short-term economic and financial outlook. Secondly, it provides the macroeconomic and financial framework prepared with three scenarios: (1) a "PRGS" scenario that involves moderate to robust growth levels, compliance with major macroeconomic equilibria and a substantial commitment from the technical and financial partners to support PRGS implementation; (2) an "MDG" scenario of accelerated growth accompanied with a major investment program from the technical and financial partners with a view to achieving the MDGs by 2015; and (3) an "IMF" scenario based on the International Monetary Fund's projections. The PRGS implementation strategy is based on the first scenario.

\subsection{RECENT DEVELOPMENTS IN THE ECONOMIC ENVIRONMENT IN THE COMOROS}

According to the provisional data from the Office of the General Commissioner for Planning, the country registered a real GDP growth rate of 0.8 percent in 2007 , and approximately 0.2 percent is projected in 2008 - the lowest levels in 10 years. This slowdown is considered to be attributed primarily to the restriction in the banking sector's supply of credit to public enterprises, which has led to a shortage of certain commodities such as rice and petroleum products, and the energy crisis that has afflicted the Comoros since the latter half of 2008, bringing all economic sectors to a standstill.

In the fiscal area, despite the increase in domestic revenue, and primarily from taxes (up 9.7 percent as compared with 2007), the increase in current expenditure (up 22 percent) has led to a deterioration in the key budget balances, leading to a basic budget deficit of approximately 3.5 percent of GDP in 2008 as against approximately 2.9 percent in 2007. 
Cash tensions have led to accumulated wage payment arrears, increased domestic debt, primarily with private enterprises, and the failure to make matured external debt payments. The overall deficit (not including grants) widened to more than 13 percent of GDP, as against 10 percent in 2007, while the overall deficit improved slightly at -2.5 percent of GDP, as against -3.2 percent in 2007. In nominal value, the basic budget deficit widened from CF 4.7 billion in 2007 to CF 6.1 billion in 2008 .

The provisional data from the Directorate General of Budget (DGB) indicate tax revenue of CF 18.3 billion in December 2008, as against CF 16.7 billion in December 2007. This improvement is explained in particular by substantial growth in customs revenue, which essentially doubled during the period. Non-tax revenue increased by 13.6 percent to CF 5.1 billion from CF 4.5 billion in 2007 owing to the difficult financial situation of the stateowned companies.

Table 5.1. Government budget revenue

Government budget revenue (in millions of CF)

\begin{tabular}{lrrr} 
& 2006 & $2007 *$ & \multicolumn{1}{c}{$2008^{*}$} \\
\hline Tax revenue & $\mathbf{1 7 , 2 6 0}$ & $\mathbf{1 6 , 6 7 8}$ & $\mathbf{1 8 , 2 8 8}$ \\
Of which: Tax on revenue and profits & 3,804 & 4,555 & 4,159 \\
$\quad$ Countervailing charge (TC) and similar taxes & 980 & 2,592 & 2,631 \\
$\quad$ International trade & 8,533 & 5,984 & 9,169 \\
Non-tax revenue & $\mathbf{4 , 2 9 6}$ & $\mathbf{4 , 4 8 2}$ & $\mathbf{5 , 0 9 1}$ \\
Of which: Service revenue & 1,678 & & \\
Total revenue & $\mathbf{2 1 , 5 5 6}$ & $\mathbf{2 1 , 1 6 0}$ & $\mathbf{2 3 , 3 7 9}$ \\
Sources: Ministry of Finance, IMF. & & & \\
*Provisional figures. & & & \\
\hline
\end{tabular}

Total expenditure and net lending increased by 22 percent to represent 26 percent of GDP in 2008. These developments are considered to be linked to the increase in current expenditure and the increase in capital expenditure on road rehabilitation in the capital mainly (an increase of 55 percent).

Table 5.2. Current government budget expenditure

\begin{tabular}{lrrr}
\multicolumn{4}{c}{ Government budget expenditure (in millions of CF) } \\
& \multicolumn{1}{c}{2006} & \multicolumn{1}{c}{ 2007 } & \multicolumn{1}{c}{$2008^{*}$} \\
\hline Wages and salaries & 13,205 & 15,392 & 15,690 \\
Goods and services & 5,568 & 5,122 & 8,122 \\
Transfers & 3,392 & 3,382 & 2,678 \\
Debt interest & 1,144 & 778 & 1,217 \\
Other current expenditure & 2,457 & 2,624 & 2,092 \\
Total expenditure & $\mathbf{2 5 , 7 6 6}$ & $\mathbf{2 7 , 2 9 8}$ & $\mathbf{2 9 , 7 9 9}$
\end{tabular}

Sources: Ministry of Finance, IMF.

*Provisional figures. 
The public debt situation has improved substantially with the settlement of the AfDB arrears following the Paris Donors' Conference in December 2007. In December 2008, the government signed a post-conflict program with the IMF that has led to CF 1.8 billion (US\$5.5 million) in disbursements, helping to reduce domestic arrears and thereby to consolidate the central bank's external position. At end-2008, outstanding debt reportedly represented 68.5 percent of GDP, as compared with 65.7 percent in 2007. The situation has become so critical that the key development partners of the Comoros were forced to accept the postponing of the maturities of the government's main debt service obligations.

Revenue and expenditure projections by main budget item are provided below. State budget projections for 2009 register CF 24.4 billion in revenue and CF 25.9 billion in expenditure, yielding a current deficit of CF 1.5 billion. Projected public debt for 2009 is CF 4.4 billion.

Table 5.3. General government budget

\begin{tabular}{lr} 
General budget & (in millions of CF) \\
& 2009 \\
\hline Tax revenue & 18,145 \\
Non-tax revenue & 6,239 \\
Exceptional revenue & \\
External revenue & 11,426 \\
Total revenue & $\mathbf{2 9 , 5 7 1}$ \\
Current expenditure & 30,069 \\
Staff remuneration & 17,125 \\
Goods and services & 6,308 \\
Transfers & 3,512 \\
Debt interest & 758 \\
Current expenditure, external financing & 2,366 \\
& \\
Capital expenditure & 11,007 \\
Own financing & 1,006 \\
External financing & 9,465 \\
Financed with counterpart funds & 536 \\
& \\
Total expenditure & $\mathbf{4 1 , 0 7 6}$ \\
Primary balance & \\
Sources: 2009 Budget Law & $\mathbf{3 , 5 6 6}$ \\
\hline
\end{tabular}

The energy crisis and restricted access to bank credit in 2009 dominated the economic situation in the Comoros. Still today, activity is interrupted by blackouts, diminishing the signs of economic recovery.

The key productive sectors, including transportation and trade, also registered a decline in 2008 as a result of the energy and financial crisis. However, sound performance in agricultural 
production intended for the local market, supported by the increase in world commodity prices, and the relative improvement in the building and public works sectors reduced the impact of the crisis somewhat for agricultural producers. The real GDP growth rate was below 1 percent as a result of substantial inflation (approximately 7 percent) aggravated primarily by elevated fuel and transportation costs.

The key export products (vanilla and cloves) declined substantially as a result of the steady decline in world prices, the strength of the Comorian franc, and low productivity in these sectors. Exports dropped to CF 2.2 billion as compared with nearly CF 5 billion in 2007, registering a decline of more than 55 percent.

Table 5.4. Comoros - Export Trends

Comoros - Export Trends 2006-2008

\begin{tabular}{|c|c|c|c|c|c|c|c|}
\hline \multirow[t]{2}{*}{ Products } & \multicolumn{3}{|c|}{ Quantities (tons) } & \multicolumn{3}{|c|}{ Values (Millions of CF) } & \multirow{2}{*}{$\begin{array}{c}\text { Var } \\
\text { (val) } \\
08 / 07 \\
\text { in \% }\end{array}$} \\
\hline & 2006 & 2007 & $2008 *$ & 2006 & 2007 & $2008 *$ & \\
\hline Vanilla & 60 & 74 & 35 & 21,009 & 1,274 & 643 & -50 \\
\hline Cloves & 1,670 & 2,722 & 915 & 2,054 & 2,866 & 679 & -76 \\
\hline Ylang ylang & 40 & 31 & 47 & 913 & 711 & 796 & +12 \\
\hline $\begin{array}{l}\text { Other } \\
\text { essences }\end{array}$ & 0.1 & 0.1 & 0.1 & 54 & 54 & 19 & -64 \\
\hline $\begin{array}{l}\text { Other } \\
\text { products }\end{array}$ & 687 & 687 & 941 & 60 & 60 & 74 & +23 \\
\hline Total & 2,457 & 3,514 & 1,939 & 4,089 & 4,964 & 2,212 & -55 \\
\hline $\begin{array}{l}\text { Source: Dire } \\
\text { *Provisional }\end{array}$ & $\begin{array}{l}\text { te Gene } \\
\text { es, BCC }\end{array}$ & $\begin{array}{l}\text { lof Cus } \\
\text { stimates }\end{array}$ & & & & & \\
\hline
\end{tabular}

The value of imports increased by 27 percent in keeping with the increase in petroleum and food prices on the international markets, despite shortages of certain products, specifically rice, for which the quantities imported were halved.

Substantial fund transfers from Comorian expatriates, representing approximately 25 percent of GDP, supported construction and household consumption activities - two factors underlying an increase in imports, primarily of cement, construction materials, and automobiles. The petroleum bill also increased. 
Table 5.5. Comoros - Import trends

Comoros -Import Trends 2006-2008

Quantities (tons) Values (In millions of

Change

CF) $\quad(\%)$

$08 / 07$

Products

\begin{tabular}{|c|c|c|c|c|c|c|c|}
\hline & 2006 & 2007 & 2008 & 2006 & 2007 & 2008 & \\
\hline Rice & 32,137 & 32,281 & 19,404 & 4,037 & 5,871 & 5,114 & +13 \\
\hline Meat, fish & 4,995 & 5,116 & 5,808 & 3,044 & 3,359 & 3,799 & +13 \\
\hline Flour & 5,475 & 5,204 & 5,452 & 891 & 939 & 1,250 & +33 \\
\hline Sugar & 5,537 & 4,026 & 3,646 & 1,361 & 950 & 746 & -21 \\
\hline Dairy products & 1,958 & 1,489 & 1,592 & 1,154 & 902 & 1,155 & +28 \\
\hline Pharmaceuticals & 197 & 204 & 201 & 700 & 549 & 625 & +14 \\
\hline Fabrics, apparel & 1,162 & 898 & 957 & 703 & 751 & 501 & -33 \\
\hline $\begin{array}{l}\text { Petroleum } \\
\text { products }\end{array}$ & 55,132 & 35,837 & 36,460 & 9,888 & 10,649 & 12,505 & +17 \\
\hline Cement & 66,823 & 41,508 & 63,529 & 3,129 & 2,432 & 3,264 & +34 \\
\hline Vehicles & 2,169 & 2,540 & 3,440 & 2,944 & 2,989 & 9,532 & +219 \\
\hline $\begin{array}{l}\text { Iron, cast iron, } \\
\text { steel }\end{array}$ & 6,673 & 3,167 & 4,957 & 2,763 & 1,133 & 1,856 & +64 \\
\hline Other & 20,697 & 26,679 & 68,112 & 21,681 & 19,191 & 22,865 & +19 \\
\hline Total & 202,955 & 164,949 & 220,796 & 45,189 & 49,716 & 63,213 & +27 \\
\hline
\end{tabular}

According to the available provisional data, the trade deficit amounted to CF 62 billion in 2008, as against CF 44.8 billion in 2007, equivalent to 9.5 percent of GDP in 2008, as compared with 6.7 percent of GDP in 2007. The coverage rate of imports with exports therefore deteriorated substantially, from 10 percent in 2007 to 3.5 percent in 2008, correlating directly with the decline in exports and the increase in imports.

The data on foreign trade imbalances are also indicative of the overvaluation of the Comorian Franc as compared with the currencies of the countries in the subregion. In fact, the EDIC data show that the CF has appreciated substantially in respect of other Indian Ocean country currencies, and this effect has reduced the country's comparative advantages in the traditional export sectors.

\subsection{SHORT-TERM ECONOMIC OUTLOOK}

The government's macroeconomic objectives for 2009 are: (i) a real GDP growth rate of 0.8 percent; (ii) an average inflation rate of less than 5 percent; (iii) a recurrent budget deficit limited to 8.5 percent of GDP; (iv) investments equivalent to 12.3 percent of GDP; (v) a primary budget balance improvement of 1 percent of GDP, substantially reflecting the need to reduce expenditure, primarily in the wage bill; and (vi) a slight decline in net bank claims on government with a view to a sustained increase in bank credit to the private sector. 
Where fiscal management is concerned, the 2009 budget aims mainly to reduce the primary budget deficit (excluding grants) to 1.6 percent of GDP, as against 2.7 percent in 2008. This adjustment will be obtained with savings from expenditure on security, the wage bill, and mechanisms to address the energy crisis. Expected total public revenue and total expenditure were assessed respectively at CF 24.4 billion, equivalent to 13 percent of GDP, and CF 40.5 billion, equivalent to 21.5 percent of GDP. In light of the program and project grants already identified, in the amount of CF 13.8 billion, or 7.3 percent of GDP according to the IMF report, and a clear reduction in payment arrears of approximately CF 2.5 billion, equivalent to 1.3 percent of GDP, the overall budget deficit (cash basis) can be expected to amount to CF 2.5 billion in 2009, as compared with 1.3 percent in 2008 .

Anticipated macroeconomic performance, the growth outlook, and fiscal forecasts for 2009 are insufficient to address the stakes and challenges the country must tackle if it is to break the vicious cycle of poverty in which it is now locked. The current situation in fact is characterized by a double gap, with a substantial external deficit explained by insufficient exports of goods and services, and a domestic deficit related to poor economic performance with reduced enterprise, household, and therefore also government revenue. The government therefore has no headroom. Debt is accelerating, and debt service has reached unsustainable levels. This situation in turn has led to net negative transfers, ruling out any possibility of financing economic development and therefore of reducing poverty.

The state's net financing requirement for the 2009 fiscal year is assessed at approximately CF 8.5 billion, equivalent to 4.5 percent of GDP. This financing gap reflects CF 4.5 billion in external debt service, including CF 3.3 billion in current debt service and CF 1.2 billion in arrears. The government must address negative net transfers of CF 3.7 billion, equivalent to 2 percent of GDP. Substantial, sustained growth will be essential to break this vicious cycle which is literally suffocating the development process, rather than accompanying and expanding it.

The government is aware of the need to improve financial intermediation to stimulate private sector development and support growth. Two new foreign banks (Eximbank of Tanzania and Banque Fédérale des Comores) began operating on the local market in 2008. This activity should give some new impetus to the private sector and enable a gradual recovery in commercial activity.

The diagnostic study on trade integration (EDIC) once again highlighted the need to develop the Comoros's substantial tourism potential by attracting foreign direct investment (FDI). In light of the country's existing potential, we deem that incoming FDI could increase from an average of 0.4 percent of GDP per annum for the period 2000-07 to approximately 2 percent of GDP in the medium term, deriving primarily from tourism investments from the Gulf States (Kuwait and the United Arab Emirates).

In addition, effective improvement in the investment climate may attract FDI and encourage the population to devote an increasing share of the substantial remittances from Comorian expatriates to productive investments rather than exclusively consumption. The draft Investment Code, approved by Parliament in 2007, can be expected to support this trend. Moreover, the establishment of a single window for investors and the opening of the National Agency for 
Investment Promotion (ANPI) should help create a more dynamic environment more conducive to investment.

Last, foreign trade liberalization is also in progress with the conversion into indirect domestic taxes of specific customs duties levied on key products. Ad valorem customs duties were also adjusted to a maximum level of 20 percent.

\subsection{MACROECONOMIC FRAMEWORK}

The macroeconomic conditions to be achieved, the growth levels to be attained in the economic sectors, and the contributions from the technical and financial partners to finance the poverty reduction and growth strategy are specified in the macroeconomic framework, which also includes the guidelines for the program the government negotiated with the IMF and anticipates a positive outlook for PRGS negotiations following the 2009 midterm assessment under the Emergency Post Conflict Assistance (EPCA) program completed in March 2009. Last, it reflects the estimated costs for the Comoros to achieve the MDGs.

The quantified implications of the sectoral programs are specified to reflect projected sector growth. These forecasts are based on investment in the sectors involved and reflect each sector's contribution to national growth formation. The macroeconomic framework was prepared using the following three scenarios:

1. The "PRGS" macroeconomic framework presents the projections of the benchmark situation. It includes the quantitative incidence of the sector strategies adopted under the PRGS with the medium-term economic growth profile and macroeconomic framework;

2. The second "MDG" scenario reflects the assessment of the costs for the Comoros to reach the Millennium Development Goals, considering the massive investments from the technical and financial partners and a substantial improvement in the country's aid absorption capacity;

3. The third "IMF" scenario considers the simulations prepared by the International Monetary Fund in connection with the 2008 Joint Consultations with the Union of the Comoros under Article IV of the Articles of Association. This scenario is based on recent trends in the country's economic performance and reflects the world economic scenario. The IMF's projections stop at 2013, while the PRGS projections are staggered until 2014. The projections were therefore extended to 2014 by replicating the 2013 figures so that comparisons could be made with the other scenarios.

\subsubsection{PRGS SCENARIO}

According to this scenario, economic growth during 2010-2014 will be based primarily on: (i) a sustained evolution in agricultural sector activities; (ii) development in the tourism sector; (iii) new impetus and growth in the banking and financial intermediation sector; (iv) resolution of the energy crisis to enhance productivity in all economic sectors; and (v) effects induced by the new investments inherent in PRGS implementation. 
Real GDP growth levels in 2009 should be situated at approximately 1.2 percent, slightly above the target of 0.8 percent initially anticipated by the government. Effective PRGS implementation should put the Comorian economy back on track in terms of more sustained real growth, to reach 2.5 percent real GDP growth by 2010 , and to move towards 5.6 percent by 2014 . During the period 2010-2014, real GDP growth should average approximately 4.3 percent.

This relatively sound economic performance can be expected to result from a combined improvement in activities and investments in the primary, secondary, and tertiary sectors. For the period 2010-2014, these sectors can be expected to register average annual growth rates respectively of 4.6 percent, 2.18 percent, and 3 percent.

Below are the requirements to achieve these objectives:

(a) The government must observe substantial budget discipline and fiscal restraint to generate a minimum of resources required to finance the PRGS;

(b) The wage bill must remain constant or contract following implementation of the public sector reforms;

(c) Additional resources must be allocated to PRGS implementation through increased investments, particularly in the key sectors of agriculture, stockbreeding, fishing, and tourism;

(d) Substantial investment is particularly important in the agricultural sector owing to its importance in GDP formation and its preponderant role in the economy as the key source of wealth, revenue, and job creation;

(e) Reforms aiming to improve the investment climate must be executed to attract further foreign direct investment to support tourism sector development;

(f) The government must emphasize promotion of tourism sector activities to exploit the enormous potential this sector offers;

(g) More tax revenue must be mobilized and collected;

(h) The government must take the steps required to reduce external debt service under the HIPC Initiative;

(i) The money supply must increase substantially to accompany economic growth, and inflation levels must be controlled;

(j) Dynamic performance in the banking sector must lead to easier access to credit for the poor to support the development of income-generating activities, and for the private sector.

\section{Sector growth assumptions 2010-2014}

The primary sector will remain the key driving force for medium-term growth. The expected growth rate will be 2.5 percent in 2010 to reach 5.9 percent by 2014 , driven primarily by the 
agriculture and fishing subsectors. With substantial investments planned in the agriculture sector, particularly to modernize the productive apparatus, substantially increase productivity, and improve marketing channels through road construction and increased access, agricultural production should increase by 15 percent. The acquisition of new fishing boats, increased processing and storage capacities with more cold chambers and export facilities, combined with the rationalized issue of licenses to foreign boats should generate real growth of 15 percent in the fishing sector. Growth in stockbreeding should be a more modest 6 percent as a result of the existing constraints in this subsector. The forestry subsector should also register moderate growth of 6 percent while consolidating the Comoros as the world's number one producer of ylang ylang.

The secondary sector should register a modest contribution to GDP formation during the period 2010-2014, owing to substantial adjustments to be made, specifically in connection with the weakness in the manufacturing industry subsector of the Comorian economy. Projected growth levels for 2010 and 2014 are respectively 0.5 percent and 1.7 percent. Growth in the manufacturing industry will remain moderate (6.5 percent) and should be driven in the medium term by the possible launch of processing activities in the fishing subsector.

The energy and water subsector can be expected to grow an average of 12 percent with the investments undertaken to modernize facilities. The improved situation in this subsector should have positive effects on productivity in other economic sectors. In this connection, road construction, with substantial investments from the European Union, and private investment in property construction should afford the building and public works subsector a growth level of 7.5 percent. The contribution of this subsector to national wealth formation should, however, remain modest. By contrast, the agricultural sector can be expected to benefit from the construction of roads that will help facilitate production flows.

In this scenario, tertiary sector growth will be driven strongly by activities in the hotel subsector with an anticipated 15.5 percent in average growth during 2010-2014, owing primarily to development in the tourism sector. The revitalization of banking and microfinance activities has potential to increase the volume and therefore the accessibility of credit. Substantial growth in the financial sector (an average of 15 percent) should drive the overall tertiary sector.

Transportation and telecommunications should also register substantial growth (an average of 15 percent per annum for the period 2010-2014) with investments in mobile telephony and telecommunications, as well as liberalization of the sector. The connection of the submarine cable that is in progress should substantially increase capacities in the telecommunication sector and help reduce the cost of services. Last, improved roads, establishment of new airlines, and construction of an international airport in Nzwani are all investments that will support the expected dynamics in the transportation subsector.

Demand should be driven by external demand that should undergo resurgence with the world recovery beginning in 2010. The 4 percent average increase in exports for the period 2010-2014, the recovery in final consumption and investment, characterized in particular by the increase in FDI, can be expected to provide substantial impetus for growth. The domestic financing investment rate should remain low, however, increasing from 1 percent in 2010 to approximately 2.3 percent in 2014. By contrast, investment with external financing should increase substantially 
by an average of approximately 12 percent for the period 2010-2014. The investment rate can be expected to increase to 6.9 percent in 2009 , to 14.3 percent in 2012 , and might decline slightly to 13.3 percent in 2014.

Fiscal consolidation should be undertaken and pursued with a steady increase in budget revenue from 13.6 percent of GDP in 2010 to 15 percent of GDP in 2014. A special effort to control current expenditure, particularly the wage bill, will lead to a reduction in its share of GDP from 15.2 percent in 2010 to 13.5 percent in 2014. The primary balance of GDP should therefore be expected to improve to generate a slight surplus beginning in 2013.

Last, the PRGS scenario reflects only a small share (3 percent) of financing requirements to achieve the MDGs, estimated at US\$29.5 billion during the period 2008-2015.

Table 5.6, Key macroeconomic aggregates for the PRGS framework (*)

\begin{tabular}{lrrrrrr} 
Projections & $\mathbf{2 0 0 9}$ & $\mathbf{2 0 1 0}$ & $\mathbf{2 0 1 1}$ & $\mathbf{2 0 1 2}$ & $\mathbf{2 0 1 3}$ & $\mathbf{2 0 1 4}$ \\
\hline GDP at market prices (billions of CF) & 184.20 & 194.88 & 208.01 & 223.27 & 242.13 & 262.76 \\
Budget revenue & 23.95 & 26.50 & 28.71 & 32.37 & 35.59 & 39.41 \\
Tax revenue & 18.97 & 21.24 & 23.09 & 26.35 & 29.06 & 32.32 \\
Nontax revenue & 4.97 & 5.26 & 5.62 & 6.03 & 6.54 & 7.09 \\
Total expenditure & 40.7 & 57.24 & 61.1 & 65.26 & 69.02 & 70.67 \\
Capital expenditure & 12.71 & 27.1 & 29.3 & 31.9 & 33.3 & 34.90 \\
Current expenditure & 27.99 & 30.14 & 31.80 & 33.36 & 35.72 & 35.77 \\
Wages & 16.30 & 16.79 & 16.95 & 17.46 & 17.63 & 17.98 \\
Wages / Total revenue (in percent) & $\mathbf{6 8 . 1 \%}$ & $\mathbf{6 3 . 3 \%}$ & $\mathbf{5 9 . 1 \%}$ & $\mathbf{5 3 . 9 \%}$ & $\mathbf{4 9 . 5 \%}$ & $\mathbf{4 5 . 6 \%}$ \\
Internally-financed capital expenditure & 1.01 & 2 & 3.1 & 4.2 & 5.1 & 6.1 \\
Externally-financed capital & 11.7 & 25.1 & 26.2 & 27.7 & 28.2 & 28.8 \\
expenditure & 12.34 & 12.12 & 13.20 & 14.58 & 16.17 & 16.5 \\
External financing & 11.04 & 12.12 & 13.20 & 14.58 & 16.17 & 16.5 \\
Project grants & 1.30 & 0 & 0 & 0 & 0 & 0 \\
Nonproject grants & $\mathbf{4 . 0}$ & $\mathbf{- 3 . 6}$ & $\mathbf{- 3 . 1}$ & $\mathbf{- 1 . 0}$ & $\mathbf{- 0 . 1}$ & $\mathbf{3 . 6}$ \\
Primary balance & -16.8 & -30.7 & -32.4 & -32.9 & -33.4 & -31.3 \\
Overall balance (not including grants) & $\mathbf{4 . 4 2}$ & $\mathbf{1 8 . 6 1}$ & $\mathbf{1 9 . 1 9}$ & $\mathbf{1 8 . 3 1}$ & $\mathbf{1 7 . 2 5}$ & $\mathbf{1 4 . 7 6}$ \\
Financing gap & $\mathbf{1 . 2}$ & $\mathbf{2 . 5}$ & $\mathbf{3 . 6}$ & $\mathbf{4 . 4}$ & $\mathbf{5 . 5}$ & $\mathbf{5 . 6}$ \\
Real GDP growth (in percent) & r. & &
\end{tabular}

Source: Ministry of Finance, Budget, and Planning, Office of the General Commissioner for Planning. (*) In billions of Comorian francs, unless otherwise indicated. 
Table 5.7. Key macroeconomic aggregates under the PRGS framework $(* *)$

\begin{tabular}{lrrrrrr} 
Projections & $\mathbf{2 0 0 9}$ & $\mathbf{2 0 1 0}$ & $\mathbf{2 0 1 1}$ & $\mathbf{2 0 1 2}$ & $\mathbf{2 0 1 3}$ & $\mathbf{2 0 1 4}$ \\
\hline GDP at market prices (billions of CF) & 184.20 & 194.88 & 208.01 & 223.27 & 242.13 & 262.76 \\
Budget revenue & 10.3 & 10.9 & 11.1 & 11.8 & 12 & 12.3 \\
Tax revenue & 2.7 & 2.7 & 2.7 & 2.7 & 2.7 & 2.7 \\
Nontax revenue & 13 & 13.6 & 13.8 & 14.5 & 14.7 & 15 \\
Total expenditure & 19.5 & 29.1 & 29.1 & 28.9 & 28.4 & 26.8 \\
Capital expenditure & 6.9 & 13.9 & 14.1 & 14.3 & 13.8 & 13.3 \\
Current expenditure & 12.6 & 15.2 & 15 & 14.6 & 14.6 & 13.5 \\
Wages & 8.9 & 8.8 & 8.3 & 8 & 7.6 & 7.1 \\
Wages/Total revenue (in percent) & 68.07 & 63.35 & 59.05 & 53.93 & 49.53 & 45.63 \\
Internally-financed capital & 0.5 & 1 & 1.5 & 1.9 & 2.1 & 2.3 \\
expenditure & & & & & 12.3 \\
Externally-financed capital & 6.4 & 12.9 & 12.6 & 12.4 & 11.6 & 11 \\
expenditure & 6 & 6.2 & 6.3 & 6.5 & 6.7 & 6.3 \\
External financing & 6 & 6.2 & 6.3 & 6.5 & 6.7 & 6.3 \\
Project grants & 0.7 & 0 & 0 & 0 & 0 & 0 \\
Nonproject grants & $\mathbf{- 2 . 2}$ & $\mathbf{- 1 . 9}$ & $\mathbf{- 1 . 5}$ & $\mathbf{- 0 . 4}$ & $\mathbf{- 0 . 1}$ & $\mathbf{1 . 4}$ \\
Primary balance & -9.1 & -15.8 & -15.6 & -14.7 & -13.8 & -11.9 \\
Overall balance not including grants & $\mathbf{2 . 4}$ & $\mathbf{9 . 6}$ & $\mathbf{9 . 2}$ & $\mathbf{8 . 2}$ & $\mathbf{7 . 1}$ & $\mathbf{5 . 6}$ \\
Financing gap & $\mathbf{1 . 2}$ & $\mathbf{2 . 5}$ & $\mathbf{3 . 6}$ & $\mathbf{4 . 4}$ & $\mathbf{5 . 5}$ & $\mathbf{5 . 6}$ \\
Real GDP growth (in percent) & & & & & \\
\hline
\end{tabular}

(**) As a percentage of GDP, unless otherwise indicted.

\subsubsection{MDG SCENARIO}

The foregoing scenario (PRGS) reflects only a fraction of the financing requirements to achieve the MDGs. The MDG scenario is based on the MDG costing study conducted by the ministerial departments and reflects all costs related to MDG achievement.

This scenario involves substantial investments from the technical and financial partners in the agriculture, education, gender, health, water and sanitation, energy, and transportation sectors, with the assumption of a significant improvement in the government's capacity to absorb external resources.

The tables below indicate the level of investments required by the MDG sector, in Comorian francs and U.S. dollars for comparative purposes. 
Table 5.8. Aggregate costs of achieving the Millennium Development Goals by 2015

\begin{tabular}{|c|c|c|c|c|c|c|c|c|c|}
\hline \multicolumn{10}{|l|}{$\begin{array}{l}\text { ENERGY } \\
\text { In US\$ }\end{array}$} \\
\hline Operations & 2008 & 2009 & 2010 & 2011 & 2012 & 2013 & 2014 & 2015 & $2008-2015$ \\
\hline Improved cooking systems & $1,179,125$ & $2,204,289$ & $3,279,197$ & $4,405,741$ & $5,585,876$ & $6,821,628$ & $8,115,090$ & $9,468,428$ & $41,059,374$ \\
\hline $\begin{array}{l}\text { Electrification (network/non- } \\
\text { network) }\end{array}$ & $161,738,026$ & $329,276,437$ & $504,732,559$ & $688,404,292$ & $880,599,879$ & $1,081,638,263$ & $1,291,849,449$ & $1,511,574,882$ & $6,449,813,787$ \\
\hline Power & 98,399 & 127,260 & 157,147 & 188,430 & 221,159 & 255,388 & 291,171 & 328,565 & $1,667,520$ \\
\hline Total cost & $163,015,550$ & $331,607,986$ & $508,168,904$ & $692,998,463$ & $886,406,915$ & $1,088,715,279$ & $1,300,255,710$ & $1,521,371,875$ & $6,492,540,68$ \\
\hline \multicolumn{10}{|l|}{ In Comorian francs } \\
\hline Operations & 2008 & 2009 & 2010 & 2011 & 2012 & 2013 & 2014 & 2015 & $2008-2015$ \\
\hline Improved cooking systems & $365,528,619$ & $683,329,564$ & $1,016,551,145$ & $1,365,779,668$ & $1,731,621,694$ & $2,114,704,720$ & $2,515,677,877$ & $2,935,212,661$ & $12,728,405,948$ \\
\hline $\begin{array}{l}\text { Electrification (network/non- } \\
\text { network) }\end{array}$ & $50,138,788,036$ & $102,075,695,325$ & $156,467,093,307$ & $213,405,330,416$ & $272,985,962,423$ & $335,307,861,536$ & $400,473,329,310$ & $468,588,213,516$ & $1,999,442,273,868$ \\
\hline Power & $30,503,743$ & $39,450,625$ & $48,715,707$ & $58,413,338$ & $68,559,404$ & $79,170,321$ & $90,263,048$ & $101,855,111$ & $516,931,297$ \\
\hline Total cost & $50,534,820,398$ & $102,798,475,514$ & $157,532,360,159$ & $214,829,523,422$ & $274,786,143,521$ & $337,501,736,576$ & $403,079,270,235$ & $471,625,281,288$ & $2,012,687,611,113$ \\
\hline \multirow{2}{*}{\multicolumn{10}{|c|}{ ROADS/TRANSPORTATION }} \\
\hline In USS & & & & & & & & & \\
\hline Operations & 2008 & 2009 & 2010 & 2011 & 2012 & 2013 & 2014 & 2015 & $2008-2015$ \\
\hline National roads & $28,293,110$ & $29,534,501$ & $30,775,892$ & $32,017,283$ & $33,258,674$ & $34,500,065$ & $35,741,456$ & $36,982,848$ & $261,103,829$ \\
\hline Urban roads & $4,845,798$ & $5,203,634$ & $5,561,470$ & $5,919,305$ & $6,277,141$ & $6,634,977$ & $6,992,813$ & $7,350,648$ & $48,785,786$ \\
\hline Rural roads & $17,571,345$ & $18,330,520$ & $19,089,695$ & $19,848,870$ & $20,608,045$ & $21,367,220$ & $22,126,395$ & $21,510,261$ & $160,452,348$ \\
\hline Bridge construction & $260,894,879$ & $276,591,025$ & $292,287,172$ & $307,983,318$ & $323,679,464$ & $339,375,611$ & $355,071,757$ & $370,767,904$ & $2,526,651,130$ \\
\hline Maritime transportation & $84,115,746$ & $96,304,556$ & $108,493,367$ & $120,682,177$ & $132,870,988$ & $145,059,798$ & $157,248,609$ & $169,437,419$ & $1,014,212,661$ \\
\hline Air transportation & $30,700,804$ & $32,623,051$ & $33,922,185$ & $35,832,351$ & $36,590,765$ & $38,470,462$ & $39,963,543$ & $41,844,224$ & $289,947,385$ \\
\hline Total cost & $426,421,681$ & $458,587,287$ & $490,129,780$ & $522,283,305$ & $553,285,077$ & $585,408,133$ & $617,144,573$ & $647,893,304$ & $4,301,153,139$ \\
\hline \multicolumn{10}{|l|}{ In Comorian francs } \\
\hline Operations & 2008 & 2009 & 2010 & 2011 & 2012 & 2013 & 2014 & 2015 & 2008-2015 \\
\hline National roads & $8,770,863,985$ & $9,155,695,235$ & $9,540,526,485$ & $9,925,357,735$ & $10,310,188,985$ & $10,695,020,235$ & $11,079,851,485$ & $11,464,682,735$ & $80,942,186,883$ \\
\hline Urban roads & $1,502,197,473$ & $1,613,126,545$ & $1,724,055,616$ & $1,834,984,688$ & $1,945,913,759$ & $2,056,842,830$ & $2,167,771,902$ & $2,278,700,973$ & $15,123,593,786$ \\
\hline Rural roads & $5,447,116,820$ & $5,682,461,070$ & $5,917,805,320$ & $6,153,149,570$ & $6,388,493,820$ & $6,623,838,070$ & $6,859,182,320$ & $6,668,180,913$ & $49,740,227,903$ \\
\hline Bridge construction & $80,877,412,365$ & $85,743,217,771$ & $90,609,023,177$ & $95,474,828,583$ & $100,340,633,989$ & $105,206,439,395$ & $110,072,244,801$ & $114,938,050,207$ & $783,261,850,288$ \\
\hline Maritime transportation & $26,075,881,250$ & $29,854,412,500$ & $33,632,943,750$ & $37,411,475,000$ & $41,190,006,250$ & $44,968,537,500$ & $48,747,068,750$ & $52,525,600,000$ & $314,405,925,000$ \\
\hline Air transportation & $9,517,249,281$ & $10,113,145,951$ & $10,515,877,328$ & $11,108,028,863$ & $11,343,137,007$ & $11,925,843,150$ & $12,388,698,277$ & $12,971,709,393$ & $89,883,689,249$ \\
\hline Total cost & $132,190,721,175$ & $142,162,059,072$ & $151,940,231,676$ & $161,907,824,439$ & $171,518,373,811$ & $181,476,521,180$ & $191,314,817,535$ & $200,846,924,221$ & $1,333,357,473,109$ \\
\hline
\end{tabular}

123

CInternational Monetary Fund. Not for Redistribution 
Table 5.8. Aggregate costs of achieving the Millennium Development Goals by 2015 (continued)

\begin{tabular}{|c|c|c|c|c|c|c|c|c|c|}
\hline \multirow{2}{*}{\multicolumn{10}{|c|}{$\begin{array}{l}\text { GENDER } \\
\text { In US } \$\end{array}$}} \\
\hline & & & & & & & & & \\
\hline Operations & 2008 & 2009 & 2010 & 2011 & 2012 & 2013 & 2014 & 2015 & $2008-2015$ \\
\hline Reproductive health sensitization & 825397,4875 & 991335,8979 & 1159045,417 & 1327844,949 & 1491696,374 & 1665176,287 & 1843169,63 & 2026367,283 & 11330033,33 \\
\hline $\begin{array}{l}\text { Occupational training for young } \\
\text { girls }\end{array}$ & 932800,6363 & 1080137,29 & 1232316,749 & 1378111,67 & 1534304,028 & 1689050,82 & 1820851,245 & 1939433,576 & 11607006,01 \\
\hline Encourage political participation & 8606 & 47212,60326 & 7150,021739 & 10506 & 10506 & 10506 & 10506 & 115642,4 & 220635,025 \\
\hline Stop violence against women & 5582277,753 & 6915295,46 & 8319209,206 & 9769380,963 & 11271709,15 & 12807294,02 & 14375451,49 & 15995543,87 & 85036161,91 \\
\hline Systemic issues & 30847047,49 & 40445007,23 & 50648103,53 & 61468682,58 & 72918923,97 & 85010705,08 & 97759355,43 & 111205522,5 & 550303347,9 \\
\hline Administrative costs & 1909806,468 & 2473949,424 & 3068291,246 & 3697726,308 & 4361356,976 & 5059136,61 & 5790466,689 & 6564125,484 & 32924859,21 \\
\hline Total cost & $40,105,936$ & $51,952,938$ & $64,434,116$ & $77,652,252$ & $91,588,496$ & $106,241,869$ & $121,599,800$ & $137,846,635$ & $691,422,043$ \\
\hline \multicolumn{10}{|l|}{ In Comorian francs } \\
\hline Operations & 2008 & 2009 & 2010 & 2011 & 2012 & 2013 & 2014 & 2015 & 2008-2015 \\
\hline Reproductive health sensitization & $255,873,221$ & $307,314,128$ & $359,304,079$ & $411,631,934$ & $462,425,876$ & $516,204,649$ & $571,382,585$ & $628,173,858$ & $3,512,310,331$ \\
\hline $\begin{array}{l}\text { Occupational training for young } \\
\text { girls }\end{array}$ & $289,168,197$ & $334,842,560$ & $382,018,192$ & $427,214,618$ & $475,634,249$ & $523,605,754$ & $564,463,886$ & $601,224,409$ & $3,598,171,865$ \\
\hline Encourage political participation & $2,667,860$ & $14,635,907$ & $2,216,507$ & $3,256,860$ & $3,256,860$ & $3,256,860$ & $3,256,860$ & $35,849,144$ & $68,396,858$ \\
\hline \multirow[t]{2}{*}{ Stop violence against women } & $1,730,506,104$ & $2,143,741,593$ & $2,578,954,854$ & $3,028,508,098$ & $3,494,229,837$ & $3,970,261,145$ & $4,456,389,960$ & $4,958,618,601$ & $26,361,210,192$ \\
\hline & $9,562,584,722$ & $12,537,952,241$ & $15,700,912,094$ & $19,055,291,601$ & $22,604,866,430$ & $26,353,318,576$ & $30,305,400,183$ & $34,473,711,989$ & $170,594,037,836$ \\
\hline Administrative costs & $592,040,005$ & $766,924,321$ & $951,170,286$ & $1,146,295,156$ & $1,352,020,663$ & $1,568,332,349$ & $1,795,044,674$ & $2,034,878,900$ & $10,206,706,354$ \\
\hline Total cost & $12,432,840,109$ & $16,105,410,750$ & $19,974,576,012$ & $24,072,198,267$ & $28,392,433,914$ & $32,934,979,334$ & $37,695,938,149$ & $42,732,456,901$ & $214,340,833,436$ \\
\hline
\end{tabular}

\begin{tabular}{|c|c|c|c|c|c|c|c|c|c|}
\hline \multicolumn{10}{|l|}{$\begin{array}{l}\text { RURAL } \\
\text { DEVELOPMENT }\end{array}$} \\
\hline \multicolumn{10}{|l|}{ In USS } \\
\hline Operations & 2008 & 2009 & 2010 & 2011 & 2012 & 2013 & 2014 & 2015 & $2008-2015$ \\
\hline Agricultural productivity & $26,407,782$ & $93,205,592$ & $119,776,232$ & $146,134,501$ & $407,153,593$ & $221,609,097$ & $263,280,812$ & $\begin{array}{l}314,690,688 \\
\end{array}$ & $1,592,258,296$ \\
\hline Community mobilization & $27,796,653$ & $36,945,968$ & $47,293,091$ & $58,869,876$ & $71,798,407$ & $86,224,254$ & $102,372,343$ & $120,603,882$ & $551,904,473$ \\
\hline Small-scale irrigation & 545,313 & 685,028 & 824,932 & 988,497 & $1,206,124$ & $1,539,978$ & $2,160,752$ & $3,955,370$ & $11,905,994$ \\
\hline Research & 359,274 & 436,587 & 528,934 & 639,594 & 772,725 & 933,796 & $1,129,860$ & $1,370,542$ & $6,171,314$ \\
\hline Total cost & $55,109,023$ & $131,273,176$ & $168,423,189$ & $206,632,467$ & $480,930,850$ & $310,307,124$ & $368,943,766$ & $440,620,482$ & $2,162,240,077$ \\
\hline \multicolumn{10}{|l|}{ In Comorian francs } \\
\hline Operations & 2008 & 2009 & 2010 & 2011 & 2012 & 2013 & 2014 & 2015 & 2008-2015 \\
\hline Agricultural productivity & $\begin{array}{r}8,186,412,372 \\
\end{array}$ & $28,893,733,499$ & $37,130,631,914$ & $45,301,695,335$ & $126,217,613,785$ & $68,698,820,053$ & $81,617,051,610$ & $97,554,113,196$ & $493,600,071,764$ \\
\hline Community mobilization & $8,616,962,436$ & $11,453,250,124$ & $14,660,858,122$ & $18,249,661,443$ & $22,257,506,264$ & $26,729,518,623$ & $31,735,426,204$ & $37,387,203,433$ & $171,090,386,649$ \\
\hline Small-scale irrigation & $169,047,136$ & $212,358,757$ & $255,728,853$ & $306,433,935$ & $373,898,541$ & $477,393,173$ & $669,833,062$ & $1,226,164,647$ & $3,690,858,103$ \\
\hline Research & $111,375,052$ & $135,342,092$ & $163,969,686$ & $198,274,136$ & $239,544,840$ & $289,476,743$ & $350,256,685$ & $424,868,156$ & $1,913,107,390$ \\
\hline Total cost & $17,083,796,996$ & $40,694,684,472$ & $52,211,188,575$ & $64,056,064,850$ & $149,088,563,429$ & $96,195,208,591$ & $114,372,567,561$ & $136,592,349,431$ & $670,294,423,906$ \\
\hline
\end{tabular}


Table 5.8. Aggregate costs of achieving the Millennium Development Goals by 2015 (continued)

\begin{tabular}{|c|c|c|c|c|c|c|c|c|c|}
\hline $\begin{array}{l}\text { Water and } \\
\text { sanitation }\end{array}$ & & & & & & & & & \\
\hline In US\$ & & & & & & & & & \\
\hline Operations & 2008 & 2009 & 2010 & 2011 & 2012 & 2013 & 2014 & 2015 & 2008-2015 \\
\hline Water & $57,554,291$ & $60,245,365$ & $62,936,440$ & $65,627,514$ & $68,318,588$ & $71,009,662$ & $73,700,736$ & 76,391,811 & $535,784,408$ \\
\hline Sanitation & $1,321,388,195$ & $1,403,404,177$ & $1,485,420,160$ & $1,567,436,143$ & $1,649,452,126$ & $1,731,468,108$ & $1,813,484,091$ & $1,895,500,074$ & $12,867,553,074$ \\
\hline $\begin{array}{l}\text { Wastewater } \\
\text { treatment }\end{array}$ & - & - & - & & & - & - & - & - \\
\hline $\begin{array}{l}\text { Hygiene in the } \\
\text { schools }\end{array}$ & - & - & - & - & - & - & - & - & - \\
\hline $\begin{array}{l}\text { Supplementary } \\
\text { treatment }\end{array}$ & - & - & - & - & - & - & - & - & - \\
\hline Total cost & $1,378,942,486$ & $1,463,649,543$ & $1,548,356,600$ & $1,633,063,657$ & $1,717,770,714$ & $1,802,477,770$ & $1,887,184,827$ & $1,971,891,884$ & $13,403,337,481$ \\
\hline In Comorian francs & & & & & & & & & \\
\hline Operations & 2008 & 2009 & 2010 & 2011 & 2012 & 2013 & 2014 & 2015 & 2008-2015 \\
\hline Water & $17,841,830,304$ & $18,676,063,303$ & $19,510,296,302$ & $20,344,529,301$ & $21,178,762,300$ & $22,012,995,299$ & $22,847,228,299$ & $23,681,461,298$ & $166,093,166,405$ \\
\hline Sanitation & $409,630,340,374$ & $435,055,295,010$ & $460,480,249,646$ & $485,905,204,282$ & $511,330,158,918$ & $536,755,113,554$ & $562,180,068,190$ & $587,605,022,826$ & $\begin{array}{r}3,988,941,452,80 \\
0\end{array}$ \\
\hline $\begin{array}{l}\text { Wastewater } \\
\text { treatment }\end{array}$ & - & & & & & & & & \\
\hline $\begin{array}{l}\text { Hygiene in the } \\
\text { schools }\end{array}$ & - & & & & & & & & \\
\hline $\begin{array}{l}\text { Supplementary } \\
\text { treatment }\end{array}$ & - & & & & & & & & \\
\hline Total cost & $427,472,170,678$ & $453,731,358,313$ & $479,990,545,948$ & $506,249,733,583$ & $532,508,921,218$ & $558,768,108,853$ & $585,027,296,488$ & $611,286,484,123$ & $\begin{array}{r}4,155,034,619,20 \\
5\end{array}$ \\
\hline EDUCATION & & & & & & & & & \\
\hline In US\$ & & & & & & & & & \\
\hline Operations & 2008 & 2009 & 2010 & 2011 & 2012 & 2013 & 2014 & 2015 & 2008-2015 \\
\hline $\begin{array}{l}\text { Preschool } \\
\text { education }\end{array}$ & $4,307,395$ & $4,497,315$ & $4,680,743$ & $4,861,971$ & $5,043,595$ & $5,227,286$ & $5,414,180$ & $5,605,094$ & $39,637,577$ \\
\hline $\begin{array}{l}\text { Primary } \\
\text { education }\end{array}$ & $37,557,605$ & $38,093,865$ & $44,037,509$ & $50,735,010$ & $47,232,681$ & $51,574,435$ & $56,556,872$ & $62,347,075$ & $388,135,051$ \\
\hline $\begin{array}{l}\text { Secondary } \\
\text { education }\end{array}$ & $12,011,718$ & $6,963,103$ & $12,576,898$ & $18,954,152$ & $26,364,760$ & $28,543,606$ & $31,490,089$ & $34,523,858$ & $171,428,184$ \\
\hline Adult literacy & 328,795 & 348,499 & 368,982 & 390,272 & 412,395 & 435,381 & 459,258 & 484,058 & $3,227,640$ \\
\hline Total & $54,205,513$ & $49,902,781$ & $61,664,132$ & $74,941,404$ & $79,053,431$ & $85,780,708$ & $93,920,399$ & $102,960,084$ & $602,428,452$ \\
\hline In Comorian francs & & & & & & & & & \\
\hline Operations & 2008 & 2009 & 2010 & 2011 & 2012 & 2013 & 2014 & 2015 & 2008-2015 \\
\hline $\begin{array}{l}\text { Preschool } \\
\text { education }\end{array}$ & $1,335,292,391$ & $1,394,167,547$ & $1,451,030,329$ & $1,507,210,878$ & $1,563,514,309$ & $1,620,458,505$ & 1,678,395,834 & $1,737,579,193$ & $12,287,648,986$ \\
\hline $\begin{array}{l}\text { Primary } \\
\text { education }\end{array}$ & $11,642,857,695$ & $11,809,097,996$ & $13,651,627,741$ & $15,727,853,020$ & $14,642,131,139$ & $15,988,074,965$ & $17,532,630,232$ & $19,327,593,123$ & $120,321,865,910$ \\
\hline $\begin{array}{l}\text { Secondary } \\
\text { education }\end{array}$ & $3,723,632,651$ & $2,158,562,014$ & $3,898,838,520$ & $5,875,787,145$ & $8,173,075,524$ & $8,848,517,811$ & $9,761,927,494$ & $10,702,395,906$ & $53,142,737,064$ \\
\hline Adult literacy & $101,926,446$ & $108,034,579$ & $114,384,414$ & $120,984,220$ & $127,842,526$ & $134,968,132$ & $142,370,116$ & $150,057,845$ & $1,000,568,278$ \\
\hline Total & $16,803,709,183$ & $15,469,862,135$ & $\begin{array}{l}19,115,881,004 \\
\end{array}$ & $23,231,835,263$ & $24,506,563,497$ & $26,592,019,412$ & $29,115,323,676$ & $31,917,626,068$ & $186,752,820,238$ \\
\hline
\end{tabular}

125

CInternational Monetary Fund. Not for Redistribution 
Table 5.8. Aggregate costs of achieving the Millennium Development Goals by 2015 (continued)

\begin{tabular}{|c|c|c|c|c|c|c|c|c|c|}
\hline HEALTH & & & & & & & & & \\
\hline \multicolumn{10}{|l|}{ In USS } \\
\hline Operations & 2008 & 2009 & 2010 & 2011 & 2012 & 2013 & 2014 & 2015 & $2008-2015$ \\
\hline Systemic costs & $65,019,176$ & $59,234,734$ & $64,675,020$ & $87,754,815$ & $112,133,862$ & $163,259,545$ & $190,528,660$ & $219,890,066$ & $962,495,877$ \\
\hline Child health & $107,170,221$ & $107,673,303$ & $110,835,300$ & $\begin{array}{l}167,574,843 \\
\end{array}$ & $227,651,760$ & $353,241,469$ & $422,162,142$ & $4993,703,594$ & $1,990,012,631$ \\
\hline Maternal health & $3,240,176$ & $3,091,789$ & $3,80,851$ & $3,328,065$ & $3,613,235$ & $4,133,054$ & $4,471,302$ & $4,826,415$ & $29,784,885$ \\
\hline HIV/AIDS & $1,270,324$ & $5,043,950$ & $8,965,018$ & $13,031,837$ & $17,250,574$ & $21,619,849$ & $26,150,011$ & $30,811,212$ & $124,142,775$ \\
\hline Malaria & $1,674,597$ & $1,718,151$ & $1,763,265$ & $1,809,959$ & $1,858,232$ & $1,908,069$ & $1,959,447$ & $2,012,546$ & $14,704,266$ \\
\hline Tuberculosis & 31,992 & 32,824 & 33,686 & 34,578 & 34,752 & 35,684 & 36,645 & 37,233 & 277,394 \\
\hline \begin{tabular}{|l|l|} 
Total cost \\
\end{tabular} & $178,406,486$ & $176,794,749$ & $189,353,139$ & $273,534,096$ & $362,542,415$ & $544,197,670$ & $645,308,207$ & $751,281,066$ & $3,121,417,829$ \\
\hline \multirow{2}{*}{\multicolumn{10}{|c|}{ In Comorian francs }} \\
\hline & & & & & & & & & \\
\hline Operations & 2008 & 2009 & 2010 & 2011 & 2012 & 2013 & 2014 & 2015 & 2008-2015 \\
\hline Systemic costs & $20,155,944,709$ & $18,362,767,415$ & $20,049,256,105$ & $27,203,992,558$ & $34,761,497,184$ & $50,610,458,818$ & $59,063,884,482$ & $68,165,920,598$ & $298,373,721,868$ \\
\hline Child health & $33,222,768,528$ & $33,378,723,796$ & $34,358,942,871$ & $51,948,201,315$ & $70,572,045,736$ & $109,504,855,509$ & $130,870,263,971$ & $153,048,114,032$ & $616,903,915,758$ \\
\hline Maternal health & $1,004,454,592$ & $958,454,446$ & $955,063,766$ & $1,031,700,061$ & $1,120,102,763$ & $1,281,246,639$ & $1,386,103,551$ & $1,496,188,517$ & $9,233,314,334$ \\
\hline HIV/AIDS & $393,800,442$ & $1,563,624,491$ & $2,779,155,554$ & $4,039,869,450$ & $5,347,677,963$ & $6,702,153,224$ & $8,106,503,450$ & $9,551,475,763$ & $38,484,260,338$ \\
\hline Malaria & $519,124,977$ & $532,626,805$ & $546,612,095$ & $561,087,380$ & $576,051,844$ & $591,501,404$ & $607,428,710$ & $623,889,294$ & $4,558,322,509$ \\
\hline Tuberculosis & $9,917,441$ & $10,175,382$ & $10,442,559$ & $10,719,097$ & $10,773,229$ & $11,062,164$ & $11,360,034$ & $11,542,379$ & $85,992,286$ \\
\hline Total cost & $55,306,010,690$ & $54,806,372,335$ & $58,699,472,950$ & $84,795,569,862$ & $112,388,148,720$ & $168,701,277,758$ & $200,045,544,198$ & $232,897,130,582$ & $967,639,527,095$ \\
\hline
\end{tabular}

\begin{tabular}{|c|c|c|c|c|c|c|c|c|c|}
\hline TOTAL SECTOR MDG & & & & & & & & & \\
\hline \multicolumn{10}{|l|}{ In USS } \\
\hline Operations & 2008 & 2009 & 2010 & 2011 & 2012 & 2013 & 2014 & 2015 & $2008-2015$ \\
\hline ENERGY & $163,015,550$ & $331,607,986$ & $508,168,904$ & $692,998,463$ & $886,406,915$ & $1,088,715,279$ & $1,300,255,710$ & $1,521,371,875$ & $6,492,540,681$ \\
\hline ROADS/TRANSPORTATION & $426,421,681$ & $458,587,287$ & $490,129,780$ & $522,283,305$ & $553,285,077$ & $585,408,133$ & $617,144,573$ & $647,893,304$ & $4,301,153,139$ \\
\hline GENDER & 825,397 & 991,336 & $1,159,045$ & $1,327,845$ & $1,491,696$ & $1,665,176$ & $1,843,170$ & $2,026,367$ & $11,330,033$ \\
\hline RURAL DEVELOPMENT & $26,407,782$ & $93,205,592$ & $119,776,232$ & $146,134,501$ & $407,153,593$ & $221,609,097$ & $263,280,812$ & $314,690,688$ & $1,592,258,296$ \\
\hline HEALTH & $178,406,486$ & $176,794,749$ & $189,353,139$ & $273,534,096$ & $362,542,415$ & $544,197,670$ & $645,308,207$ & $751,281,066$ & $3,121,417,829$ \\
\hline EDUCATION & $54,205,513$ & $49,902,781$ & $61,664,132$ & $74,941,404$ & $79,053,431$ & $85,780,708$ & $93,920,399$ & $102,960,084$ & $602,428,452$ \\
\hline SANITATION & $1,378,942,486$ & $1,463,649,543$ & $1,548,356,600$ & $1,633,063,657$ & $1,717,770,714$ & $1,802,477,770$ & $1,887,184,827$ & $1,971,891,884$ & $13,403,337,481$ \\
\hline Total cost & $2,228,224,896$ & $2,574,739,274$ & $2,918,607,831$ & $3,344,283,270$ & $4,007,703,840$ & $4,329,853,834$ & $4,808,937,698$ & $5,312,115,269$ & $29,524,465,912$ \\
\hline \multicolumn{10}{|l|}{ In Comorian francs } \\
\hline Operations & 2008 & 2009 & 2010 & 2011 & 2012 & 2013 & 2014 & 2015 & $2008-2015$ \\
\hline ENERGY & $50,534,820,398$ & $102,798,475,514$ & $157,532,360,159$ & $214,829,523,422$ & $274,786,143,521$ & $337,501,736,576$ & $403,079,270,235$ & $471,625,281,288$ & $2,012,687,611,113$ \\
\hline ROADS/TRANSPORTATION & $8,770,863,985$ & $9,155,695,235$ & $9,540,526,485$ & $9,925,357,735$ & $10,310,188,985$ & $10,695,020,235$ & $11,079,851,485$ & $11,464,682,735$ & $80,942,186,883$ \\
\hline GENDER & $12,432,840,109$ & $16,105,410,750$ & $19,974,576,012$ & $24,072,198,267$ & $28,392,433,914$ & $32,934,979,334$ & $37,695,938,149$ & $42,732,456,901$ & $214,340,833,436$ \\
\hline RURAL DEVELOPMENT & $17,083,796,996$ & $40,694,684,472$ & $52,211,188,575$ & $64,056,064,850$ & $149,088,563,429$ & $96,195,208,591$ & $114,372,567,561$ & $136,592,349,431$ & $670,294,423,906$ \\
\hline HEALTH & $55,306,010,690$ & $54,806,372,335$ & $58,699,472,950$ & $84,795,569,862$ & $112,388,148,720$ & $168,701,277,758$ & $200,045,544,198$ & $232,897,130,582$ & $967,639,527,095$ \\
\hline EDUCATION & $16,803,709,183$ & $15,469,862,135$ & $19,115,881,004$ & $23,231,835,263$ & $24,506,563,497$ & $26,592,019,412$ & $29,115,323,676$ & $31,917,626,068$ & $186,752,820,238$ \\
\hline SANITATION & $427,472,170,678$ & $453,731,358,313$ & $479,990,545,948$ & $506,249,733,583$ & $532,508,921,218$ & $558,768,108,853$ & $585,027,296,488$ & $611,286,484,123$ & $4,155,034,619,205$ \\
\hline Total cost & $588,404,212,040$ & $692,761,858,755$ & $797,064,551,133$ & $927,160,282,982$ & $1,131,980,963,285$ & $1,231,388,350,760$ & $1,380,415,791,792$ & $1,538,516,011,129$ & $8,287,692,021,876$ \\
\hline
\end{tabular}




\subsubsection{IMF SCENARIO}

With reference to recent trends and the efforts in connection with IMF Emergency Post Conflict Assistance, the Comoros can be expected to experience a decline in real GDP growth as compared with the previous scenario. In fact, the growth rate should be situated at an average of 3.6 percent for the period 2010-2014, as against 4.3 percent in the PRGS scenario.

The investment rate should reach an average of 14.5 percent per annum although with low levels of domestic savings peaking at 5.2 percent in 2013.

Where fiscal affairs are concerned, the efforts undertaken to control the wage bill and public expenditure will generally be reflected in the financing deficit to be arranged over the years to achieve 2.1 percent of GDP by 2013, as compared with 4.8 percent in 2009. The domestic primary balance should also improve to register a slight surplus of 0.3 percent of GDP in 2013, as against -1.6 percent in 2009 .

Table 5.9. Key macroeconomic aggregates from the macroeconomic framework under the IMF scenario $(*)$

\begin{tabular}{lrrrrr} 
Projections & $\mathbf{2 0 0 9}$ & $\mathbf{2 0 1 0}$ & $\mathbf{2 0 1 1}$ & $\mathbf{2 0 1 2}$ & $\mathbf{2 0 1 3}$ \\
\hline GDP at market prices (billions of CF) & 192.82 & 199.45 & 211.84 & 226.96 & 244.36 \\
Budget revenue & 24.48 & 25.94 & 28.39 & 31.55 & 34.94 \\
Tax revenue & 18.31 & 19.62 & 21.68 & 24.36 & 27.20 \\
Nontax revenue & 6.17 & 6.32 & 6.71 & 7.19 & 7.74 \\
Total expenditure & 40.80 & 42.48 & 45.40 & 49.04 & 52.84 \\
Capital expenditure & 12.30 & 13.30 & 14.60 & 16.26 & 18.36 \\
Current expenditure & 28.50 & 29.18 & 30.80 & 32.77 & 34.49 \\
Wages & 16.90 & 17.09 & 17.60 & 18.48 & 19.13 \\
Wages/Total revenue (in percent) & $\mathbf{6 9 \%}$ & $\mathbf{6 6 \%}$ & $\mathbf{6 2 \%}$ & $\mathbf{5 9 \%}$ & $\mathbf{5 5 \%}$ \\
Internally-financed capital expenditure & 1.03 & 1.25 & 1.41 & 1.71 & 2.23 \\
Externally-financed capital expenditure & 10.74 & 11.47 & 12.57 & 13.88 & 15.39 \\
External financing & 16.79 & 6.20 & 6.30 & 6.50 & 6.70 \\
Project grants & 11.33 & 6.20 & 6.30 & 6.50 & 6.70 \\
Nonproject grants & 5.46 & 0 & 0 & 0 & 0 \\
Primary balance & $\mathbf{- 3 . 2 0}$ & $\mathbf{- 2 . 6 0}$ & $\mathbf{- 1 . 8 0}$ & $\mathbf{- 0 . 6 0}$ & $\mathbf{0 . 6 0}$ \\
Overall balance not including grants & -16.3 & -16.5 & -17.0 & -2.8 & -1.6 \\
Financing gap & $\mathbf{9 . 2 2}$ & $\mathbf{6 . 9 7}$ & $\mathbf{6 . 5 0}$ & $\mathbf{6 . 4 9}$ & $\mathbf{5 . 1 5}$ \\
Real GDP growth rate (in percent) & $\mathbf{1 . 0}$ & $\mathbf{2 . 0}$ & $\mathbf{3 . 0}$ & $\mathbf{3 . 5 0}$ & $\mathbf{4 . 1 0}$ \\
Sources: Comorian authorities and IMF staff estimates and forecasts. & & & \\
*) In billions of Comorian francs unless otherwise indicated. & & & & \\
\hline
\end{tabular}


Table 5.10. Key macroeconomic aggregates from the macroeconomic framework under the IMF scenario $(* *)$

\begin{tabular}{|c|c|c|c|c|c|}
\hline Projections & 2009 & 2010 & 2011 & 2012 & 2013 \\
\hline GDP at market prices (billions of CF) & 192.82 & 199.45 & 211.84 & 226.96 & 244.36 \\
\hline Budget revenue & 12.7 & 13 & 13.4 & 13.9 & 14.3 \\
\hline Tax revenue & 9.5 & 9.8 & 10.2 & 10.7 & 11.1 \\
\hline Nontax revenue & 3.2 & 3.2 & 3.2 & 3.2 & 3.2 \\
\hline Total expenditure & 21.2 & 21.3 & 21.4 & 21.6 & 21.6 \\
\hline Capital expenditure & 6.4 & 6.7 & 6.9 & 7.2 & 7.5 \\
\hline Current expenditure & 14.8 & 14.6 & 14.5 & 14.4 & 14.1 \\
\hline Wages & 8.8 & 8.6 & 8.3 & 8.1 & 7.8 \\
\hline Wages/Total revenue (in percent) & $69 \%$ & $66 \%$ & $62 \%$ & $59 \%$ & $55 \%$ \\
\hline Internally-financed capital expenditure & 0.5 & 0.6 & 0.7 & 0.8 & 0.9 \\
\hline $\begin{array}{l}\text { Externally-financed capital } \\
\text { expenditure }\end{array}$ & 5.6 & 5.8 & 5.9 & 6.1 & 6.3 \\
\hline External financing & 5.9 & 6.1 & 6.3 & 6.5 & 6.7 \\
\hline Project grants & 5.9 & 6.1 & 6.3 & 6.5 & 6.7 \\
\hline Nonproject grants & 0 & 0 & 0 & 0 & 0 \\
\hline Primary balance & -1.6 & -1.3 & -0.8 & -0.3 & 0.3 \\
\hline Overall balance not including grants & -8.5 & -8.3 & -8 & -1.2 & -0.7 \\
\hline Financing gap & 4.8 & 3.5 & 3.1 & 2.9 & 2.1 \\
\hline Real GDP growth rate (in percent) & 1 & 2 & 3 & 3.5 & 4 \\
\hline \multicolumn{6}{|c|}{$\begin{array}{l}\text { Sources: Comorian authorities and IMF staff estimates and forecasts. } \\
\text { (*) In percent of GDP unless otherwise indicated. }\end{array}$} \\
\hline
\end{tabular}

Table 5.11 below shows the different scenarios on a comparative basis. 
Table 5.11. Comparative analysis of the three scenarios

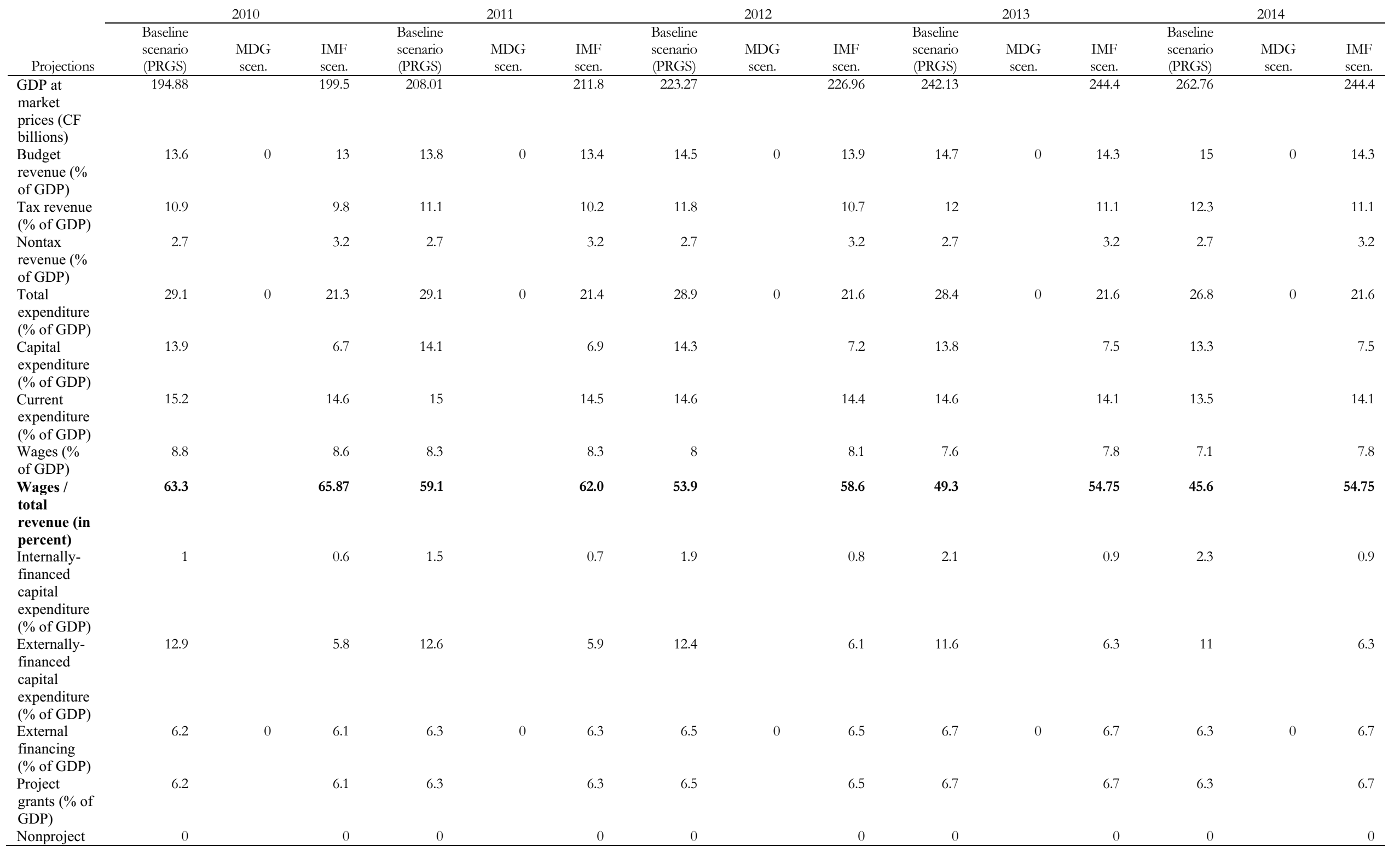


grants (\% of

$$
\text { GDP) }
$$

Primary

Prim

of GDP)

Overall

including

grants (\% of

GDP)

Financing

gap (CF 


\section{CHAPTER VI}

ESTIMATED PRGS FINANCING REQUIREMENTS 


\subsection{INTRODUCTION}

During the period 2010-2014, the government intends to focus its efforts on and direct those of the technical and financial partners to the implementation of the priority programs identified. The strategy includes a total of 32 priority programs. The required financial resources, including those already mobilized, are estimated at CF 463 billion for the period, equivalent to an average of CF 92 billion per annum. The financial resources to be obtained during the period amount to CF 418 billion, equivalent to an average of CF 83 billion per year.

Table 6.1. Requirements by core strategy for the period 2010-2014 (millions of CF)

Total

Core strategies

$\begin{array}{cccc}\begin{array}{c}\text { Financing } \\ \text { acquired }\end{array} & \begin{array}{c}\text { Financing } \\ \text { required }\end{array} & \begin{array}{c}\text { (CF } \\ \text { millions) }\end{array} & \% \\ & & & \end{array}$

Core strategy I. Stabilize the economy

$20,389 \quad 234,285 \quad \mathbf{2 5 4 , 6 7 4} \quad 55.0$

and lay the groundwork for strong and

equitable growth

Core strategy II. Strengthen key sectors

802

55,025

55,826

12.0

by focusing on institution building and

ensuring a broader role for the private

sector

Core strategy III. Strengthen governance

6,560

14,817

21,377

4.6

and social cohesion

Core strategy IV. Improve the health

8,406

62,234

70,641

15.2

status of the general public

Core strategy V. Promote education and

4,020

28,768

32,788

7.1

vocational training with the aim of

developing human capital

Core strategy VI. Promote environmental

5,013

23,030

28,043

6.1

sustainability and civilian security

Total

45,190

418,159

463,349

100 
Table 6.2. Requirements by major sector for the period 2010-2014 (millions of CF)

Total

$\begin{array}{cccc}\text { Financing } & \text { Financing } & (\mathrm{CF} & \% \\ \text { acquired } & \text { required } & \text { millions }) & \end{array}$

\begin{tabular}{|c|c|c|c|c|}
\hline Agriculture & 47 & 15,808 & 15,854 & 3.4 \\
\hline Fishing & 558 & 18,607 & 19,165 & 4.1 \\
\hline Stockbreeding & 0 & 9,781 & 9,781 & 2.1 \\
\hline Tourism & 0 & 6,025 & 6,025 & 1.3 \\
\hline Energy & 850 & 70,154 & 71,004 & 15.3 \\
\hline Drinking water and sanitation & 14,190 & 26,445 & 40,635 & 8.8 \\
\hline Economic and communication & 3,616 & 67,025 & 70,641 & 15.2 \\
\hline \multicolumn{5}{|l|}{ infrastructure } \\
\hline Environment and public security & 5,013 & 23,030 & 28,043 & 6.1 \\
\hline Education & 4,020 & 28,768 & 32,788 & 7.1 \\
\hline Health & 8,406 & 62,234 & 70,641 & 15.2 \\
\hline Private and financial sector & 197 & 4,804 & 5,001 & 1.1 \\
\hline Governance and social cohesion & 6,560 & 14,817 & 21,377 & 4.6 \\
\hline Fiscal reform and commercial policy & 1,733 & 70,661 & 72,394 & 15.6 \\
\hline Total & 45,190 & 418,159 & 463,349 & 100 \\
\hline
\end{tabular}


Resources currently available for the period amount to CF 46.1 billion, equivalent to 9.2 billion per annum (Annex 1).

In addition, the PRGS budgeting exercise indicates financing gaps far exceeding the estimates in the PRGS macroeconomic framework scenario, but much lower than the requirements assessed in the MDG budget exercise.

The distribution of financing required by core strategy and PRGS priority program is presented in the tables below. 


\subsection{CORE STRATEGY I: STABILIZE THE ECONOMY AND LAY THE GROUNDWORK FOR STRONG AND EQUITABLE GROWTH}

The budget for Core Strategy 1 by program for the period 2010-2014 is approximately CF 255 billion, of which CF 234 billion must be acquired.

Table 6.3. Budget for Core Strategy 1 by program for the period 2010-2014 (millions de CF)

\begin{tabular}{|c|c|c|c|c|c|c|c|c|c|c|c|c|}
\hline \multirow{3}{*}{ Programs } & \multicolumn{2}{|c|}{2010} & \multicolumn{2}{|c|}{2011} & \multicolumn{2}{|c|}{2012} & \multicolumn{2}{|c|}{2013} & \multicolumn{2}{|c|}{2014} & \multirow{2}{*}{\multicolumn{2}{|c|}{$\frac{2010-2014}{\text { Grand total }}$}} \\
\hline & & & & & & & & & & & & \\
\hline & Acquired & $\begin{array}{l}\text { Re- } \\
\text { quired }\end{array}$ & Acq. & Req. & Acq. & Req. & Acq. & Req. & Acq. & Req. & Acq. & Req. \\
\hline $\begin{array}{l}\text { Program 1. Improve } \\
\text { state and fiscal } \\
\text { operations }\end{array}$ & 578 & 17,056 & 253 & 15,437 & 199 & 15,587 & 218 & 15,710 & 143 & 4,793 & 1,391 & 68,583 \\
\hline $\begin{array}{l}\text { Program } 1.2 \\
\text { Integrate and } \\
\text { facilitate domestic } \\
\text { and international } \\
\text { trade }\end{array}$ & 119 & 713 & 113 & 405 & 110 & 406 & 0 & 292 & 0 & 262 & 342 & 2,078 \\
\hline $\begin{array}{l}\text { 1.3. Improve } \\
\text { energy supply at } \\
\text { low cost }\end{array}$ & 330 & 13,938 & 260 & 13,924 & 260 & 13,924 & 0 & 14,184 & 0 & 14,184 & 850 & 70,154 \\
\hline $\begin{array}{l}\text { 1.4. Improve } \\
\text { communication } \\
\text { infrastructure }\end{array}$ & 3,616 & 11,559 & 0 & 12,255 & 0 & 11,034 & 0 & 15,595 & 0 & 16,582 & 3,616 & 67,025 \\
\hline $\begin{array}{l}\text { 1.5. Increase access } \\
\text { to drinking water, } \\
\text { sanitation, and } \\
\text { sustainable resource } \\
\text { management }\end{array}$ & 3,030 & 5,097 & 2,790 & 5,337 & 2,790 & 5,337 & 2,790 & 5,337 & 2,790 & 5,337 & 14,190 & 26,445 \\
\hline $\begin{array}{l}\text { Total programs, Core } \\
\text { Strategy } 1\end{array}$ & 7,673 & 48,363 & 3,416 & 47,358 & 3,359 & 46,288 & 3,008 & 51,118 & 2,933 & 41,158 & 20,389 & 234,285 \\
\hline
\end{tabular}




\subsection{CORE STRATEGY II. STRENGTHEN KEY SECTORS BY FOCUSING ON INSTITUTION BUILDING AND ENSURING A BROADER ROLE FOR THE}

PRIVATE SECTOR

The budget for the period 2010-2014 amounts to CF 55.8 billion, of which CF 55 billion is required.

Table 6.4. Budget for Core Strategy 2 by program for the period 2010-2014 (millions of CF)

\begin{tabular}{|c|c|c|c|c|c|c|c|c|c|c|c|c|}
\hline \multirow[t]{2}{*}{ Programs } & \multicolumn{2}{|c|}{2010} & \multicolumn{2}{|c|}{2011} & \multicolumn{2}{|c|}{2012} & \multicolumn{2}{|c|}{2013} & \multicolumn{2}{|c|}{2014} & \multicolumn{2}{|c|}{$\begin{array}{c}2010-2014 \\
\text { Grand total }\end{array}$} \\
\hline & Acq. & Req. & Acq. & Req. & Acq. & Req. & Acq. & Req. & Acq. & Req. & Acq. & Req. \\
\hline $\begin{array}{l}\text { Program 2.1. Support } \\
\text { private sector } \\
\text { organization }\end{array}$ & 123 & 1,607 & 36 & 397 & 26 & 210 & 1 & 5 & 1 & 5 & 287 & 2,224 \\
\hline $\begin{array}{l}\text { Program 2.2. Financial } \\
\text { intermediation and } \\
\text { microcredit }\end{array}$ & 5 & 700 & 10 & 420 & 0 & 180 & 0 & 1,295 & 0 & 0 & 10 & 2,580 \\
\hline $\begin{array}{l}\text { Program } 2.3 \text {. Support } \\
\text { property restructuring } \\
\text { and consolidation }\end{array}$ & 10 & 221 & 5 & 557 & 5 & 732 & 0 & 50 & 0 & 50 & 20 & 1,610 \\
\hline $\begin{array}{l}\text { Program 2.4. Support } \\
\text { the creation of a } \\
\text { favorable environment } \\
\text { for agriculture sector } \\
\text { development }\end{array}$ & 9 & 1,708 & 9 & 966 & 9 & 906 & 0 & 1,197 & 0 & 1,197 & 27 & 5,974 \\
\hline $\begin{array}{l}\text { Program } 2.5 \text {. Restore } \\
\text { agricultural and } \\
\text { agrofood production }\end{array}$ & 0 & 2,569 & 0 & 2,758 & 0 & 2,769 & 0 & 33 & 0 & 95 & 0 & 8,224 \\
\hline $\begin{array}{l}\text { Program 2.6. Protect } \\
\text { livestock against } \\
\text { exotic infectious } \\
\text { diseases and intensify } \\
\text { animal production } \\
\text { sectors }\end{array}$ & 0 & 993 & 0 & 1,307 & 0 & 2,072 & 0 & 2,560 & 0 & 3,127 & 0 & 9,781 \\
\hline
\end{tabular}




\begin{tabular}{|c|c|c|c|c|c|c|c|c|c|c|c|c|}
\hline $\begin{array}{l}\text { Program 2.7. Create a } \\
\text { favorable environment } \\
\text { for balanced sectoral } \\
\text { development }\end{array}$ & 22 & 108 & 0 & 44 & 3 & 47 & 8 & 42 & 12 & 68 & 45 & 309 \\
\hline $\begin{array}{l}\text { Program } 2.8 \text {. Develop } \\
\text { the conservation, } \\
\text { processing, and } \\
\text { marketing system for } \\
\text { fish products }\end{array}$ & 113 & 2,862 & 100 & 2,037 & 100 & 3,622 & 115 & 4,446 & 85 & 5,331 & 513 & 18,298 \\
\hline $\begin{array}{l}\text { Program 2.9. Support } \\
\text { tourism development }\end{array}$ & 0 & 1,570 & 0 & 1,415 & 0 & 1,360 & 0 & 980 & 0 & 700 & 0 & 6,025 \\
\hline Total Core Strategy 2 & 282 & 12,338 & 160 & 9,901 & 143 & $\mathbf{1 1 , 8 9 8}$ & 124 & 10,608 & 98 & 10,573 & 802 & 55,025 \\
\hline
\end{tabular}




\subsection{CORE STRATEGY III. STRENGTHEN GOVERNANCE AND SOCIAL COHESION}

The budget for the period 2010-2014 amounts to CF 21.7 billion, of which CF 14.8 is required.

Table 6.5. Budget for Core Strategy 3 by program for the period 2010-2014 (millions of CF)

2010

2011

2012

2013
2014

2010-2014

Grand total

Programs

Program 1. Promote social

Acq. $\quad$ Req. $\quad$ Acq.

Req. $\quad$ Acq. $\quad$ Req. $\quad$ Acq.

$\begin{array}{rrrrr}\text { Req. } & \text { Acq. } & \text { Req. } & \text { Acq. } & \text { Req. } \\ 865 & 180 & 635 & 2,247 & 4,857\end{array}$

cohesion, solidarity, and

consolidation of peace

\section{Program 2 Promote}

1,081

688

469

700

334

507

114

377

10

2,008

2,282

and enhance fiscal

transparency

Program 3. Strengthen the

institution

Program 4. Fight terrorism

$0 \quad 1,475$

945

0

765

360

195

285

115

645

3,495

and transverse crime and

strengthen civilian security

Total Core Strategy 3

475

1,030

6,560 


\subsection{CORE STRATEGY IV: IMPROVE THE HEALTH STATUS OF THE GENERAL PUBLIC}

The budget by program for the period 2010-2014 amounts to CF 70.6 billion, CF 62.2 of which is required.

Table 6.6. Budget for Core Strategy 4 by program for the period 2010-2014 (millions de CF)

\begin{tabular}{|c|c|c|c|c|c|c|c|c|c|c|c|c|}
\hline \multirow[t]{2}{*}{ Programs } & \multicolumn{2}{|c|}{2010} & \multicolumn{2}{|c|}{2011} & \multicolumn{2}{|c|}{2012} & \multicolumn{2}{|c|}{2013} & \multicolumn{2}{|c|}{2014} & \multicolumn{2}{|c|}{$\begin{array}{c}2010-2014 \\
\text { Grand total }\end{array}$} \\
\hline & Acq. & Req. & Acq. & Req. & Acq. & Req. & Acq. & Req. & Acq. & Req. & Acq. & Req. \\
\hline $\begin{array}{l}\text { Program 4.1. Fight } \\
\text { malaria and } \\
\text { priority diseases }\end{array}$ & 1,407 & 2,200 & 626 & 2,435 & 659 & 2,347 & 1,670 & 2,064 & 764 & 2,166 & 5,126 & 11,211 \\
\hline $\begin{array}{l}\text { Program } 4.2 \text {. } \\
\text { Integrated sexual } \\
\text { and reproductive } \\
\text { health } \\
\text { development }\end{array}$ & 2 & 878 & 2 & 1,453 & 2 & 1,293 & 0 & 1,308 & 0 & 1,313 & 6 & 6,245 \\
\hline $\begin{array}{l}\text { Program 4.3. Fight } \\
\text { HIV/AIDS and } \\
\text { sexually- } \\
\text { transmissible } \\
\text { infections }\end{array}$ & 20 & 88 & 20 & 108 & 20 & 216 & 20 & 135 & 20 & 149 & 100 & 696 \\
\hline $\begin{array}{l}\text { Program } 4.4 . \\
\text { Strengthen the } \\
\text { efficacy of all } \\
\text { aspects of the } \\
\text { health system }\end{array}$ & 3,122 & 6,657 & 53 & 9,378 & 0 & 8,594 & 0 & 9,539 & 0 & 9,915 & 3,174 & 44,083 \\
\hline $\begin{array}{l}\text { Total Core } \\
\text { Strategy } 4\end{array}$ & 4,550 & 9,822 & 701 & 13,374 & 681 & 12,450 & 1,690 & 13,045 & 784 & 13,543 & 8,406 & 62,234 \\
\hline
\end{tabular}




\subsection{CORE STRATEgY V: Promote EDUCATION AND VOCATIONAL TRAINING WiTH THE AIM OF DEVELOPING HUMAN CAPITAL}

The budget by program for Core Strategy 5 the period 2010-2014 amounts to CF 32.8 billion, CF 4 billion of which is required.

Table 6.7. Budget for Core Strategy 5 by program for the period 2010-2014 (millions de CF)

\begin{tabular}{|c|c|c|c|c|c|c|c|c|c|c|c|c|}
\hline \multirow[t]{2}{*}{ Programs } & \multicolumn{2}{|c|}{2010} & \multicolumn{2}{|c|}{2011} & \multicolumn{2}{|c|}{2012} & \multicolumn{2}{|c|}{2013} & \multicolumn{2}{|c|}{2014} & \multicolumn{2}{|c|}{$\begin{array}{c}2010-2014 \\
\text { Grand total }\end{array}$} \\
\hline & Acq. & Req. & Acq. & Req. & Acq. & Req. & Acq. & Req. & Acq. & Req. & Acq. & Req. \\
\hline $\begin{array}{l}\text { Priority Program } 1 . \\
\text { Develop education, } \\
\text { technical instruction, } \\
\text { and occupational } \\
\text { training to reflect job } \\
\text { market requirements }\end{array}$ & 458 & 72 & 609 & 124 & 773 & 228 & 878 & 435 & 0 & 1,853 & 2,718 & 2,711 \\
\hline $\begin{array}{l}\text { Priority Program } 2 . \\
\text { Improve access to } \\
\text { quality basic (preschool } \\
\text { and elementary school) } \\
\text { and secondary } \\
\text { education }\end{array}$ & 538 & 3,174 & 690 & 3,560 & 5 & 4,654 & 0 & 3,871 & 26 & 3,987 & 1,258 & 19,246 \\
\hline $\begin{array}{l}\text { Priority Program } 3 . \\
\text { Develop competent } \\
\text { human resources and } \\
\text { the sectoral (SWAP) } \\
\text { program in education }\end{array}$ & 17 & 241 & 12 & 571 & 17 & 782 & 0 & 1,006 & 0 & 1,223 & 45 & 3,822 \\
\hline $\begin{array}{l}\text { Priority Program } 4 . \\
\text { Promote literacy, sports, } \\
\text { and cultural activities }\end{array}$ & 0 & 343 & 0 & 518 & 0 & 625 & 0 & 0713 & 0 & 790 & 0 & 2,989 \\
\hline Total Core Strategy 5 & 1,012 & 3,829 & 1,311 & 4,772 & 795 & 6,289 & 878 & 6,024 & 26 & 7,854 & 4,020 & 28,768 \\
\hline
\end{tabular}




\subsection{Core Strategy VI: Promote enVironmental SUStainabiLity AND CIVILIAN SECURITY}

The budget by program for the period 2010-2014 amounts to CF 28 billion, CF 23 billion of which is required.

Table 6.8. Budget for Core Strategy 6 by program for the period 2010-2014 (millions de CF)

\begin{tabular}{|c|c|c|c|c|c|c|c|c|c|c|c|c|}
\hline \multirow[t]{2}{*}{ Programs } & \multicolumn{2}{|c|}{2010} & \multicolumn{2}{|c|}{2011} & \multicolumn{2}{|c|}{2012} & \multicolumn{2}{|c|}{2013} & \multicolumn{2}{|c|}{2014} & \multicolumn{2}{|c|}{$\begin{array}{c}2010-2014 \\
\text { Grand total }\end{array}$} \\
\hline & Acq. & Req. & Acq. & Req. & Acq. & Req. & Acq. & Req. & Acq. & Req. & Acq. & Req. \\
\hline $\begin{array}{l}\text { Program 6.1. Conserve } \\
\text { biodiversity and } \\
\text { equitably share its } \\
\text { advantages }\end{array}$ & 156 & 317 & 10 & 322 & 10 & 300 & 8 & 250 & 8 & 200 & 192 & 1,535 \\
\hline $\begin{array}{l}\text { Program } 6.2 \text {. Conserve } \\
\text { and upgrade agro- } \\
\text { biodiversity }\end{array}$ & 0 & 1,200 & 0 & 1,230 & 0 & 1,100 & 0 & 1,010 & 0 & 700 & 0 & 5,240 \\
\hline $\begin{array}{l}\text { Program } 6.3 \text {. Adapt to } \\
\text { climate change }\end{array}$ & 1,012 & 3,200 & 810 & 2,200 & 630 & 2,500 & 430 & 1,500 & 430 & 1,100 & 3,312 & 10,500 \\
\hline $\begin{array}{l}\text { Program 6.4. Fiscal } \\
\text { rehabilitation with an } \\
\text { ecological approach }\end{array}$ & 260 & 850 & 260 & 950 & 260 & 950 & 260 & 850 & 260 & 750 & 1,300 & 4,350 \\
\hline $\begin{array}{l}\text { Program } 6.5 \text {. Capacity } \\
\text { building for multisector } \\
\text { environmental } \\
\text { management and } \\
\text { coordination }\end{array}$ & 0 & 293 & 0 & 272 & 0 & 225 & 0 & 195 & 0 & 195 & 0 & 1,180 \\
\hline $\begin{array}{l}\text { Program 6.6. Implement } \\
\text { a preparation, response, } \\
\text { and management } \\
\text { systems for natural and } \\
\text { climate risks and } \\
\text { disasters }\end{array}$ & 117 & 35 & 92 & 35 & 0 & 54 & 0 & 54 & 0 & 47 & 209 & 225 \\
\hline Total, Core Strategy 6 & 1,545 & 5,895 & 1,172 & 5,009 & 900 & 5,129 & 698 & 3,859 & 698 & 2,992 & 5,013 & 23,030 \\
\hline
\end{tabular}

The financial resources required from 2015 will be determined to reflect progress in priority programs and in the overall strategy. Based on these assessments, a new program for the period 2015-2019 should be developed to reflect achievements. 


\section{CHAPTER VII}

PRGS MONITORING AND EVALUATION FRAMEWORK 


\subsection{CONTEXT}

The poverty reduction and growth strategy (PRGS) 2010-2014 aims to reach several objectivesspecifically robust, sustained economic growth, a sustainable reduction in monetary poverty, and improved living conditions and socioeconomic well-being for households. The degree to which these goals are reached will be measured using a monitoring and evaluation system. This system is an essential component in PRGS implementation. Data collection, processing, and analysis; and the periodic drafting of progress and performance reports are essential components in monitoring and evaluation of performance in connection with the policies and programs implemented under the PRGS, to assist in its steering, and in the decision-making process.

Unfortunately, the interim PRGS monitoring and evaluation mechanism did not function as expected for a number of reasons. We should bear in mind the specific sociopolitical situation that has been present in the country for the past three years, that prevented major progress in PRGS implementation and in applying the monitoring and evaluation system. Other factors have also distorted the use of the system. Among other factors, we observe a lack of central coordination for the system, an absence of resources to enable the organizations involved to conduct proper monitoring and evaluation activities, insufficient qualified personnel possessing the required specialized skills, and an absence of technical tools that would have made it possible to implement the system. In addition, the expectations of the users and decision-makers concerning PRGS monitoring and evaluation were insufficiently clear.

The government acknowledges the failings of the interim PRGS monitoring system and intends make changes so that it can operate more effectively. There are plans in connection with PRGS implementation to build institutional capacities in this system and to rehabilitate the system used to collect and analyze the sectoral data and those describing household living conditions, in particular. Efforts will also be made to enhance accountability of the decentralized units through support to the Sectoral Technical Groups (GTS) and the Committees for Development Planning, Monitoring, and Evaluation (COPSED). There are plans, in particular, to build institutional capacities in operational planning and monitoring of program and project execution, and to ensure these processes are implemented with appropriate accompanying measures.

The government also intends to strengthen the National Statistics Directorate so that it can more effectively coordinate the program of surveys required for PRGS monitoring and evaluation. At the institutional level, it will also be important to involve the decentralized units of the island planning ministries and civil society in monitoring activities, to enhance public ownership of the PRGS, and the participative process, and thus to improve the quality of services and the efficacy of policy and program implementation.

The adopted technical and institutional system is simple and reflects the country's geographic and institutional context. It takes due account of the government's limited human and financial capacities and optimizes use of the existing structures already involved in PRGS implementation whenever possible. 


\subsection{PRINCIPLES AND OBJECTIVES OF THE MONITORING AND EVALUATION SYSTEM}

Implementation of the monitoring and evaluation system will rely on a combination of qualitative and quantitative methods, and views according to each discipline to reflect the multidimensional nature of living conditions and poverty. Cross-cutting issues such as gender and human rights, trade, access to modern information and production technologies, and MDG attainment will be systematically considered in the monitoring and evaluation methodologies and activities.

The approach will be as participative and inclusive as possible.

The PRGS monitoring and evaluation system is governed by the following six principles:

1. Consolidation of existing progress;

2. Promotion of the participative approach and national ownership;

3. Gradual adoption of the results-based management approach at the national and sectoral levels;

4. Accountability of the technical ministries and islands in the execution and monitoring of different priority programs in their respective areas of authority;

5. New impetus for and strengthening of the statistical system at the central, sectoral, and decentralized levels;

6. Involvement of civil society in the monitoring and evaluation process.

The system should be gradually implemented to reflect resource and capacity constraints, with institutional and human capacity building activities, and intermediate outputs at each stage. Rather than implement a complex superstructure involving many changing structures that would risk burdening the start of the system with discussions on authority sharing and significant financing requirements, it was decided to begin with a pragmatic approach, commencing with rapid actions designed to produce results in the short term that decision makers and users of the system would consider to be useful. The system will then be expanded and enhanced through the gradual development of strategic partnerships between the structures involved.

The PRGS monitoring and evaluation system is designed to provide data and analyses meeting the following characteristics:

1. Relevant in PRGS monitoring and useful in decision making. To that end, it will be essential to coordinate effectively the players involved and the various operations to collect, analyze and disseminate the data, and in the preparation of progress and performance reports;

2. Representative of and faithful to the islands and socioeconomic sectors. It will be important to ensure that data collection and processing tools are rigorously applied and to conduct disaggregated analyses useful in decision making; 
3. Regular, useful, and timely. Effective coordination of the system will be essential to observe schedules for collection, analysis, production of reports, and dissemination of the information to users.

The monitoring and evaluation system will contribute to:

1. Reduce data duplications to save substantial financial, human, and material resources and to reduce confusion when different values are registered for the same indicator;

2. Make the data and analyses available to all users, requiring an effective information management system and communication strategy. An integrated information management system must be implemented gradually for effective public management of programs and adequate monitoring

\subsection{INSTITUTIONAL FRAMEWORK FOR MONITORING AND EVALUATION}

The institutional framework adopted for the implementation of the PRGS monitoring and evaluation system is based on seven structures and involves the sectoral ministries and institutions participating in the implementation of development programs and projects.

1. Interministerial Monitoring and Coordination Committee;

2. Strategic Committee for Coordination of Development Assistance;

3. PRGS Technical Steering Committee (Office of the General Commissioner for Planning);

4. Permanent Technical Secretariat for PRGS Monitoring and Evaluation;

5. National Statistics Directorate, decentralized agencies of the Ministry of Planning in the three islands;

6. Sectoral Technical Groups;

7. Committees for Development Planning and Monitoring and Evaluation (COPSED) in the three islands.

The institutional framework of this scheme is illustrated in Figure 7.1. below. 


\section{Figure 7.1. Institutional framework for PRGS monitoring and evaluation}

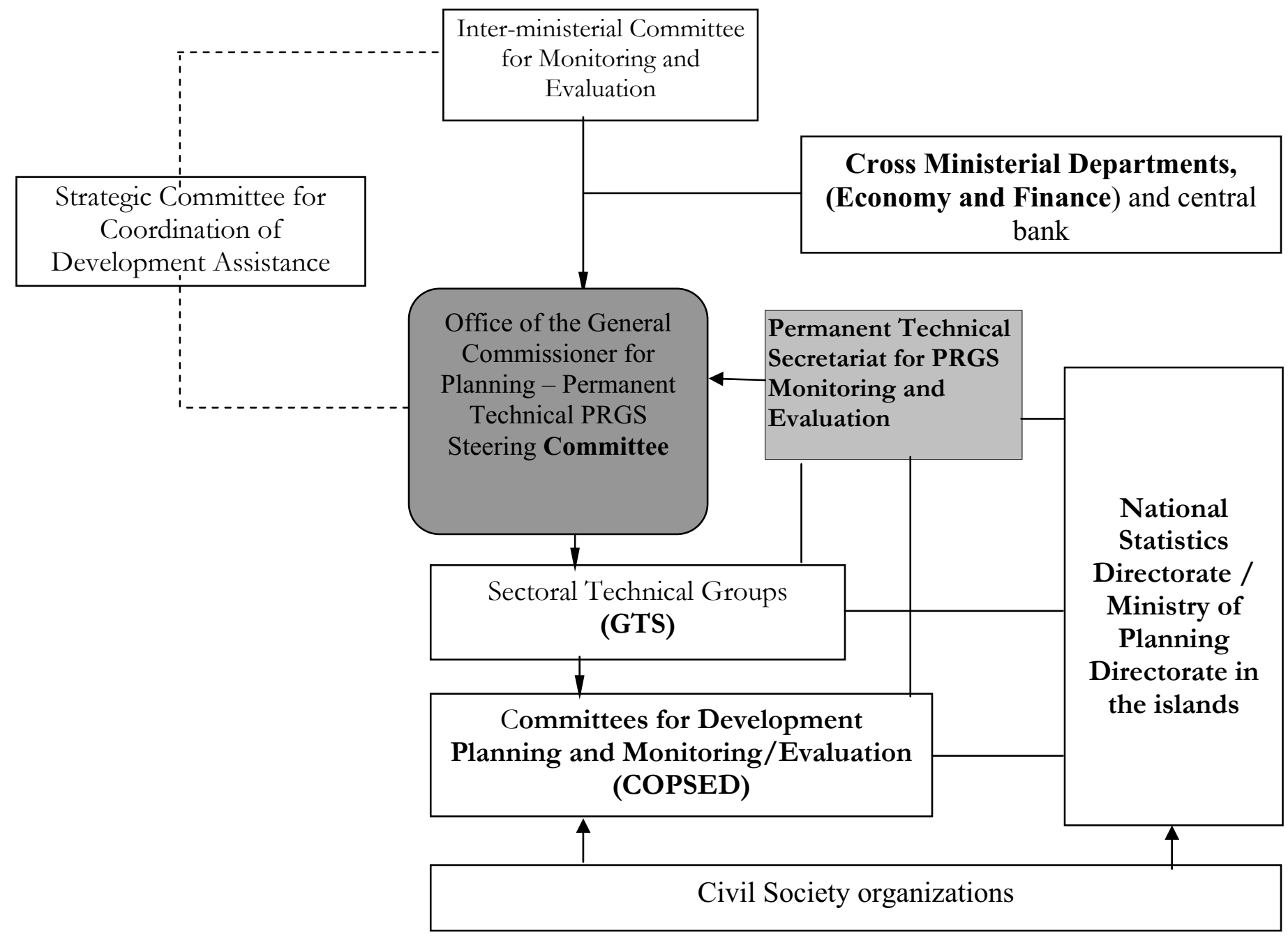


The Interministerial Committee on Monitoring and Coordination is the government body responsible for policy decisions and dialog with the development partners. The Committee will coordinate organization of ad hoc meetings too keep abreast of PRGS implementation progress. The Committee is responsible for making the necessary decisions to improve coordination and efficacy in the scheme for implementing development policies, programs, and projects in connection with the PRGS. The Interministerial Committee for Monitoring and Coordination is chaired by the Secretary-General of the government. It is comprised of all members of the Council of Ministers and its secretariat is covered by the Office of the General Commissioner for Planning, which chairs the Technical PRGS Steering Committee and oversees the monitoring and evaluation system.

The Interministerial Committee for Monitoring and Coordination will work closely with the Strategic Committee for Coordination of Development Assistance, which is responsible for effective coordination and optimization of development aid in the Comoros. When required, the Committee may ask the PRGS Steering Secretariat to report on the status of the PRGS or certain programs or projects. The Strategic Committee on Coordination of Development Assistance is chaired by the head of state. It is comprised of members of the Extraordinary Council of Ministers and representatives from the technical and financial partners. The Office of the General Commissioner for Planning provides the secretariat.

The PRGS Technical Steering Committee is responsible for supervising, coordinating, and steering PRGS monitoring and evaluation. This Committee is at heart of the monitoring and evaluation system. It is supported by the Permanent Secretariat for PRGS Monitoring and Evaluation, which works closely with the Committee and covers its secretariat functions. It ensures that the monitoring and evaluation system is functioning adequately and that the monitoring and reporting timetables are being observed.

The Office of the General Commissioner for Planning, through the Steering Committee and the Permanent PRGS Monitoring and Evaluation Secretariat, is responsible for reporting on PRGS progress to the Interministerial Committee on Monitoring and Coordination. It will also be responsible for reporting to the Strategic Committee on Coordination of Development Assistance on execution of priority programs and projects implemented in the PRGS framework.

More specifically, the PRGS Technical Steering Secretariat has the following responsibilities:

1. To coordinate the PRGS monitoring and evaluation system and implementation;

2. To ensure that the adopted performance indicators are consistent with the PRGS core strategies and MDGs, and that they are useful in assessing progress in the area of growth and poverty reduction;

3. To propose a working program to monitor changes in living conditions and poverty, coordinate studies on the causes of poverty and impact assessments for certain operations that have been implemented;

4. To coordinate and contribute to the preparation of annual reports on the progress of PRSP implementation; 
5. To execute and coordinate execution of topical studies in connection with the PRGS and reflecting the requirements of decision makers and monitoring and evaluation system users.

This committee will also be responsible for disseminating the results of studies and progress reports prepared by the players in the PRGS monitoring and evaluation system. These activities include publication of studies and progress reports, organization of workshops to present the results to decision makers, dissemination of information to the players from civil society and the public at large, and in general the development of a communication network with the sectoral ministries and island representatives.

The PRGS Technical Steering Committee is comprised of members of the Strategic Committee for Coordination of Development Assistance instituted under Decree 09 062/PR, plus all ministry secretaries-general and island planning directors. The PRGS Steering Committee is chaired by the General Commissioner for Planning.

The Permanent Technical Secretariat for PRGS Monitoring and Evaluation will work closely with the Sectoral Technical Groups that are responsible for planning, implementation, and management of programs and projects, monitoring of program and project execution, and collection of sectoral data. These are the mainstays for the overall institutional framework and oversee day-to-day PRGS implementation. The Secretariat is responsible for preparing the annual strategy implementation report, and in this capacity, it works with the Sectoral technical Groups, which play a central role in preparing annual performance reports for programs and projects. These activities will entail close cooperation with the island Development Planning and Monitoring/Evaluation Committees, coordinated by the Technical Steering Secretariat and the PRGS Monitoring and Evaluation Committee.

The Sectoral Technical Groups (GTS) of the sectoral ministries produce important information in PRGS monitoring and evaluation. They contribute, in particular, to the monitoring of priority program execution by providing information on the status of programs and projects. Against this backdrop, implementation of Medium-Term Sectoral Expenditure Frameworks (CDS-MT) and preparation of the Annual Working Plan (PTA) will be used as an operational basis for implementation and monitoring of PRGS priority program execution. This technical system will enable the ministries to analyze the degree to which the results of their programs have been achieved on an annual basis, depending on the resources that have been allocated to them. The establishment of program budgets will facilitate monitoring of priority program execution through a results-based management approach.

The Sectoral Technical Groups are chaired by the secretaries-general of the sectoral ministries and are comprised of technical staff of the ministries and technical and financial partners. They will participate in implementation of sectoral strategies and approaches and on monitoring sector financing, under the terms of Presidential Decree 09 062/PR in respect of the implementation of the institutional system for the coordination of assistance.

The Committees for Development Planning and Monitoring and Evaluation (COPSED) produce fundamental information for PRGS monitoring and evaluation at the island level. They work closely with the GTS on planning, implementation, and monitoring and evaluation of 
development programs and projects. The COPSEDs work directly with the beneficiaries and are therefore front-line structures in the monitoring and evaluation system. They will participate actively in the system activities for their respective islands.

The National Statistics Directorate is the agency responsible for statistical data collection and analysis. In the framework of the PRSP monitoring and evaluation system, the National Statistics Directorate will be responsible for coordination of the collection system in close collaboration with the decentralized units of the Ministry of Planning in the islands, through the implementation of the National Strategy for Statistical Development (SNDS). Accordingly, it will be responsible for conducting and supervising national data collection activities, producing various reports on the country's socioeconomic development and household living conditions, and contributing to progress and performance reports in connection with the agencies involved in PRGS monitoring and evaluation activities.

The National Statistics Directorate will be supported by the Statistics Services of the decentralized Ministry of Planning units in the islands. These structures will be technically strengthened to play a key role in the field data collection system.

The National Statistics Directorate will discharge its duties to carry out major national surveys, and specifically the census, the Health and Demographic Survey (enquête Démographie et Santé-DHS), and the comprehensive household survey (enquête intégrée auprès des ménages-EIM). It should also work closely with the Permanent Secretariat for PRGS Monitoring and Evaluation to serve as lead manager in the following activities:

1. To identify users' information requirements for the monitoring and evaluation system and indicators for which information is required;

2. To collect and format the secondary data required for PRGS monitoring;

3. To conduct surveys on household living conditions;

4. To analyze the data on household living conditions and poverty;

5. To participate in conducting ad hoc surveys in connection with PRGS program and project monitoring and evaluation.

Among the other partners in the system, the Ministry of Finance/Budget Directorate, the Ministry of Economy, and the central bank will also play a key role in the PRGS monitoring and evaluation system by producing studies and information on the economy, government revenue and expenditure, and on macroeconomic and financial indicators. These data will be used in connection with PRGS monitoring and evaluation to assess the economy's overall and sectoral performance. The relevant services of the ministries will be involved in drafting certain sections of the annual PRGS progress report.

Last, civil society will participate in the monitoring and evaluation system at several levels. First, as a direct beneficiary of development programs and projects, it will provide assessments on the services received. Accordingly, it will participate in the various surveys in connection with PRGS 
monitoring and evaluation by providing important information in assessing results and future requirements. It will subsequently participate directly in monitoring and evaluation activities, and specifically in the organization, promotion, and reporting of public perceptions of the programs and projects that have been implemented. Last, civil society will participate in awareness meetings on results and conclusions of the reports produced by players in the system. The lessons will be shared with civil society, along with recommendations to make the projects implemented more efficient and effective.

\subsection{FEATURES OF THE MONITORING AND EVALUATION SYSTEM}

The monitoring and evaluation system is designed to produce information useful in decision making. It includes three complementary components:

1. Monitoring of selected PRGS performance indicators;

2. Monitoring of the execution of programs and projects to be implemented in the PRGS framework;

3. Evaluation of policies and programs implemented in the PRGS framework.

\section{- Monitoring of performance indicators}

The first component entails the assessment of changes in the population's living conditions and the performance of the Comorian economy, through the measurement of selected performance indicators (effects and impacts). This approach will essentially involve annual or biennial monitoring and measurement of the performance indicators presented in Annex I to this paper, which will provide the information and data required to prepare an annual PRGS progress report.

This component consists in organizing and supervising activities to monitor poverty, household living conditions, and the economic and social situation in general. The aim is systematic production of baseline indicators for each priority area identified in the PRGS. This component will in particular provide data on: (i) trends in poverty; (ii) overall economic and sectoral growth and the macroeconomic framework; (iii) infrastructure development; (iv) private sector development; (v) social sector (education, health, and social security); and (vi) governance.

\section{- Monitoring of PRGS priority program execution}

The second component will monitor execution of programs and projects implemented in connection with the PRGS. This component will monitor the use of financial resources and the attainment of the annual results targets established by the agencies involved in the implementation of their respective annual working plans.

Each sector responsible for program and project implementation will be required to produce an annual performance report establishing the linkages between the use of the resources obtained and the results achieved, as compared with the targets envisaged for the period. These reports will be used as benchmark documents in producing the annual PRGS progress report. 
Execution monitoring involves collection and analysis information on finance, use of resources, and indicators on the process, activities, outputs, and effects of the programs and projects. The annual program and project performance reports will more specifically cover:

1. Measurement of performance in the area of financial management (input indicators);

2. Measurement of institutional performance and governance in management of processes and execution of activities according to the adopted timetables and budgets (process and activity indicators);

3. Measurement and monitoring of performance in accordance with the adopted targets to determine any discrepancies between projections and performance (output indicators);

4. Measurement of perceptions, satisfaction, and use of services by the target populations (effect indicators). Surveys of beneficiaries will be an important factor in the monitoring and evaluation system. They will provide users' assessments of the services made available to them by the administrative agencies, project supervisors, and public enterprises.

This information will be used to analyze discrepancies between the forecasts and physical and budget outputs in execution of priority program and activities, so that recommendations can be made for adjustments in execution of operations or programs, or budgets reallocated to optimize the efforts to reach the adopted objectives.

\section{- Policy analysis and program and project evaluation}

The third component involves policy, program, and project evaluation. Such evaluations will be carried out on an ad hoc basis to reflect the requirements of decision makers and the availability of resources. This component may include ex ante assessments of potential projects, midterm and completion evaluations, and ex post impact assessments. The latter will aim to measure the impact of a given program or policy on socioeconomic players or on the target populations.

The evaluations will be based on administrative data and the data from surveys collected by the sectoral departments, from specific surveys of target groups, and primary data collected in connection with household surveys conducted by the National Statistics Directorate.

The assessments will aim to measure the effects of policies, programs, and projects on the target groups and on the PRGS development goals (growth, poverty, and social development). The evaluations will be used to establish linkages between program and project execution and the results on the development and well-being of the target groups. Evaluation studies should be programmed according to the effective implementation timetables of the sector projects and programs, and the decision makers' requirements, so that sectoral programs and strategies and those under the PRGS can be revised accordingly.

They will also be used to assess the efficacy of priority programs in light of the long-term objectives defined in the PRGS. The Permanent Technical Secretariat for PRGS Monitoring and Evaluation will essentially identify and select relevant problem scenarios for analysis, identify service providers, which may be internal or external players under programs and projects 
(research centers, consulting firms, consultants, etc.), allocate resources, and supervise execution, dissemination of studies, and use the results to improve policies, programs, and strategies for intervention.

The monitoring and evaluation system will provide decision makers with relevant information and PRGS progress reports on an annual basis; annual performance reports on programs and projects implemented by the agencies involved, and satisfaction reports, in which the target groups assess the services offered under the programs and projects implemented. The system will use the results of the assessments to provide ad hoc comprehensive analyses.

\subsection{Progress RePORTS AND OUTPUT TIMETABLE}

The progress report on PRGS implementation constitutes the synthetic document for all outputs from the PRGS monitoring and evaluation system. It will be prepared with a participative approach, on an annual basis. The Office of the General Commissioner for Planning will coordinate the efforts to prepare the report, which will include the following components:

A summary of cyclical factors, recent developments, and achievements in PRGS implementation structured by PRGS core strategy, and a summary of action plan execution;

This synthetic document will also use performance reports on priority program implementation. These reports will analyze the execution of programs and projects. It should be an administrative duty of the ministries involved to prepare these reports on an annual basis.

A statistical annex should be used to consolidate the information, specifically covering living conditions and poverty, economic growth, the macro framework, infrastructure, private sector, social sector (health, education, and social security), and governance. This annex is the key output for monitoring the performance indicators.

An annex involving programs and projects will present a summary of the annual working plans organized by sector.

To comply with the report production timetable, the system should maintain, supply, and centralize information on: (i) the indicators in Annex 1; and (ii) technical and financial execution of programs and projects.

The various monitoring and assessment reports and studies can be archived at a website to facilitate dissemination and consultation by users. It is important to ensure that the monitoring and evaluation system outputs are highly visible. Other output communication channels will be envisaged to ensure that the results gain proper support and to promote the exchange of good practices.

\subsection{IMPLICATIONS FOR THE NATIONAL STRATEGY ON STATISTICAL DEVELOPMENT}

Monitoring and evaluation of the activities incorporated into the core strategies requires a critical mass of information, which means that the national statistics system should be strengthened. Against this backdrop, implementation of the national statistics development strategy provides an 
opportunity to ensure that the monitoring and evaluation system is operating effectively. Implementation of this strategy in fact aims to meet the requirements of statistics users by developing key areas in data collection, investing in the basic infrastructure for effective information collection and management, building analytical capacities, strengthening data dissemination, and enhancing coordination with the other components of the system. All of these factors will make it possible to consolidate the monitoring and evaluation system.

\subsection{IMPLICATIONS ON CAPACITY BUILDING}

The multiple challenges related to the national statistical information management system and the innovations embodied in the establishment of the information system for monitoring and evaluation focusing on poverty reduction and participative development management bring to light a number of areas where support is required for the implementation and monitoring and evaluation system to operate effectively.

The players in the system should have collection and analysis tools and standard guides to assist them in preparing the various progress and performance reports. A precise production timetable for producing the various reports must be prepared and observed by all parties involved.

All players in the national system for planning, program management, and monitoring and evaluation activities should benefit from capacity building and accompaniment in the implementation of monitoring and evaluation tools. The quality and relevance of monitoring and evaluation rely largely on efforts to be made upstream to strengthen the national planning system, particularly in the civil society sectors and agencies involved in program and project implementation. It will, in fact, be difficult to implement an effective monitoring and evaluation system if the precepts for operational planning of programs and projects are not observed. This effort primarily entails an understanding of the tools as the logical framework, the capacity to define and document the relevant performance indicators, to design budgets and establish realistic timetables, to prepare contracting plans and manage the government contracting cycle, to oversee program and project implementation, and to implement rigorous controls, audits, etc. It will therefore be important to provide a capacity building program for PRGS implementation, monitoring, and evaluation, covering the overall cycle of programming, implementation, and monitoring and evaluation of policies, programs, and projects, targeting the players involved.

At the institutional level, the problems observed during the interim phase must be corrected to promote effective circulation of information between the stakeholders, to improve the operation of cooperation and steering structures, and prepare precise specifications for all agencies involved in PRGS monitoring and evaluation.

\subsection{IMPLICATIONS ON EFFICACY AND HARMONIZATION OF OFFICIAL DEVELOPMENT ASSISTANCE}

The PRGSP is a reference document to steer the process of development and the operations of all technical and financial partners in respect of the national priorities. A prior survey of all technical and financial partners was conducted. The numerous consultations between the government and the technical and financial partners brought to light the importance of continuing the mutual coordination efforts to ensure that assistance is more effective. 
The 2010-2014 action plan, which will be used in PRGS implementation, will be validated jointly by the government and the technical and financial partners. Through this action plan, the government intends to: (i) strengthen assistance coordination based on the national priorities and affirm its leadership; (ii) enhance transparency, efficacy, and responsibility in the management of resources allocated to development; (iii) consolidate program approaches and common assistance implementation mechanisms; and (iv) harmonize management of the technical partners' missions and analytical activities to reduce the relevant costs.

The government will also endeavor to strengthen the dialog with the technical and financial partners through the consolidation of joint sectoral technical groups based on the priorities defined in the PRGS. The following will be organized in this connection: (i) joint annual sectoral reviews; and (ii) a joint annual PRGS review. The government intends for these reviews to be conducted within the first half of each year so that the recommendations can be taken into account in preparing the program budgets and the general state budget. 


\section{CONCLUSION}

The poverty reduction and growth strategy (PRGS) is the new unifying framework for all sectoral strategies and constitutes the reference document for the government's interventions during the period 2010-2014. The PRGS was prepared and validated with the participation of all sectors of Comorian society.

The success of this strategy will depend largely on the government's capacity to ensure that it gains support from the various players involved. This will require:

- $\quad$ Effective support for the content of the strategy from the agencies responsible for its implementation, the central and island governments, and from the local governments;

- $\quad$ Sustained efforts by the government to mobilize and effectively use resources, as a priority, for effective implementation of priority programs;

- Institutional and human capacity building at all levels (central and island) to ensure effective PRGS monitoring and assessment;

- Greater harmonization of assistance from the technical and financial partners in accordance with the Paris Declaration.

To minimize the risks, the government intends to strengthen the steering mechanism and institute a coordination mechanism involving all players. This institutional mechanism will include the implementation of a powerful monitoring and evaluation system, responsible for monitoring progress achieved and proposing any corrective measures that may be required.

To make the PRGS operational, the Government will prepare an action plan for PRGS implementation. This action plan will make it possible to specify in the medium term the priority programs and investments that will help accelerate growth and lead to sustainable poverty reduction. This action plan will provide the linkages between the PRGS, sectoral strategies, and the resources required to reach the established objectives. 


\section{ANNEX 1}

Performance IndicAtors For PRGS MONITORING 
Table A1. PRGSP performance indicators and targets - 2010-2014

\begin{tabular}{|c|c|c|c|c|c|c|c|c|}
\hline \multirow[b]{2}{*}{ PRGSP performance indicators } & \multirow{2}{*}{$\begin{array}{l}\text { Bench- } \\
\text { mark } \\
\text { value }\end{array}$} & \multirow[b]{2}{*}{ Unit } & \multirow{2}{*}{$\begin{array}{l}\text { Bench- } \\
\text { mark } \\
\text { year }\end{array}$} & \multicolumn{5}{|c|}{ Targets } \\
\hline & & & & $\begin{array}{l}20 \\
10\end{array}$ & $\begin{array}{l}20 \\
11\end{array}$ & $\begin{array}{l}20 \\
12\end{array}$ & $\begin{array}{l}20 \\
13\end{array}$ & $\begin{array}{l}20 \\
14\end{array}$ \\
\hline \multicolumn{9}{|l|}{ Real growth rate } \\
\hline - GDP & 0.8 & $\%$ & 2007 & 2.5 & 3.6 & 4.4 & 5.5 & 5.8 \\
\hline $\begin{array}{l}\text { - Agricultural, fishing, and } \\
\text { stockbreeding sector }\end{array}$ & 4.0 & $\%$ & 2007 & 6.8 & 9.2 & 10.2 & 11.3 & 11.3 \\
\hline - Tourism sector & 5.2 & $\%$ & 2007 & 3.1 & 3.1 & 3.1 & 3.1 & 3.1 \\
\hline Outstanding external debt & 2,041 & $\begin{array}{r}\text { Milli } \\
\text { ons } \\
\text { of } \\
\mathrm{CF}\end{array}$ & 2008 & 2204 & 2094 & 5691 & 6364 & \\
\hline External debt services & 706 & $\begin{array}{r}\text { Milli } \\
\text { ons } \\
\text { of } \\
\text { CF }\end{array}$ & 2008 & 659 & 634 & 608 & 575 & \\
\hline Annual growth rate, tax revenue & $\begin{array}{l}\text { CF } 22 \\
\text { billion }\end{array}$ & $\%$ & 2008 & 5 & 5 & 4 & 3 & 3 \\
\hline Annual rate of increase, exports & & $\%$ & & 3 & 6 & 9 & 10 & 10 \\
\hline Electrification rate & 40 & $\%$ & 2005 & 50 & 60 & 70 & 85 & 90 \\
\hline $\begin{array}{l}\text { Proportion of disenclosed } \\
\text { villages }\end{array}$ & 70 & $\%$ & & 75 & 80 & 85 & 90 & 95 \\
\hline Private investment growth rate & 12 & $\%$ & & 15 & 17 & 18 & 20 & 25 \\
\hline $\begin{array}{l}\text { Annual agricultural investment } \\
\text { growth rate }\end{array}$ & 5 & $\%$ & & 10 & 12 & 12 & 10 & 10 \\
\hline $\begin{array}{l}\text { Proportion of the population } \\
\text { living below the poverty line } \\
\text { (P0) }\end{array}$ & 44.8 & $\%$ & 2004 & - & - & - & - & 35 \\
\hline Depth of poverty (P1) & 12.8 & $\%$ & 2004 & - & - & - & - & 10 \\
\hline Severity of poverty (P2) & 6.2 & $\%$ & 2004 & - & - & - & - & 5 \\
\hline Inequality coefficient (Gini) & 55.7 & $\%$ & 2004 & - & - & - & - & 45 \\
\hline $\begin{array}{l}\text { Proportion of underweight } \\
\text { children }\end{array}$ & 25 & $\%$ & 2008 & 25 & 20 & 15 & 10 & 5 \\
\hline $\begin{array}{l}\text { Proportion of growth retardation } \\
\text { in children }\end{array}$ & 43.1 & $\%$ & 2004 & & & & & \\
\hline $\begin{array}{l}\text { Net primary school enrollment } \\
\text { rate }\end{array}$ & 73.0 & $\%$ & 2007 & 80.0 & 83.0 & 87.0 & 90.0 & 95.0 \\
\hline $\begin{array}{l}\text { Proportion of children reaching } \\
\text { the } 5^{\text {th }} \text { year of school }\end{array}$ & 71.0 & $\%$ & 2007 & 76.0 & 78.0 & 80.0 & 85.0 & 90.0 \\
\hline $\begin{array}{l}\text { Literacy rate in young adults, } \\
\text { percent of the population } 12-24 \\
\text { years of age }\end{array}$ & 70.8 & $\%$ & 2008 & 76.3 & 79.1 & 81.8 & 84.5 & 87.3 \\
\hline $\begin{array}{l}\text { Ratio, number of girls to boys } \\
\text { enrolled in primary school }\end{array}$ & 0.63 & $\%$ & 2008 & 0.74 & 0.79 & 0.84 & 0.90 & 0.95 \\
\hline $\begin{array}{l}\text { Ratio, number of girls to boys } \\
\text { enrolled in secondary school }\end{array}$ & 0.38 & $\%$ & 2008 & 0.56 & 0.65 & 0.73 & 0.82 & 0.91 \\
\hline $\begin{array}{l}\text { Ratio, female to male } \\
\text { population able to read and } \\
\text { write (proportion of the } \\
\text { population } 15-24 \text { years of age) }\end{array}$ & 61.9 & $\%$ & 2003 & 69.7 & 71.0 & 73.2 & 76.0 & 79.7 \\
\hline Share of women in non- & 13.7 & $\%$ & 2004 & & & & & \\
\hline
\end{tabular}




\begin{tabular}{|c|c|c|c|c|c|c|c|c|}
\hline \multirow[b]{2}{*}{ PRGSP performance indicators } & \multirow{2}{*}{$\begin{array}{l}\text { Bench- } \\
\text { mark } \\
\text { value }\end{array}$} & \multirow[b]{2}{*}{ Unit } & \multirow{2}{*}{$\begin{array}{l}\text { Bench- } \\
\text { mark } \\
\text { year }\end{array}$} & \multicolumn{5}{|c|}{ Targets } \\
\hline & & & & $\begin{array}{l}20 \\
10\end{array}$ & $\begin{array}{l}20 \\
11\end{array}$ & $\begin{array}{l}20 \\
12\end{array}$ & $\begin{array}{l}20 \\
13\end{array}$ & $\begin{array}{l}20 \\
14\end{array}$ \\
\hline $\begin{array}{l}\text { agricultural salaried } \\
\text { employment }\end{array}$ & & & & & & & & \\
\hline $\begin{array}{l}\text { Women members of parliament, } \\
\text { percent of total }\end{array}$ & 2.3 & $\%$ & 2004 & & & & & \\
\hline Neonatal mortality rate & 29 & $/ 1,000$ & 2007 & 25 & 22 & 21 & 20 & 19 \\
\hline $\begin{array}{l}\text { Infant mortality rate per } 1,000 \\
\text { live births }\end{array}$ & 48.4 & $/ 1,000$ & 2005 & & & & & \\
\hline Maternal mortality rate & 400 & $/ 100,000$ & 2005 & 380 & 338 & 295 & 255 & 215 \\
\hline $\begin{array}{l}\text { Proportion of births in health } \\
\text { facilities }\end{array}$ & 13.9 & $\%$ & 2005 & 40 & 50 & 55 & 60 & 65 \\
\hline STI prevalence rate & & $\%$ & & 3.6 & 2 & 1.5 & $<1$ & $<1$ \\
\hline HIV/AIDS prevalence rate & 0.025 & $\%$ & & 0.025 & 0.025 & 0.025 & $<0.015$ & $<0.015$ \\
\hline $\begin{array}{l}\text { Mortality rate related to malaria, } \\
\text { all ages combined }\end{array}$ & 25 & $\%$ & 2008 & 25 & 20 & 15 & 10 & 5 \\
\hline Malaria prevalence rate & 35 & $\%$ & & 32 & 30 & 25 & 15 & 5 \\
\hline $\begin{array}{l}\text { Population having regular } \\
\text { access to an improved water } \\
\text { source }\end{array}$ & 25 & $\%$ & 2008 & 35 & 45 & 60 & 70 & 80 \\
\hline $\begin{array}{l}\text { Population having regular } \\
\text { access to an improved water } \\
\text { source in rural areas }\end{array}$ & 20 & $\%$ & 2008 & 25 & 30 & 40 & 50 & 60 \\
\hline $\begin{array}{l}\text { Population having regular } \\
\text { access to an improved water } \\
\text { source in urban areas }\end{array}$ & 35 & $\%$ & 2008 & 45 & 50 & 70 & 80 & 90 \\
\hline $\begin{array}{l}\text { Rate of increase in tourism } \\
\text { arrivals }\end{array}$ & 14,000 & Tourists & 2006 & $10 \%$ & $20 \%$ & $25 \%$ & $25 \%$ & $25 \%$ \\
\hline
\end{tabular}




\section{ANNEX 2}

SURVEY OF PROGRAMS AND PROJECTS IN PROGRESS SUPPORTING ACHIEVEMENT OF THE PRGS OBJECTIVES 


\section{INTRODUCTION}

This survey of projects and programs in support of the PRGS objectives was prepared based on the work of the Sectoral Technical Groups (GTS) with information collected from the Office of the General Commissioner for Planning, sectoral ministries, project units, and from donors and lenders, when possible.

Although it is possible that certain small projects may have been omitted from this list, most of the projects and programs in progress throughout the Comoros extending beyond 2010 have been identified to the best of the GTS members' knowledge.

The level of financing for these projects/programs was estimated with the available information and the classification of projects/programs by core strategy and operating sector reflecting the main purpose or dominant component of the project.

In respect of the six core strategies adopted in the PRGS, we observe a total of 20 projects and programs for which financing has been acquired, including 2010, throughout the Comoros, totaling approximately CF 46.1 billion, covering the period 2010-2014.

The projects are distributed as follows among the PRGS core strategies and priority programs:

Core Strategy I. Stabilize the economy and lay the groundwork for strong and equitable growth

Core Strategy II. Strengthen key sectors by focusing on institution building and ensuring a broader role for the private sector

Core Strategy III. Strengthen governance and social cohesion

Core Strategy IV. Improve the health status of the general public

Core Strategy V. Promote education and vocational training with the aim of developing human capital

Core Strategy VI. Promote a healthy environment and ensure sustainable development. 


\section{CORE STRATEGY I. STABILIZE THE ECONOMY AND LAY THE GROUNDWORK FOR STRONG AND EQUITABLE GROWTH}

Four priority programs have been identified:

Program 1.1. Enhance government and fiscal operations

Program 1.2. Integrate and facilitate domestic and international trade

Program 1.3. Improve the energy supply at a low cost

Program 1.4. Improve basic economic infrastructure and communication services

Financing in progress by program as listed below:

\section{Program 1.1. Enhance government and fiscal operations}

One program is under way in the fiscal area, in the amount of CF 1.1 billion, financed by AfDB. The project focuses on strengthening the public sector through budget support.

\begin{tabular}{|c|c|c|c|c|c|c|}
\hline $\begin{array}{l}\text { Names of } \\
\text { programs/projects } \\
\text { identified }\end{array}$ & $\begin{array}{l}\text { Priority activities } \\
\text { involved }\end{array}$ & $\begin{array}{l}\text { Regions } \\
\text { covered }\end{array}$ & $\begin{array}{l}\text { Total financing } \\
\text { (in millions of CF) }\end{array}$ & $\begin{array}{l}\text { Donors } \\
\text { and } \\
\text { creditors }\end{array}$ & $\begin{array}{l}\text { Period } \\
\text { covered }\end{array}$ & Type of activities \\
\hline $\begin{array}{l}\text { Fragile States Facility } \\
\text { (FSF) (Budget support) }\end{array}$ & $\begin{array}{l}\text { Strengthening of } \\
\text { the macroeconomic } \\
\text { framework and } \\
\text { effective fiscal } \\
\text { management }\end{array}$ & Country & 1,103 & AfDB & $2009-2010$ & \begin{tabular}{|l} 
Budget support: \\
- \\
- \\
Effection of key reforms; \\
medium term
\end{tabular} \\
\hline Sector subtotal & & & 1,103 & & & \\
\hline
\end{tabular}




\section{Program 1.2. Integrate and facilitate domestic and international trade}

Only one program under UNDP financing, involving approximately CF 500 million, focuses on trade integration in the PRGS, and technical support to facilitate the integration of the Comoros into international trade.

\begin{tabular}{|c|c|c|c|c|c|c|}
\hline $\begin{array}{l}\text { Name of } \\
\text { program/project } \\
\text { identified }\end{array}$ & $\begin{array}{l}\text { Priority activities } \\
\text { involved }\end{array}$ & $\begin{array}{l}\text { Regions } \\
\text { covered }\end{array}$ & $\begin{array}{l}\text { Total financing } \\
\text { (in CF) }\end{array}$ & $\begin{array}{l}\text { Donors and } \\
\text { creditors }\end{array}$ & $\begin{array}{l}\text { Period } \\
\text { covered }\end{array}$ & Type of activities \\
\hline $\begin{array}{l}\text { Trade integration } \\
\text { (Diagnostic study on } \\
\text { trade integration-- } \\
\text { EDIC) }\end{array}$ & $\begin{array}{l}\text { Adapt trade policy to } \\
\text { development and } \\
\text { poverty reduction } \\
\text { policies }\end{array}$ & Country & 491 & UNDP & $2008-2012$ & $\begin{array}{l}\text { 1) Integrate trade policy into the national development } \\
\text { and poverty reduction plans (PRSP); } \\
\text { 2) Facilitate coordinated provision of technical } \\
\text { assistance in the area of trade to meet the } \\
\text { requirements identified by least developed } \\
\text { countries for world economic integration. }\end{array}$ \\
\hline Sector subtotal & & & 491 & & & \\
\hline
\end{tabular}

Program 1.3. Improve the energy supply at a low cost

No projects have obtained financing under this program for 2010.

\section{Program 1.4. Improve basic economic infrastructure and communication services}

The program entails one project, in the amount of CF 13.3 billion, financed by the European Union, for the period 2010-2013. The project aims to implement a sectoral policy in the transportation infrastructure sector, and to execute certain works.

\begin{tabular}{|l|l|l|l|l|l|l|}
\hline $\begin{array}{l}\text { Name of program/project } \\
\text { identified }\end{array}$ & $\begin{array}{l}\text { Priority } \\
\text { activities } \\
\text { involved }\end{array}$ & $\begin{array}{l}\text { Regions } \\
\text { covered }\end{array}$ & $\begin{array}{l}\text { Total financing } \\
\text { (in CF) }\end{array}$ & $\begin{array}{l}\text { Donors and } \\
\text { creditors }\end{array}$ & $\begin{array}{l}\text { Period } \\
\text { covered }\end{array}$ & Type of activities \\
\hline $\begin{array}{l}\text { Transportation } \\
\text { infrastructure }\end{array}$ & $\begin{array}{l}\text { Transportation } \\
\text { infrastructure }\end{array}$ & Country & 13,257 & EU 10 $\mathrm{EDF}$ & 2010-2013 & $\begin{array}{l}\text { Establishment of sector policy on transportation } \\
\text { infrastructure and construction of infrastructure }\end{array}$ \\
\hline Sector subtotal & & & $\mathbf{1 3 , 2 5 7}$ & & & \\
\hline
\end{tabular}




\section{CORE STRATEGY II. STRENGTHEN KEY SECTORS BY FOCUSING ON INSTITUTION BUILDING AND ENSURING A BROADER ROLE FOR THE}

PRIVATE SECTOR

A total of nine priority programs have been identified:

\section{Institution building}

Program 2.1. Support private sector organization

Program 2.2. Financial intermediation and microcredit

\section{Restore growth through key sectors}

\section{- Agriculture and stockbreeding subsector}

Program 2.3. Enhance security of property resources

Program 2.4. Support the creation of a favorable environment for agriculture sector development

Program 2.5. Restore agricultural and agrofood production

Program 2.6. Protect livestock from exotic infectious diseases and intensify animal production sectors

- Fishing sector

Program 2.7. Create an environment favorable to the balanced development of the sector

Program 2.8. Develop a conservation, processing, and marketing system for fish products

\section{- Tourism sector}

Program 2.9. Support tourism development

\section{- Microfinance subsector}


Financing in progress by subsector and program as listed below:

\section{- Agriculture subsector}

Two projects are in progress. The first is under financing from IFAD in the amount of CF 1.9 billion and the second under AFD financing in the amount of CF 1.8 billion. The National Program for Sustainable Human Development (PNDHD) project aims to reduce poverty by strengthening the community systems for management and exploitation of natural resources. The Project to Strengthen and Diversify Agricultural Sectors in the Comoros (PREDIVAC) aims to diversify the agricultural sectors, strengthen the Farmers' Union of the Comoros (SNAC) and disenclose the village of Jimilime.

\begin{tabular}{|l|l|l|l|l|l|l|}
\hline $\begin{array}{l}\text { Name of } \\
\text { program/project } \\
\text { identified }\end{array}$ & $\begin{array}{l}\text { Priority activities } \\
\text { involved }\end{array}$ & $\begin{array}{l}\text { Regions } \\
\text { covered }\end{array}$ & $\begin{array}{l}\text { Total financing } \\
\text { (in CF) }\end{array}$ & $\begin{array}{l}\text { Donors and } \\
\text { creditors }\end{array}$ & $\begin{array}{l}\text { Period } \\
\text { covered }\end{array}$ & Type of activities \\
\hline PNDHD & & Country & 1,905 & IFAD & 2008-2013 & $\begin{array}{l}\text { Contribute to the poverty reduction effort in the } \\
\text { least favored rural areas. For that purpose, a } \\
\text { community system for management and } \\
\text { sustainable exploitation of natural resources will } \\
\text { be established while attempting to increase } \\
\text { agricultural productivity, income, food security, } \\
\text { and to improve household living conditions. }\end{array}$ \\
\hline PREDIVAC & & Country & 1,841 & AFD & $2007-2011$ & $\begin{array}{l}\text { Diversification of agricultural sectors and } \\
\text { strengthening of the SNAC; } \\
\text { Increased access to the village of Jimilimé }\end{array}$ \\
\hline Sector subtotal & & & $\mathbf{3 , 7 4 6}$ & & & \\
\hline
\end{tabular}

\section{- Stockbreeding subsector}

No financing has been acquired for projects in this subsector for 2010 . 
- Fishing subsector

This sector includes one project in progress under state financing (Exim Bank loan). The project will contribute to the sustainable use of fish resources.

\begin{tabular}{|l|l|l|l|l|l|l|}
\hline $\begin{array}{l}\text { Name of } \\
\text { program/project } \\
\text { identified }\end{array}$ & $\begin{array}{l}\text { Priority } \\
\text { activities } \\
\text { involved }\end{array}$ & $\begin{array}{l}\text { Regions } \\
\text { covered }\end{array}$ & $\begin{array}{l}\text { Total financing } \\
\text { (in CF) }\end{array}$ & $\begin{array}{l}\text { Donors and } \\
\text { creditors }\end{array}$ & $\begin{array}{l}\text { Period } \\
\text { covered }\end{array}$ & Type of activities \\
\hline $\begin{array}{l}\text { Support for the fishing } \\
\text { subsector }\end{array}$ & $\begin{array}{l}\text { To strengthen } \\
\text { the sector }\end{array}$ & Country & 3,500 & State & $2009-2012$ & To strengthen all fishing sectors. \\
\hline Sector subtotal & & & $\mathbf{3 , 5 0 0}$ & & & \\
\hline
\end{tabular}

- Tourism subsector

No financing has been acquired for projects in this subsector for 2010. 


\section{- Microfinance subsector}

Two projects, financed by UNDP, are under way in this subsector, with a total amount of CF 2.9 billion. They aim to strengthen the sector and provide support for young entrepreneurs.

\begin{tabular}{|l|l|l|l|l|l|l|}
\hline $\begin{array}{l}\text { Name of program/project } \\
\text { identified }\end{array}$ & $\begin{array}{l}\text { Priority } \\
\text { activities } \\
\text { involved }\end{array}$ & $\begin{array}{l}\text { Regions } \\
\text { covered }\end{array}$ & $\begin{array}{l}\text { Total } \\
\text { financing (in } \\
\text { CF) }\end{array}$ & $\begin{array}{l}\text { Donors and } \\
\text { creditors }\end{array}$ & $\begin{array}{l}\text { Period } \\
\text { covered }\end{array}$ & Type of activities \\
\hline $\begin{array}{l}\text { Program to support inclusive } \\
\text { financing in the Comoros (PAFIC) }\end{array}$ & $\begin{array}{l}\text { To strengthen } \\
\text { financial } \\
\text { infrastructure } \\
\text { in the } \\
\text { microfinance } \\
\text { and inclusive } \\
\text { finance sectors }\end{array}$ & Country & 982 & $\begin{array}{l}\text { United } \\
\text { Nations } \\
\text { Capital } \\
\text { Development } \\
\text { Fund } \\
\text { (UNCDF) / } \\
\text { UNDP }\end{array}$ & $\begin{array}{l}\text { - Develop and implement a national } \\
\text { policy and strategy for coordination } \\
\text { and monitoring; } \\
\text { - Strengthen the central bank in its } \\
\text { supervision role for the sector; } \\
\text { - Examine the legal and regulatory } \\
\text { framework for appropriate, } \\
\text { effective surveillance; } \\
\text { - Establish appropriate financial } \\
\text { infrastructure; } \\
\text {-Improve and expand decentralized } \\
\text { financial institutions to offer } \\
\text { innovative products and services. }\end{array}$ \\
\hline
\end{tabular}




\begin{tabular}{|c|c|c|c|c|c|c|}
\hline $\begin{array}{l}\text { Name of program/project } \\
\text { identified }\end{array}$ & $\begin{array}{l}\text { Priority } \\
\text { activities } \\
\text { involved }\end{array}$ & $\begin{array}{l}\text { Regions } \\
\text { covered }\end{array}$ & $\begin{array}{l}\text { Total } \\
\text { financing (in } \\
\text { CF) }\end{array}$ & $\begin{array}{l}\text { Donors and } \\
\text { creditors }\end{array}$ & $\begin{array}{l}\text { Period } \\
\text { covered }\end{array}$ & Type of activities \\
\hline $\begin{array}{l}\text { Economic revitalization } \\
\text { component focusing on young } \\
\text { people (FCP) }\end{array}$ & $\begin{array}{l}\text { Support for } \\
\text { young people } \\
\text { with special } \\
\text { priority for } \\
\text { Mwali }\end{array}$ & Country & 1,964 & UNDP & 2009-2011 & $\begin{array}{l}\text { 1. Young people at risk and women: } \\
\text { Preparation of a program to create } \\
\text { jobs and accountability for young } \\
\text { people, support for development of a } \\
\text { financing mechanism through } \\
\text { microcredit facilities, training to } \\
\text { manage and promote small-scale } \\
\text { enterprises, trade apprenticeships, } \\
\text { help in starting artisanal activities at } \\
\text { the community level, support for } \\
\text { local health and socio-psychological } \\
\text { counseling centers, support for local } \\
\text { units to facilitate access for women } \\
\text { and children to primary health care, } \\
\text { education, and income sources. } \\
\text { 2. Special priority operation in Mwali: } \\
\text { develop and support initiatives to } \\
\text { promote jobs for young people on } \\
\text { the island in connection with the } \\
\text { modernization of the agricultural } \\
\text { system, encourage women to become } \\
\text { more involved in economic and } \\
\text { social affairs, and support for the } \\
\text { agriculture and fishing sectors. }\end{array}$ \\
\hline Sector subtotal & & & 2,946 & & & \\
\hline
\end{tabular}




\section{CORE STRATEGY III. STRENGTHEN GOVERNANCE AND SOCIAL COHESION}

Four programs were identified:

Program 3.1. Promote good governance, social cohesion, solidarity, and consolidation of peace

Program 3.2. Improve the legal framework, promote anticorruption measures, and strengthen transparency in fiscal management

Program 3.3. Strengthen the capacities of the judiciary institution

Program 3.4. Fight terrorism and transnational crime, and strengthen civil security

The following financing is in progress by program:

Program 3.1. Promote good governance, social cohesion, solidarity, and consolidation of peace

Program 3.2. Improve the legal framework, promote anticorruption measures, and strengthen transparency in fiscal management

Three projects involve good governance, capacity building for the administration, and social cohesion. The $10^{\text {th }}$ EDF project in the amount of

CF 3.3 billion, the AfDB project in the amount of CF 2.9 billion, and the UNDP project in the amount of CF 420 million.

\begin{tabular}{|l|l|l|l|l|l|l|}
\hline $\begin{array}{l}\text { Name of program/project } \\
\text { identified }\end{array}$ & $\begin{array}{l}\text { Priority activities } \\
\text { involved }\end{array}$ & $\begin{array}{l}\text { Regions } \\
\text { covered }\end{array}$ & $\begin{array}{l}\text { Total financing } \\
\text { (in CF) }\end{array}$ & $\begin{array}{l}\text { Donors and } \\
\text { creditors }\end{array}$ & $\begin{array}{l}\text { Period } \\
\text { covered }\end{array}$ & Type of activities \\
\hline $\begin{array}{l}\text { Good governance in public } \\
\text { affairs }\end{array}$ & $\begin{array}{l}\text { Capacity building } \\
\text { for the public } \\
\text { sector }\end{array}$ & Country & 3,314 & $10^{\text {th }}$ EDF & $2009-2013$ & $\begin{array}{l}\text { Capacity building for officers of the public sector in } \\
\text { management and administration of public affairs. } \\
\text { Technical assistance for the Office of the } \\
\text { Commissioner for Planning, accompaniment for the } \\
\text { implementation of a water management plan, support } \\
\text { for justice, and nongovernment players. }\end{array}$ \\
\hline $\begin{array}{l}\text { Capacity building in the } \\
\text { area of planning }\end{array}$ & $\begin{array}{l}\text { Capacity building } \\
\text { in planning: } \\
\text { institutional } \\
\text { support for the } \\
\text { budget, treasury, } \\
\text { debt and statistical } \\
\text { activities, and } \\
\text { private sector } \\
\text { organizations }\end{array}$ & Country & 2,800 & $\begin{array}{l}\text { Improved fiscal, debt, and statistics management: } \\
\text { Support for macroeconomic management; } \\
\text { Support for the preparation of national } \\
\text { accounting records; } \\
\text { Support for the preparation of price statistics }\end{array}$ \\
\hline
\end{tabular}




\begin{tabular}{|l|l|l|l|l|l|l|}
\hline $\begin{array}{l}\text { Name of program/project } \\
\text { identified }\end{array}$ & $\begin{array}{l}\text { Priority activities } \\
\text { involved }\end{array}$ & $\begin{array}{l}\text { Regions } \\
\text { covered }\end{array}$ & $\begin{array}{l}\text { Total financing } \\
\text { (in CF) }\end{array}$ & $\begin{array}{l}\text { Donors and } \\
\text { creditors }\end{array}$ & $\begin{array}{l}\text { Period } \\
\text { covered }\end{array}$ & Type of activities \\
\hline $\begin{array}{l}\text { Governance and social } \\
\text { cohesion (FCP) }\end{array}$ & $\begin{array}{l}\text { Inter-Comorian } \\
\text { dialog and } \\
\text { national } \\
\text { reconciliation }\end{array}$ & Country & 246 & $\begin{array}{l}\text { Inter-Comorian dialog and national reconciliation: } \\
\text { support the initiation and implementation of the } \\
\text { preparatory phases of the dialog, contribute to the } \\
\text { creation of structures and mechanisms to ensure } \\
\text { continuation, support for initiatives promoting the free } \\
\text { inter-island circulation of persons, encourage and } \\
\text { facilitate the introduction of civic education in the } \\
\text { schools and its promotion in the media, rehabilitation } \\
\text { of infrastructure and capital goods, training and } \\
\text { specialization of judges and justice assistants, } \\
\text { establishment of the required judiciary units. }\end{array}$ \\
\hline Sector subtotal & & $\mathbf{6 3 1 7}$ & UNDP & \\
\hline
\end{tabular}




\section{Program 3.3. Strengthen the capacities of the judiciary institution}

Only one UNDP financing project, in the amount of CF 344 million, targets justice reform and promotion of human rights.

\begin{tabular}{|l|l|l|l|l|l|l|}
\hline $\begin{array}{l}\text { Name of program/project } \\
\text { identified }\end{array}$ & $\begin{array}{l}\text { Priority } \\
\text { activities } \\
\text { involved }\end{array}$ & $\begin{array}{l}\text { Regions } \\
\text { covered }\end{array}$ & $\begin{array}{l}\text { Total financing } \\
\text { (in CF) }\end{array}$ & $\begin{array}{l}\text { Donors and } \\
\text { creditors }\end{array}$ & $\begin{array}{l}\text { Period } \\
\text { covered }\end{array}$ & Type of activities \\
\hline $\begin{array}{l}\text { Governance and social cohesion } \\
\text { (FCP) }\end{array}$ & $\begin{array}{l}\text { Justice reform } \\
\text { and human } \\
\text { rights } \\
\text { promotion }\end{array}$ & Country & 344 & $\begin{array}{l}\text { Justice reforms and human rights promotion: } \\
\text { rehabilitation of penitentiary infrastructure and } \\
\text { logistics, making the national consultative committee } \\
\text { on human rights operational, capacity building for the } \\
\text { latter and for an observatory on detention facilities, } \\
\text { contribution to the development of a national policy on } \\
\text { human rights. }\end{array}$ \\
\hline Sector subtotal & & $\mathbf{3 4 4}$ & 2009-2015 \\
\hline
\end{tabular}




\section{Program 3.4. Fight terrorism and transnational crime, and strengthen civil security}

One UNDP project supports the consolidation of peace and security. The project amounts to CF 1.2 billion.

\begin{tabular}{|l|l|l|l|l|l|l|}
\hline $\begin{array}{l}\text { Name of program/project } \\
\text { identified }\end{array}$ & $\begin{array}{l}\text { Priority } \\
\text { activities } \\
\text { involved }\end{array}$ & $\begin{array}{l}\text { Regions } \\
\text { covered }\end{array}$ & $\begin{array}{l}\text { Total financing } \\
\text { (in CF) }\end{array}$ & $\begin{array}{l}\text { Donors and } \\
\text { creditors }\end{array}$ & $\begin{array}{l}\text { Period } \\
\text { covered }\end{array}$ & Type of activities \\
\hline Peace consolidation fund & $\begin{array}{l}\text { Security and } \\
\text { stability }\end{array}$ & Country & 1,719 & UNDP & 2009-2011 & $\begin{array}{l}\text { Security reforms: strengthening of the command and } \\
\text { control structures, rehabilitation of infrastructure, } \\
\text { equipment of a newly-organized police force, human } \\
\text { rights training, infrastructure and logistics support for } \\
\text { national initiatives to patrol and secure the maritime } \\
\text { borders. }\end{array}$ \\
Sector subtotal & & $\begin{array}{l}\text { Disarmament, Demobilization and Reintegration } \\
\text { (DDR) program: Support for public disarmament, and } \\
\text { technical and financial assistance for the } \\
\text { socioeconomic reintegration of former soldiers. }\end{array}$ \\
\hline
\end{tabular}

\section{CORE STRATEGY IV: IMPROVE THE HEALTH OF GENERAL THE PUBLIC}

Five priority programs have been identified:

Program 4.1. Fight malaria and priority diseases

Program 4.2. Integrated sexual and reproductive health development

Program 4.3. Fight HIV/AIDS and sexually transmissible infections

Program 4.4. Strengthen the efficacy of all aspects of the health system

Program 4.5. Improve hygiene and sanitation in the hospitals 


\section{Program 4.1: Fight malaria and priority diseases}

One project is in progress, in the amount of CF 5.3 billion, financed by the World Fund, to Fight Malaria and Prevent Priority Diseases.

\begin{tabular}{|l|l|l|l|l|l|l|}
\hline $\begin{array}{l}\text { Name of program/project } \\
\text { identified }\end{array}$ & $\begin{array}{l}\text { Priority } \\
\text { activities } \\
\text { involved }\end{array}$ & $\begin{array}{l}\text { Regions } \\
\text { covered }\end{array}$ & $\begin{array}{l}\text { Total financing } \\
\text { (in CF) }\end{array}$ & $\begin{array}{l}\text { Donors } \\
\text { and } \\
\text { creditors }\end{array}$ & $\begin{array}{l}\text { Period } \\
\text { covered }\end{array}$ & Type of activities \\
\hline Program to fight malaria & & Country & 5,303 & $\begin{array}{l}\text { WF } \\
\text { (World } \\
\text { Fund) }\end{array}$ & 2009-2014 & $\begin{array}{l}\text { Active Detection of large-scale cases; } \\
\text { Surveillance and response for imported } \\
\text { cases of malaria; } \\
\text { Maintenance of stocks in case of epidemics; } \\
\text { Human resource capacity building. }\end{array}$ \\
\hline Sector subtotal & & & $\mathbf{5 3 0 3}$ & & & \\
\hline
\end{tabular}

Program 4.2. Integrated sexual and reproductive health development

\section{Program 4.3. Fight HIV/AIDS and sexually transmissible diseases}

No project finance has been acquired in these programs for 2010. 


\section{Program 4.4. Strengthen the efficacy of all aspects of the health system}

This program includes one project, in the amount of CF 4.9 billion, financed by AFD.

\begin{tabular}{|l|l|l|l|l|l|l|}
\hline $\begin{array}{l}\text { Name of program/project } \\
\text { identified }\end{array}$ & $\begin{array}{l}\text { Priority } \\
\text { activities } \\
\text { involved }\end{array}$ & $\begin{array}{l}\text { Regions } \\
\text { covered }\end{array}$ & $\begin{array}{l}\text { Total financing } \\
\text { (in CF) }\end{array}$ & $\begin{array}{l}\text { Donors } \\
\text { and } \\
\text { creditors }\end{array}$ & $\begin{array}{l}\text { Period } \\
\text { covered }\end{array}$ & Type of activities \\
\hline $\begin{array}{l}\text { Program to support the health } \\
\text { sector in the Comoros } \\
\text { (PASCO) }\end{array}$ & Pays & 4,910 & AFD & $2009-2013$ & $\begin{array}{l}\text { Strengthen the institutional framework to } \\
\text { prepare for implementation of the health } \\
\text { strategy; } \\
\text { Improve accessibility and quality of basic } \\
\text { health services in Nzwani and Mwali; } \\
\text { Build medical and surgical capacities in the } \\
\text { five reference hospitals (Hombo Hospital } \\
\text { Research Center (CHR), Fomboni CHR, } \\
\text { Domoni CSD, Mitsamiouli Medical and } \\
\text { Surgical Center (CMC) and Maarouf } \\
\text { National Hospital Center (CHN)) }\end{array}$ \\
\hline Sector subtotal & & & & & & \\
\hline
\end{tabular}

Program 4.5. Improve hygiene and sanitation in the hospitals.

No project finance was acquired in this program for 2010.

\section{CoRe Strategy V: Promote EDUCATION AND VOCATIONAL TRAINING WITH THE AIM OF DEVELOPING HUMAN CAPITAL}

Four programs were identified:

Priority Program 5.1. Priority Program 5.2.

Priority Program 5.3.

Priority Program 5.4.
Develop education, technical instruction, and occupational training, to reflect the requirements of the job market Improve access to and quality of basic (preschool and elementary) and secondary education

Develop competent human resources and the sectoral (SWAP) approach in education

Promote literacy, sports, and cultural activities. 


\section{Priority Program 5.1: Develop education, technical instruction, and occupational training, to reflect the requirements of the job market}

One project from the European Union, in the amount of CF 6.5 billion, was identified to support development of occupational training and technical education.

\begin{tabular}{|c|c|c|c|c|c|c|}
\hline $\begin{array}{l}\text { Name of program/project } \\
\text { identified }\end{array}$ & $\begin{array}{l}\text { Priority } \\
\text { activities } \\
\text { involved } \\
\end{array}$ & $\begin{array}{l}\text { Regions } \\
\text { covered }\end{array}$ & $\begin{array}{l}\text { Total } \\
\text { financing (in } \\
\text { CF) }\end{array}$ & $\begin{array}{l}\text { Donors } \\
\text { and } \\
\text { creditors }\end{array}$ & $\begin{array}{l}\text { Period } \\
\text { covered }\end{array}$ & Type of activities \\
\hline $\begin{array}{l}\text { Develop professional training } \\
\text { and technical education }\end{array}$ & $\begin{array}{l}\text { Professional } \\
\text { training and } \\
\text { training/ } \\
\text { apprenticeship }\end{array}$ & Country & 6,500 & $10^{\text {th }} \mathrm{EDF}$ & $2009-2013$ & $\begin{array}{l}\text { Diversify the supply of technical and } \\
\text { occupational training; } \\
\text { - Strengthen management of the technical and } \\
\text { occupational training system; } \\
\text { - Create an environment conducive to quality } \\
\text { higher education; } \\
\text { - Strengthen the partnership between the education } \\
\text { system and the labor environment; } \\
\text { - Promote basic education and the outlook of } \\
\text { preparation for active life. }\end{array}$ \\
\hline Sector subtotal & & & 6,500 & & & \\
\hline
\end{tabular}




\section{Priority program 5.2. Improve access and quality of basic (preschool and elementary) and secondary education}

One project for capacity building, to improve the supply and to reduce disparities in the formal education sector, financed jointly by the EU and UNICEF, was identified in the amount of CF 2.3 billion.

\begin{tabular}{|l|l|l|l|l|l|l|}
\hline $\begin{array}{l}\text { Name of program/project } \\
\text { identified }\end{array}$ & $\begin{array}{l}\text { Priority } \\
\text { activities } \\
\text { involved }\end{array}$ & $\begin{array}{l}\text { Regions } \\
\text { covered }\end{array}$ & $\begin{array}{l}\text { Total financing } \\
\text { (in CF) }\end{array}$ & $\begin{array}{l}\text { Donors } \\
\text { and } \\
\text { creditors }\end{array}$ & $\begin{array}{l}\text { Period } \\
\text { covered }\end{array}$ & Type of activities \\
\hline $\begin{array}{l}\text { Improved access to and } \\
\text { quality of basic (preschool } \\
\text { and elementary) and } \\
\text { secondary education }\end{array}$ & $\begin{array}{l}\text { Capacity } \\
\text { building, } \\
\text { improvement } \\
\text { of supply, } \\
\text { elimination of } \\
\text { disparities }\end{array}$ & Country & 2,300 & & $\begin{array}{l}\text { Capacity building in accommodation, supervision } \\
\text { activities, production of reference materials, and } \\
\text { integrated early childhood development; } \\
\text { Improvement of the supply in primary and } \\
\text { secondary education; } \\
\text { Eliminate school disparities and inequalities; } \\
\text { Enhance quality of teaching and learning at the } \\
\text { primary and secondary levels; } \\
\text { Strengthen the languages used in the education } \\
\text { system. }\end{array}$ \\
\hline Sector subtotal & $\begin{array}{l}9^{\text {th }} \text { EDF / } \\
\text { UNICEF }\end{array}$ & $2006-2011$ & & \\
\hline
\end{tabular}




\section{Priority Program 5.3 Develop competent human resources and the sectoral (SWAP) approach in education}

One program in this area is financed by the EU, in the amount of CF 5.5 billion. It targets occupational training capacity building.

\begin{tabular}{|l|l|l|l|l|l|l|}
\hline $\begin{array}{l}\text { Name of program/project } \\
\text { identified }\end{array}$ & $\begin{array}{l}\text { Priority } \\
\text { activities } \\
\text { involved }\end{array}$ & $\begin{array}{l}\text { Regions } \\
\text { covered }\end{array}$ & $\begin{array}{l}\text { Total financing } \\
\text { (in millions of } \\
\text { CF) }\end{array}$ & $\begin{array}{l}\text { Donors } \\
\text { and } \\
\text { creditors }\end{array}$ & $\begin{array}{l}\text { Period } \\
\text { covered }\end{array}$ & Type of activities \\
\hline $\begin{array}{l}\text { Development of competent } \\
\text { human resources and the } \\
\text { sectoral (SWAP) approach in } \\
\text { education }\end{array}$ & $\begin{array}{l}\text { Skills-based } \\
\text { approach }\end{array}$ & Country & 57 & & & $\begin{array}{l}\text { Capacity building for education management, } \\
\text { planning, and evaluation units at all levels of the } \\
\text { education system; } \\
\text { Enhance school governance and skills of } \\
\text { education staff; } \\
\text { Promote the SWAP approach for sustainable } \\
\text { human resource development; } \\
\text { Strengthen research on the Comorian language. }\end{array}$ \\
\hline Sector subtotal & & & UNICEF & $2006-2012$ \\
\hline
\end{tabular}




\section{Priority Program 5.4. Promote literacy, sports, and cultural activities}

One project financed by France in the amount of approximately CF 740 million aims to rehabilitate sports infrastructure, build management capacities, and enhance management of associations and municipalities.

\begin{tabular}{|l|l|l|l|l|l|l|}
\hline $\begin{array}{l}\text { Name of program/project } \\
\text { identified }\end{array}$ & $\begin{array}{l}\text { Priority activities } \\
\text { involved }\end{array}$ & $\begin{array}{l}\text { Regions } \\
\text { covered }\end{array}$ & $\begin{array}{l}\text { Total financing } \\
\text { (in millions of } \\
\text { CF) }\end{array}$ & $\begin{array}{l}\text { Donors } \\
\text { and } \\
\text { creditors }\end{array}$ & $\begin{array}{l}\text { Period } \\
\text { covered }\end{array}$ & Type of activities \\
\hline $\begin{array}{l}\text { Social Development Fund } \\
\text { (FSD) }\end{array}$ & $\begin{array}{l}\text { - Rehabilitation of } \\
\text { sports } \\
\text { infrastructure; } \\
\text { - Capacity building } \\
\text { in supervision and } \\
\text { management of } \\
\text { associations and } \\
\text { municipalities }\end{array}$ & Country & 737 & France & $2009-2011$ & $\begin{array}{l}\text { Implement a functional literacy policy for young } \\
\text { people and adults; } \\
\text { Promote sports activities for young people } \\
\text { Promote cultural activities; } \\
\text { Social Development Fund: develop sports } \\
\text { activities, integration of young people, and } \\
\text { support for village communities and local } \\
\text { dynamics. }\end{array}$ \\
\hline Sector subtotal & & & 737 & & \\
\hline
\end{tabular}




\section{Core strategy VI. Promote a health environment and ensure sustainable development}

\section{Controlled exploitation of the environment, and its preservation and regeneration}

\section{Environment}

One development project to build capacities to manage risks of natural disasters and adapt to climate change is in progress in the area of environmental management. This project, in the amount of CF 367 million, is financed by UNDP.

\begin{tabular}{|c|c|c|c|c|c|c|}
\hline $\begin{array}{l}\text { Name of program/project } \\
\text { identified }\end{array}$ & \begin{tabular}{|l|} 
Priority \\
activities \\
involved
\end{tabular} & $\begin{array}{l}\text { Regions } \\
\text { covered }\end{array}$ & $\begin{array}{l}\text { Total financing } \\
\text { (in millions of } \\
\text { CF) }\end{array}$ & \begin{tabular}{|l|} 
Donors \\
and \\
creditors
\end{tabular} & $\begin{array}{l}\text { Period } \\
\text { covered }\end{array}$ & Type of activities \\
\hline $\begin{array}{l}\text { Capacity building in } \\
\text { management of the risks of } \\
\text { natural and climate disasters } \\
\text { in the Union of the Comoros }\end{array}$ & $\begin{array}{l}\text { Establishment } \\
\text { of the legal } \\
\text { framework, } \\
\text { preventive } \\
\text { structures, a } \\
\text { capacity } \\
\text { building action } \\
\text { plan, and a } \\
\text { communication } \\
\text { and awareness } \\
\text { campaign }\end{array}$ & Country & 367 & UNDP & 2009_2011 & $\begin{array}{l}\text { A law to be drafted, adopted, and promulgated; } \\
\text { - Analytical capacity building; } \\
\text { - Implementation and strengthening of the risk } \\
\text { prevention and management structures; } \\
\text { - Pilot mangrove regeneration operations; } \\
\text { - Implementation of a cartographic information } \\
\text { system in high-risk areas; } \\
\text { - Equipment and supplies. }\end{array}$ \\
\hline Sector subtotal & & & 367 & & & \\
\hline
\end{tabular}




\begin{abstract}
ANNEX 3
FinANCING AVAILABLE FOR EACH PRGS CORE STRATEGY AND Priority PROGRAM
\end{abstract}


Table A3: Status of projected financing for the PRGS core strategies and priority programs, 2010-2014.

\begin{tabular}{|c|c|c|c|c|c|c|c|c|c|}
\hline \multirow[b]{2}{*}{ Core Strategy and program } & \multirow[b]{2}{*}{ Operation/project } & \multirow{2}{*}{$\begin{array}{l}\text { Total } \\
\text { financing } \\
\text { (CF } \\
\text { millions) }\end{array}$} & \multirow[b]{2}{*}{$\begin{array}{l}\text { Donors/ } \\
\text { creditors }\end{array}$} & \multicolumn{6}{|c|}{ Period Covered } \\
\hline & & & & 2010 & 2011 & 2012 & 2013 & 2014 & 2010-2014 \\
\hline \multicolumn{10}{|c|}{ Core strategy 1. Stabilize the economy and lay the groundwork for strong and equitable growth } \\
\hline 1. Improve state and fiscal operations & Support fiscal reform & 1,103 & AfDB & 735 & & & & & 735 \\
\hline $\begin{array}{l}\text { 2. International trade reform and facilitation of } \\
\text { domestic trade }\end{array}$ & Capacity building, research & 491 & $\begin{array}{r}\mathrm{UNDP} / \\
\mathrm{EDIC}\end{array}$ & 98 & 98 & 98 & & & 295 \\
\hline $\begin{array}{l}\text { 3. Improve the energy supply at a low cost, } \\
\text { access to drinking water and sanitation }\end{array}$ & $\begin{array}{l}\text { Institutional support for the drinking water sector; } \\
\text { research; works }\end{array}$ & 5,880 & AfDB & 58 & $\begin{array}{r}2,64 \\
6 \\
\end{array}$ & 2,646 & & & 5,350 \\
\hline $\begin{array}{l}\text { 4. Improve basic economic infrastructure and } \\
\text { communication services }\end{array}$ & $\begin{array}{l}\text { Support for the development of transportation } \\
\text { infrastructure }\end{array}$ & 13,257 & $10^{\text {th }} \mathrm{EDF}$ & 3,314 & $\begin{array}{r}3,31 \\
4 \\
\end{array}$ & 3,314 & 3,314 & & 13,257 \\
\hline Total Core Strategy 1 & & 20,731 & & 4,206 & 6,058 & 6,058 & 3,314 & $\mathbf{0}$ & 19,637 \\
\hline \multicolumn{10}{|c|}{ Core strategy 2. Strengthen key sectors by focusing on institution building and ensuring a broader role for the private sector } \\
\hline \multicolumn{10}{|l|}{ Private microfinance sector } \\
\hline \multicolumn{10}{|l|}{ 1. Organizational support for the private sector } \\
\hline \multirow[t]{2}{*}{ 2. Financial intermediation and microcredit } & PAFIC: Inclusive finance support program for the Comoros & 982 & $\begin{array}{l}\mathrm{UNEF} / \\
\mathrm{UNDP}\end{array}$ & 327 & 327 & 164 & & & 818 \\
\hline & $\begin{array}{l}\text { Economic revitalization component focusing on young } \\
\text { people (FCP) }\end{array}$ & 1,964 & UNDP & 982 & 491 & & & & 1,473 \\
\hline Agriculture and stockbreeding & PREDIVAC & 1,841 & AFD & 368 & 368 & & & & 737 \\
\hline 3. Strengthen property security & $\begin{array}{l}\text { PNDHD: National program for sustainable human } \\
\text { development }\end{array}$ & 1,905 & IFAD & 381 & 381 & 286 & 191 & & 1,238 \\
\hline $\begin{array}{l}\text { 4. Support to establish an environment } \\
\text { conducive to the development of the agricultural } \\
\text { sector }\end{array}$ & & & & & & & & & 0 \\
\hline $\begin{array}{l}\text { 5. Recovery of agricultural and agrofood } \\
\text { production }\end{array}$ & & & & & & & & & 0 \\
\hline $\begin{array}{l}\text { 6. Protection of livestock against exotic } \\
\text { infectious disease and intensification of animal } \\
\text { production sectors }\end{array}$ & & & & & & & & & 0 \\
\hline Fishing & Capacity building for fishing & 3,500 & $\begin{array}{l}\text { State loan - } \\
\text { Eximbank }\end{array}$ & 1,000 & 1,000 & 1,000 & & & 3,000 \\
\hline \multicolumn{10}{|l|}{$\begin{array}{l}\text { 7. Establish an environment conducive to } \\
\text { balanced development of the sector }\end{array}$} \\
\hline \multicolumn{10}{|l|}{$\begin{array}{l}\text { 8. Develop the system for preserving, } \\
\text { processing, and marketing fish products }\end{array}$} \\
\hline Tourism & & & & & & & & & \\
\hline \multicolumn{10}{|l|}{ 9. Support for tourism development } \\
\hline Total Core Strategy 2 & & 10,192 & & 3,059 & 2,568 & 1,449 & 191 & $\mathbf{0}$ & 7,266 \\
\hline
\end{tabular}




\begin{tabular}{|c|c|c|c|c|c|c|c|c|c|}
\hline \multirow[b]{2}{*}{ Core Strategy and program } & \multirow[b]{2}{*}{ Operation/project } & \multirow{2}{*}{$\begin{array}{l}\text { Total } \\
\text { financing } \\
(\text { CF } \\
\text { millions })\end{array}$} & \multirow[b]{2}{*}{$\begin{array}{l}\text { Donors/ } \\
\text { creditors }\end{array}$} & \multicolumn{6}{|c|}{ Period Covered } \\
\hline & & & & 2010 & 2011 & 2012 & 2013 & 2014 & 2010-2014 \\
\hline \multicolumn{10}{|c|}{ Core strategy 3. Strengthen governance and social cohesion } \\
\hline $\begin{array}{l}\text { 1.1. Promote good governance, social cohesion, } \\
\text { solidarity, and the consolidation of peace }\end{array}$ & & & & & & & & & 0 \\
\hline \multirow{3}{*}{$\begin{array}{l}\text { 2. Enhance the legal framework, promote } \\
\text { anticorruption measures and strengthen } \\
\text { transparency and management of public affairs }\end{array}$} & Good governance in public affairs & 3,314 & $10^{\text {th }} \mathrm{EDF}$ & 762 & 762 & 795 & 663 & & 2,983 \\
\hline & $\begin{array}{l}\text { Capacity building in the area of planning: institutional } \\
\text { support for budget, treasury, debt, and statistics, and for } \\
\text { private sector organizations }\end{array}$ & 2,757 & AfDB & 1,378 & 1,103 & & & & 2,481 \\
\hline & $\begin{array}{l}\text { Governance and social cohesion (FCP): Inter-Comorian } \\
\text { dialog and national reconciliation }\end{array}$ & 246 & UNDP & 123 & 98 & & & & 221 \\
\hline 3. Capacity building for the judicial institution & $\begin{array}{l}\text { Governance and social cohesion (FCP): justice reforms } \\
\text { and promotion of human rights }\end{array}$ & 344 & UNDP & 172 & 172 & & & & 344 \\
\hline $\begin{array}{l}\text { 4. Fight against terrorism, transnational crime, } \\
\text { and strengthening of civil security }\end{array}$ & Security and stability (FCP) & 1,719 & UNDP & 859 & 687 & & & & 1,547 \\
\hline Total Core Strategy 3 & & 8,379 & & 3,295 & 2,823 & 795 & 663 & $\mathbf{0}$ & $\mathbf{7 , 5 7 5}$ \\
\hline \multicolumn{10}{|c|}{ Core strategy 4. Improve the health status of the general public } \\
\hline 1. Fight malaria and priority diseases & Program to fight malaria (World Fund) & 5,303 & WF & 1,768 & 589 & 589 & 1669 & 687 & 5,303 \\
\hline $\begin{array}{l}\text { 2. Develop comprehensive sexual and } \\
\text { reproductive health services }\end{array}$ & & & & & & & & & 0 \\
\hline $\begin{array}{l}\text { 3. Fight against HIV/AIDS and sexually } \\
\text { transmissible infections }\end{array}$ & & & & & & & & & 0 \\
\hline $\begin{array}{l}\text { 4. Enhance efficacy and efficiency of all aspects } \\
\text { of the health system }\end{array}$ & $\begin{array}{l}\text { PASCO: Program to support the health sector in the } \\
\text { Comoros }\end{array}$ & 4,910 & AFD & 1,129 & 1,473 & 1,473 & 835 & & 4,910 \\
\hline $\begin{array}{l}\text { 5. Improve hygiene and sanitation in the } \\
\text { hospital environment }\end{array}$ & & & & & & & & & 0 \\
\hline Total Core Strategy 4 & & 10,213 & & 2,897 & 2,062 & 2,062 & 2,504 & 687 & $\mathbf{1 0 , 2 1 3}$ \\
\hline \multicolumn{10}{|c|}{ Core strategy V. Promote education and vocational training with the aim of developing human capital } \\
\hline $\begin{array}{l}\text { 1. Develop education, technical instruction, and } \\
\text { occupational training to reflect market } \\
\text { requirements }\end{array}$ & $\begin{array}{l}\text { 1. Diversify the supply of technical and occupational } \\
\text { training; } 2 \text {. Strengthen management of the technical and } \\
\text { occupational training system; } 3 \text {. Create an environment } \\
\text { to support high-quality higher education; } 4 \text {. Strengthen } \\
\text { the partnership between the education system and the } \\
\text { labor world; } 5 \text {. Promote basic education and the outlook } \\
\text { of preparing for an active working life }\end{array}$ & 6,500 & & 458 & 732 & 773 & 878 & 1,856 & 4,696 \\
\hline $\begin{array}{l}\text { 2. Enhance access to quality basic (preschool } \\
\text { and elementary) and secondary education }\end{array}$ & $\begin{array}{l}\text { 1. Build capacities to accommodate, manage, produce } \\
\text { reference materials, and cover integrated early childhood } \\
\text { development; } 2 \text {. Improve the supply of primary and } \\
\text { secondary education; } 3 \text {. Eliminate school disparities and }\end{array}$ & 2,300 & & 538 & 690 & 5 & 0 & 31 & 1,263 \\
\hline
\end{tabular}




\begin{tabular}{|c|c|c|c|c|c|c|c|c|c|}
\hline \multirow[b]{2}{*}{ Core Strategy and program } & \multirow[b]{2}{*}{ Operation/project } & \multirow{2}{*}{$\begin{array}{l}\text { Total } \\
\text { financing } \\
\text { (CF } \\
\text { millions) }\end{array}$} & \multirow[b]{2}{*}{$\begin{array}{l}\text { Donors/ } \\
\text { creditors }\end{array}$} & \multicolumn{6}{|c|}{ Period Covered } \\
\hline & & & & 2010 & 2011 & 2012 & 2013 & 2014 & 2010-2014 \\
\hline & $\begin{array}{l}\text { inequalities; } 4 \text {. Improve the quality of education and } \\
\text { learning at the primary and secondary levels; } 5 \text {. } \\
\text { Strengthen the languages used in the education system }\end{array}$ & & & & & & & & \\
\hline $\begin{array}{l}\text { 3. Develop competent human resources and the } \\
\text { sectoral (SWAP) approach in education }\end{array}$ & $\begin{array}{l}\text { 1. Strengthen structural capacities for management, } \\
\text { planning, and evaluation at all levels of the education } \\
\text { system; } 2 \text {. Enhance school governance and the skills of } \\
\text { education staff; 3. Promote the sectoral (SWAP) } \\
\text { approach in education for sustainable human resource } \\
\text { development; } 4 \text {. Strengthen research on the Comorian } \\
\text { language }\end{array}$ & 57 & & 17 & 12 & 17 & 0 & 0 & 45 \\
\hline $\begin{array}{l}\text { 4. Promote literacy, sports, and cultural } \\
\text { activities }\end{array}$ & $\begin{array}{l}\text { 1. Establish a functional literacy policy for young people } \\
\text { and adults; } 2 \text {. Promote sports activities for young people; } \\
\text { 3. Promote cultural activities and the Social } \\
\text { Development Fund: Development of sports activities, } \\
\text { integration of young people, support for village } \\
\text { communities, and local dynamics }\end{array}$ & 737 & France & 295 & 295 & & & & 589 \\
\hline \begin{tabular}{|l} 
Total Core Strategy 5 \\
\end{tabular} & & 9,594 & & 1,306 & 1,728 & 795 & 878 & $\mathbf{1 , 8 8 7}$ & 6,593 \\
\hline \multicolumn{10}{|c|}{ Core strategy 6. Promote a health environment and ensure sustainable development } \\
\hline & $\begin{array}{l}\text { Capacity building in managing the risks of natural and } \\
\text { climate disasters in the Union of the Comoros }\end{array}$ & 362 & UNDP & 163 & 36 & & & & 199 \\
\hline Total Core Strategy 6 & & 262 & & 163 & 36 & $\mathbf{0}$ & $\mathbf{0}$ & $\mathbf{0}$ & 199 \\
\hline Total available & & 60,156 & & 14,932 & 15,583 & 11,468 & 7,550 & 2,574 & 52,106 \\
\hline
\end{tabular}

